\title{
ESTABILIDADE OXIDATIVA DE ÓLEOS VEGETAIS REFINADOS: EFEITO DO AQUECIMENTO POR MICROONDAS
}

\author{
THAIS MARIA FERREIRA DE SOUZA VIEIRA \\ Engenheira Agrônoma
}

Orientadora: Prof. Dr. . MARISA APARECIDA BISMARA REGITANO D'ARCE

Dissertação apresentada à Escola Superior de Agricultura "Luiz de Queiroz", Universidade de São Paulo, para obtenção do título de Mestre em Agronomia, Área de concentração: Ciência e Tecnologia de Alimentos.

\footnotetext{
PIRACICABA

Estado de São Paulo - Brasil

Agosto - 1998
} 
Dados Internacionais de Catalogação na Publicação (CIP) DIVISĀo DE BIBLIOTECA E DOCUMENTAÇĀO - Campus "Luiz de Queiroz"/USP

Vieira, Thais Maria Ferreira de Souza

Estabilidade oxidativa de óleos vegęcais refinados: efeito do aquecimento por : microondas / Thais Maria Ferreira de Soữż Vieira. - . Piracicaba, 1998.

$70 \mathrm{p}$.

Dissertaçāo (mestrado) - Escola Superior de Agricultura Luiz de Queiroz, 1998. Bibliografia.

1. Estabilidade 2. Microondas 3. Óleo de colza 4. Öleo de Milho 5. Óleo vegetal 6. Oxidaçăo I. Título 


\section{AGRADECIMENTOS}

Aos meus pais, meus irmãos André e Sofia e meu sobrinho Matheus pelo apoio e compreensão;

À minha orientadora Marisa A. B. Regitano d'Arce, pela amizade e incentivo durante a realização do curso de mestrado e elaboração do trabalho deste dissertação;

Aos professores e funcionários do Departamento de Ciência e Tecnologia Agroindustrial, especialmente à técnica do Laboratório de Óleos e Gorduras, Maria Fernanda de Almeida Prado, pelo auxílio prestado;

Aos colegas Carlos Magno Evangelista, Mariana Micotti da Glória, Fabiana Maria de Siqueira, Renata Franco de Almeida e Renata Assis Bombo pela participação e companheirismo;

Ao Eng. Agrônomo Sérgio Bittencourt Ivancko pelas sugestões e auxílio na revisão;

Ao Prof. Dr. Amaldo A. Rodella pelas informáç̧̂̀es e auxilio para a utilização do programa de varredura para espectrofotometria;

Ao CNPq, pela bolsa concedida, e à Fapesp, pelo auxilio financeiro à pesquisa;

À empresa Rhodia-Ster, pelo fomecimento das embalagens utilizadas; à Cargill Agricola S.A., Refino de Óleos Brasil Ltda e COCAMAR (Cooperativa dos Cafeicultores e Agropecuaristas de Maringá) pelo fornecimento dos óleos refinados de soja, milho e canola;

E a todos que contribuiram direta e indiretamente para a consecução deste trabalho. 


\section{SUMÁRIO}

página

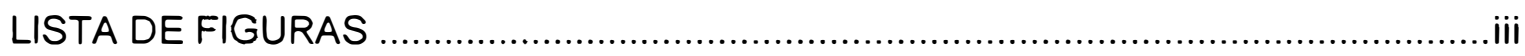

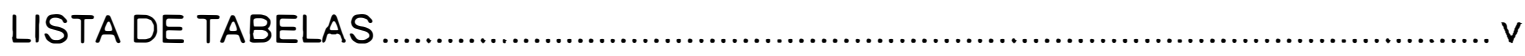

LISTA DE ABREVIATURAS E SÍMBOLOS .............................................................. vii

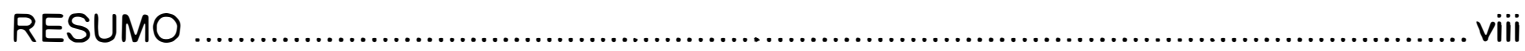

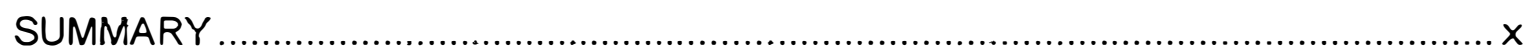

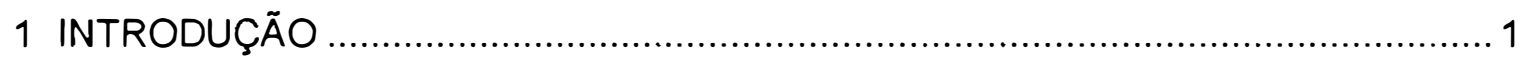

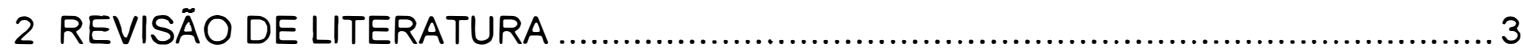

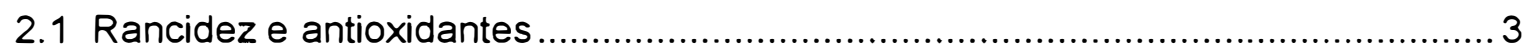

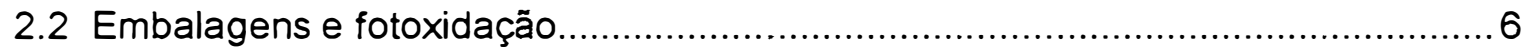

2.3 Avaliação da estabilidade oxidativa de óleos e gorduras.....................................

2.4 Efeito do aquecimento por microondas em lipídios............................................ 10

2.5 Características de óleos de canola, milho e soja ............................................ 15

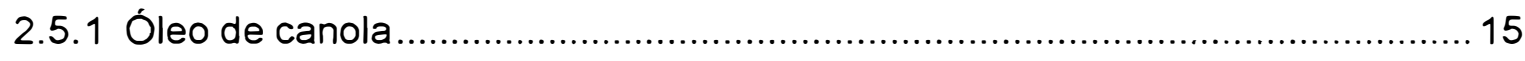

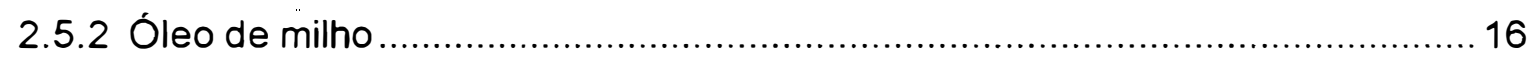

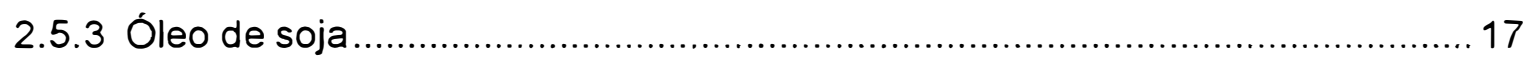

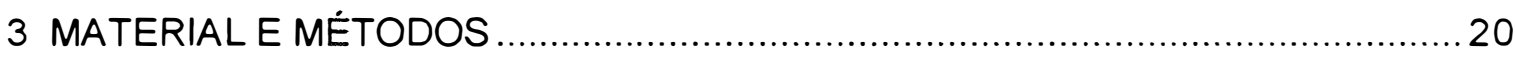

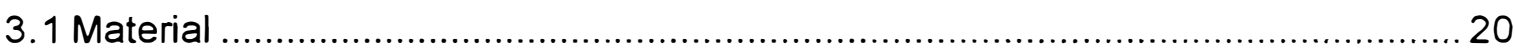

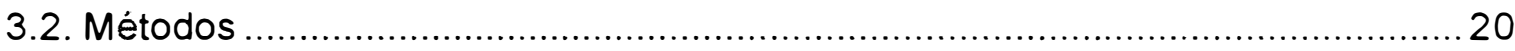

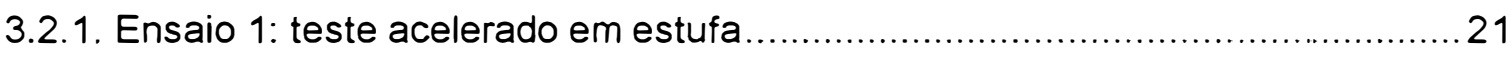

3.2.2. Ensaio 2: teste acelerado - aquecimento por microondas ............................... 21

3.2.3. Ensaio 3: armazenamento em condições normais de temperatura e

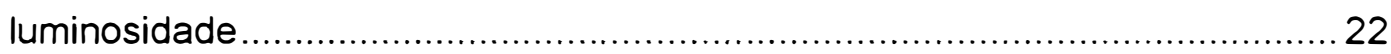

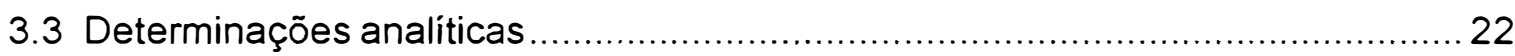

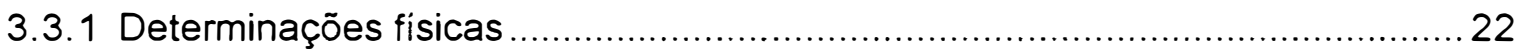

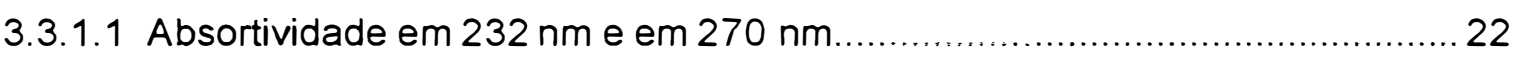

3.3.1.2 Espectro de absortividade na faixa do espectro ultravioleta - $220 \mathrm{~nm}$ a

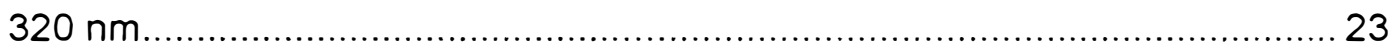

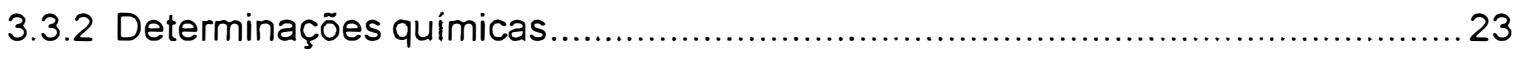

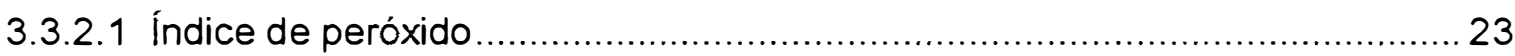




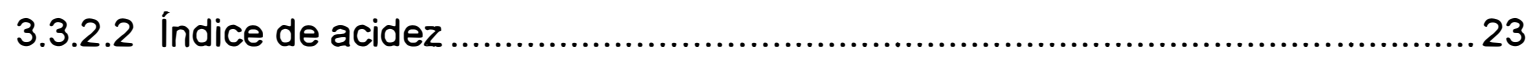

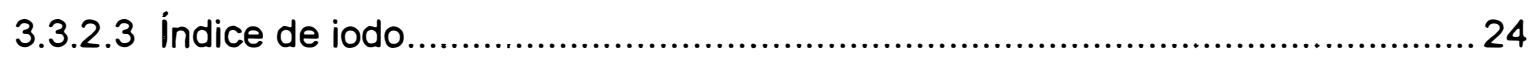

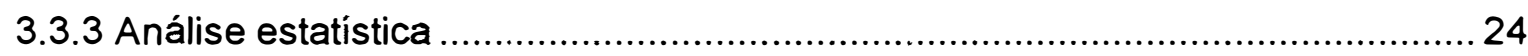

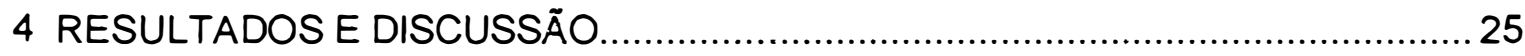

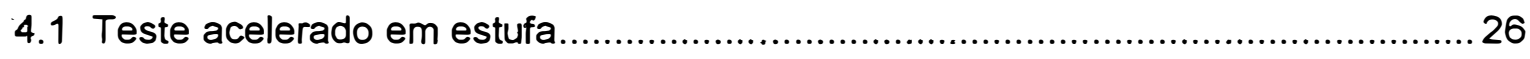

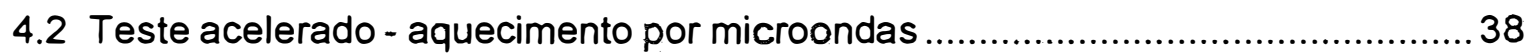

4.3 Armazenamento em condições normais de temperatura e luminosidade ............. 47

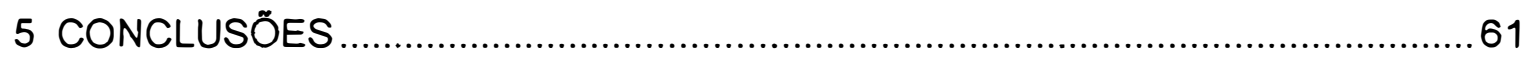

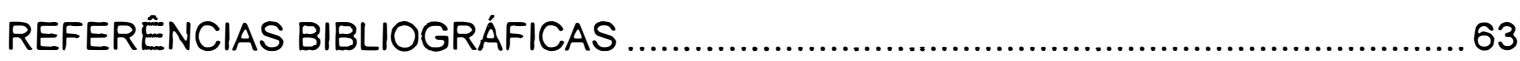




\section{LISTA DE FIGURAS}

página

1 Espectros de absortividade iniciais dos óleos de canola, milho e soja. 26

2 Índice de peróxido $\left(\right.$ meq $\mathrm{kg}^{-1}$ ) de óleo de canola submetido ao teste em estufa a $63^{\circ} \mathrm{C}$

3 Absortividade em $232 \mathrm{~nm}$ de óleo de canola submetido ao teste em estufa a $63^{\circ} \mathrm{C}$

4 Índice de peróxido (meq $\mathrm{kg}^{-1}$ ) de óleo de mitho submetido ao teste em estufa a $63^{\circ} \mathrm{C}$.

5 Absortividade em $232 \mathrm{~nm}$ de óleo de milho submetido ao teste em estufa a $63^{\circ} \mathrm{C}$

6 Índice de peróxido (meq $\left.\mathrm{kg}^{-1}\right)$ de óleo de soja submetido ao teste em estưa a $63^{\circ} \mathrm{C}$

7 Absortividade em $232 \mathrm{~nm}$ de óleo de soja submetido ao teste em estufa a $63^{\circ} \mathrm{C}$

8 Espectros de absortividade entre 220 e $320 \mathrm{~nm}$ de óleo de canola submetido ao teste em estufa a $63^{\circ} \mathrm{C}$.

9 Espectros de absortividade entre 220 e $320 \mathrm{~nm}$ de óleo de milho submetido ao teste em estufa a $63^{\circ} \mathrm{C}$

10 Espectros de absortividade entre 220 e $320 \mathrm{~nm}$ de óleo de soja súbmetido ao teste em estufa a $63^{\circ} \mathrm{C}$

11 Tempo de exposição e temperatura média dos óleos aquecidos em forno de microondas.

12 Absortividade em $232 \mathrm{~nm}$ de óleo de canola aquecido em forno de microondas.

13 Absortividade em $232 \mathrm{~nm}$ de óleo de milho aquecido em forno de microondas 
14 Absortividade em $232 \mathrm{~nm}$ de óleo de soja aquecido em forno de microondas.

15 Absortividade em $270 \mathrm{~nm}$ de óleo de canola aquecido em forno de microondas.

16 Absortividade em $270 \mathrm{~nm}$ de óleo de milho aquecido em forno de microondas.

17 Absortividade em $270 \mathrm{~nm}$ de óleo de soja aquecido em forno de microondas.

18 Espectros de absortividade entre 220 e 320 nm dos óleos de canola, milho e soja aquecidos em forno de microondas.

19 Índice de peróxido (meq $\mathrm{kg}^{-1}$ ) de óleo de canola aquecido em forno de microondas

20 Índice de peróxido $\left(m e q \mathrm{~kg}^{-1}\right)$ de óleo de milho aquecido em forno de microondas

21 Índice de peróxido (meq $\mathrm{kg}^{-1}$ ) de óleo de soja aquecido em forno de microondas

22 Índice de peróxido (meq $\mathrm{kg}^{-1}$ ) de óleo de canola armazenado em frascos de PET em condições de comercialização

23 Índice de peróxido (meq $\mathrm{kg}^{-1}$ ) de óleo de milho armazenado em frascos de PET em condições de comercialização.

24 Índice de peróxido (meq $\mathrm{kg}^{-1}$ ) de óleo de soja armazenado em-frascos de PET em condições de comercialização

25 Espectros de absortividade entre 220 e $320 \mathrm{~nm}$ dos óleos de canola, milho e soja armazenados em frascos de PET em condições de comercialização. 


\section{LISTA DE TABELAS}

página

1 Máxima absorção dos principais grupos cromóforos dos produtos da oxidação.

2 Composição padrão em ácidos graxos de óleos de canola, milho e soja. 18

3 Faixas de variação e médias $\left(\mathrm{mg} \mathrm{kg}^{-1}\right)$ de teores de tocoferóis ( $\mathrm{T}$ ) e tocotrienóis $\left(T_{3}\right)$ em óleos de canola, milho e soja.

4 Caracterização inicial dos óleos de canola, milho e soja. 25

5 Absortividade em $270 \mathrm{~nm}$ de óleo de canoia submetido ao teste em estufa a $63^{\circ} \mathrm{C}$

6 Absortividade em $270 \mathrm{~nm}$ de óleo de milho submetido ao teste em estufa a $63^{\circ} \mathrm{C}$

7 Absortividade em $270 \mathrm{~nm}$ de óleo de soja submetido ao teste em estufa a $63^{\circ} \mathrm{C}$

8 Índice de acidez (\% AGL) de óteos de canola, mitho e soja aquecidos em forno de microondas.

9 Temperatura e de umidade relativa ambientes durante 0 armazenamento em condições normais de comercialização de óleos de canola, milho e soja embalados em frascos de PET

10 Absortividade em $232 \mathrm{~nm}$ de óleo de canola armazenado em frascos de PET em condições de comercialização.

11 Absortividade em $232 \mathrm{~nm}$ de óleo de milho armazenado em frascos de PET em condições de comercialização.

12 Absortividade em $232 \mathrm{~nm}$ de óleo de soja armazenado em frascos de PET em condições de comercialização

13 Absortividade em $270 \mathrm{~nm}$ de óleo de canola armazenado em frascos de PET em condições de comercialização. 
14 Absortividade em $270 \mathrm{~nm}$ de óleo de milho armazenado em frascos de PET em condições de comercialização.

15 Absortividade em $270 \mathrm{~nm}$ de óleo de soja armazenado em frascos de PET em condições de comercialização.

16 índice de acidez (\% AGL) de óleos de canola, milho e soja armazenados em frascos de PET em condições de comercialização

17 Índice de iodo segundo Wijs (mg iodo $100 \mathrm{mg}^{-1}$ ) de óleos de canola, milho e soja armazenados em frascos de PET em condições de comercialização. 59 


\section{LISTA DE ABREVIATURAS E SIMBOLOS}

$\mathrm{AC}=$ ácido cítrico

$A G L=$ ácidos graxos livres

$\mathrm{AP}=$ palmitato de ascorbila

$\mathrm{BHA}=$ butil hidroxianisol

$\mathrm{BHT}=$ butil hidroxitolueno

C.V. = coeficiente de variação $(\%)$

$\mathrm{cm}=$ centímetros

d.m.s. = diferença mínima significativa

GLC = cromatografia gás-líquida

$\mathrm{Hz}=\mathrm{Hertz}$ - ciclos por segundo

$\min =$ minutos

$\mathrm{nm}=$ nanômetros

$\mathrm{PET}=$ polietileno tereftalato

TBA = ácido tiobarbitúrico

$T B H Q=$ terc-butil hidroquinona

UV = ultravioleta

$W=$ watts 


\section{ESTABILIDADE OXIDATIVA DE ÓLEOS VEGETAIS REFINADOS: EFEITO DO AQUECIMENTO POR MICROONDAS}

Autora: THAIS MARIA FERREIRA DE SOUZA VIEIRA

Orientadora: Prof ${ }^{a}$. Dr. ${ }^{a}$ MARISA APARECIDA BISMARA REGITANO-D'ARCE

\section{RESUMO}

O efeito do aquecimento por microondas sobre a estabilidade oxidativa de óleos refinados de canola, milho e soja foi determinado através de análises físicas (absortividade na faixa do espectro UV) e quimicas (indice de peróxido e de acidez). Amostras de óleo, adicionadas de $200 \mathrm{mg} \mathrm{kg}^{-1}$ de BHA/BHT (1:1), $200 \mathrm{mg} \mathrm{kg}^{-1} \mathrm{de}$ BHA/BHT (1:1) + $100 \mathrm{mg} \mathrm{kg}^{-1}$ de $A C$ e de $100 \mathrm{mg} \mathrm{kg}^{-1}$ de $A C$ foram aquecidas em um forno de microondas $(800 \mathrm{~W}, 2450 \mathrm{MHz})$ por periodos de 0 a $36 \mathrm{~min}$. A mistura dos antioxidantes $B H A / B H T$, adicionada ou não de $A C$, foi eficiente em retardar a oxidação dos óleos durante ensaio acelerado em estufa $\left(63^{\circ} \mathrm{C}\right)$ e, portanto, foi utilizada no ensaio acelerado em forno de microondas. $O$ aquecimento por microondas promoveu a oxidação em todos os óleos. As medidas de absortividade em $232 \mathrm{~nm}$ e em $270 \mathrm{~nm}$ foram crescentes com o aumento do periodo de exposição às microondas, indicando a ocorrência do processo oxidativo. A absortividade em 232 
$\mathrm{nm}$ do controle aumentou de 4,812, 3,568 e 4,183 para 10,579, 12,874 e 15,950 depois de 36 min de aquecimento nos óleos de canola, milho e soja, respectivamente. Devido à formação de dienos conjugados, compostos da oxidação, a absortividade em $232 \mathrm{~nm}$ se mostrou um bom indice para o acompanhamento do efeito do aquecimento por microondas sobre a estabilidade oxidativa dos três óleos. Através do espectro traçado na faixa de 220 a $320 \mathrm{~nm}$ para todas as amostras testadas foi possivel acompanhar as alterações ocorridas. $O$ indice de acidez também sofreu aumento até 36 minutos de aquecimento em todos os óleos. $O$ índice de peróxido sofreu aumentos significativos no estágio inicial de aquecimento ( 0 - $6 \mathrm{~min}$ ) em todos os óleos, mas a partir daí as alterações não puderam ser relacionadas aos valores obtidos para a absortividade em $232 \mathrm{~nm}$, devido à instabilidade dos hidroperóxidos às altas temperaturas. Os valores de absortividade em $232 \mathrm{~nm}$ do controle apresentados após 6 dias de teste acelerado em estufa foram proporcionais àqueles apresentados pelas amostras de óleos de canola, milho e soja aquecidos durante 32-36 min em forno de microondas, mas os antioxidantes que se apresentaram eficientes no teste acelerado em estufa não tiveram efeito durante 0 aquecimento por microondas. Os antioxidantes não foram eficientes em retardar a oxidação dos óleos embalados em frascos de PET e armazenados durante 180 dias em condições normais de comercialização. Assim como $\circ$ teste em estufa, o aquecimento em forno de microondas deve servir como um teste acelerado para a avaliação da estabilidade oxidativa de óleos. 


\title{
OXIDATIVE STABILITY OF REFINED, BLEACHED, DEODORIZED VEGETABLE OILS: EFFECT OF MICROWAVE HEATING
}

\author{
Author: THAIS MARIA FERREIRA DE SOUZA VIEIRA \\ Adviser: Prof. Dr. MARISA APARECIDA BISMARA REGITANO-D'ARCE
}

\section{SUMMARY}

The effect of microwave heating on the oxidative stability of canola, com and soybean oils was determined by absorptivity in the UV spectrum and by chemical analysis (peroxide and acid values). Oil samples with butylated hydroxyanisole/toluene (BHA/BHT -1:1) - $200 \mathrm{mg} \mathrm{kg}^{-1}$, BHA/BHT (1:1) - $200 \mathrm{mg} \mathrm{kg}^{-1}+$ citric acid (CA) - $100 \mathrm{mg}$ $\mathrm{kg}^{-1}$ and CA - $100 \mathrm{mg} \mathrm{kg}^{-1}$ were heated in a microwave oven (800 W, 2,450 MHz) for 0 to $36 \mathrm{~min}$. The antioxidants $\mathrm{BHA} / \mathrm{BHT}$, with or without $\mathrm{CA}$, were effective in retarding oil oxidation during an accelerated oven essay $\left(63^{\circ} \mathrm{C}\right)$ and were used in the accelerated essay in microwave oven. Microwave heating produced oxidative degradation in the three oils. Absorptivity at 232 and $270 \mathrm{~nm}$ increased gradually with an increase of microwave exposure time (0-36 $\mathrm{min}$ ) for canola, com and soybean oils. Control values of absorptivity at $232 \mathrm{~nm}$ increased from $4.812,3.568$ and 4.183 to $10.579,12.874$ and 15.950 after 36 min of heating in canola, com and soybean oil, 
respectively. The absorptivity at $232 \mathrm{~nm}$, due to the formation of conjugated dienes, was a good index for measuring the degradation of microwaved samples. UV scanning $(220-320 \mathrm{~nm})$ detected alterations in the spectrum of microwaved samples. The acid value also increased within $36 \mathrm{~min}$ of heating for all oils. Peroxide value showed a significant difference $(P<0.05)$ in the initial stage of heating $(0-6 \mathrm{~min})$ for all oils. After this period it could not be correlated with absorptivity at $232 \mathrm{~nm}$, due to the instability of hydroperoxides at high temperature. Control values of absorptivity at $232 \mathrm{~nm}$ showed by canola, com and soybean oil samples after 6 days of oven test were similar to that showed after 32-36 min of heating by microwave. However, the antioxidants that were efficient in the oven test did not show effect during microwave heating. The antioxidants were not effective in retarding oil oxidation during ambient temperature storage of samples packaged in PET flasks for 180 days. Heating in microwave oven may be employed as an accelerated test for evaluation of oil oxidative stability, as the oven test. 


\section{INTRODUÇÃO}

O mecanismo de ação do aquecimento por microondas sobre óleos e gorduras difere do aquecimento convencional. O processo de aquecimento por microondas ocorre devido à fricção e excitação molecular, levando o alimento a atingir rapidamente altas temperaturas. O aquecimento por microondas é influenciado por características do equipamento (freqüência e potência) e do alimento (massa, umidade, estado físico, densidade, temperatura, geometria, tamanho, condutividade elétrica, condutividade térmica e calor específico). Em alimentos com maior umidade o fator de perda dielétrica e a constante dielétrica são maiores e, portanto, mais completo é o aquecimento. Alimentos de baixa polaridade elétrica, como os lipídios, apresentam pouca perda dielétrica. No entanto, os baixos niveis de calor gerados por lipídios são compensados pelo seu baixo calor específico, o que faz com que sejam aquecidos rapidamente, apesar do seu baixo fator de perda dielétrica.

Poucos estudos publicados sobre as modificações nos parâmetros químicos e físicos de óleos vegetais submetidos ao aquecimento por microondas esclarecem as condições experimentais utilizadas (quantidade e distribuição das amostras de óleo expostas às microondas, potência utilizada) e a maioria desses estudos somente relaciona o uso do forno de microondas a aspectos nutricionais (perdas de vitaminas e formação de ácidos graxos trans).

A oxidação de ácidos graxos polinsaturados pode ser acompanhada pelo aumento da absorção do lipídio na faixa do espectro ultravioleta. Lipídios contendo dienos ou polienos sofrem uma alteração na posição de suas duplas ligações durante a oxidação, resultado de isomerização e conjugação. Este estudo visou a 
acompanhar as alterações oxidativas, através de análises espectrofotométricas na faixa do espectro UV, que ocorrem nos óleos refinados de canola, milho e soja submetidos ao aquecimento por microondas, mantendo condições regulares e específicas. O efeito do aquecimento por microondas e a ação de antioxidantes adicionados aos óleos foi relacionado às alterações ocorridas nos mesmos óleos quando submetidos ao teste em estufa (aquecimento convencional $-63^{\circ} \mathrm{C}$ ) e ao armazenamento em condições normais de temperatura e luminosidade.

Os óleos adicionados de antioxidantes $\left(200 \mathrm{mg} \mathrm{kg}^{-1}\right.$ de butil tridroxianisol $\mathrm{e}$ butil hidroxitolueno - BHA/BHT 1:1; $200 \mathrm{mg} \mathrm{kg}^{-1}$ de BHAJBHT 1:1+100 $\mathrm{mg} \mathrm{kg}^{-1}$ de ácido cítrico - $\mathrm{AC} ; 100 \mathrm{mg} \mathrm{kg}^{-1}$ de AC) foram anatisados quanto à absortividade em 232 e $270 \mathrm{~nm}$, espectro de absortividade entre 220 e $320 \mathrm{~nm}$, índice de peróxido e indice de acidez.

Assim como o teste acelerado em estufa, o aquecimento em forno de microondas pode ser uma ferramenta para a avaliação da estabilidade oxidativa de óleos e as relações determinadas neste estudo são importantes para a avaliação das alterações oxidativas que ocorrem em amostras aquecidas por microondas. 


\section{REVISÃO DE LITERATURA}

\subsection{Rancidez e antioxidantes}

A oxidação de lipídios tem sido mencionada desde a antigüidade como a maior causa de deterioração de óleos e gorduras que leva à formação de sabores e aromas desagradáveis nos produtos, sendo há tempo, portanto, motivo de investigação. A oxidação pode resultar em compostos de ranço que alteram as características organolépticas de produtos, tornando-os inaceitáveis para o consumidor e podendo causar outros efeitos de degradação como escurecimento ou alteração da coloração, destruição de vitaminas, perdas nutricionais e polimerização (Rovellini et al., 1997; Shahidi, 1995; Sherwin, 1978).

Muitos autores têm revisado os mecanismos envolvidos na oxidação lipidica e os conseqüentes efeitos da oxidação lipídica em alimentos. A autoxidação de ácidos graxos insaturados ocorre basicamente em três etapas: iniciação, propagação e terminação. A iniciação começa quando o átomo de hidrogênio adjacente à dupla ligação do ácido graxo é liberado por ação de luz, calor ou de ions metálicos. Formase um radical livre que reage com o oxigênio atmosférico para formar um radical peróxido instável, o qual pode tomar a liberar outro átomo de hidrogênio de um ácido graxo insaturado para a formação de um hidroperóxido e de um novo radical livre. Esse novo radical livre prossegue a oxidação e contribui para as reações em cadeia (Shahidi, 1995; Simic et al., 1992; Gray, 1978; Rovellini et al., 1997).

As reações em cadeia (propagação) podem terminar com a formação de compostos não-radicais (Shahidi, 1995). Da quebra dos hidroperóxidos surgem os 
compostos responsáveis pelo odor de ranço (álcoois, cetonas, aldeídos e hidrocarbonetos). Esses compostos podem interagir com o alimento e provocar alterações nutricionais nos alimentos (Sherwin, 1978).

Os fatores que influenciam a oxidação de lipídios são: a quantidade e disponibilidade de oxigênio presente, grau de insaturação dos ácidos graxos, presença de metais e enzimas, presença de ativadores como a luz e aporte energético em geral. $\dot{E}$ difícil avaliar o efeito de um fator específico no processo de oxidação, pois eles agem simultaneamente (Rovellini et al., 1997). Portanto, os fatores responsáveis pela iniciação do processo oxidativo autocatalítico (enzimas, metais, calor, luz e presença de oxigênio) devem ser minimizados ao máximo para que seja evitada a instalação do ranço (Johansson, 1976) e a adição de antioxidantes é uma forma de prevenir o desenvolvimento da rancidez.

O uso de antioxidantes está sujeito à legislação de cada país, assim como os limites em que podem ser utilizados em vários tipos de alimentos e suas doses máximas permitidas. No Brasil o uso de antioxidantes é regulamentado pelo Ministério da Saúde, através da Resolução n. ${ }^{\circ} 22 \pi 7$ do decreto lei n. ${ }^{\circ} 986$ (Brasil, 1991).

Compostos de estruturas fenólicas, como o BHA (butilhidroxi anisol) e o BHT (butilhidroxi tolueno) são antioxidantes que agem como receptores de radicais livres e apresentam completa dissolução em óleos (Sherwin, 1978). Freqüentemente, utilizam-se combinações de antioxidantes para a obtenção de melhores efeitos através do sinergismo. Os antioxidantes sinérgicos são utilizados para reforçar ou prolongar a ação dos antioxidantes sintéticos, pois quando usados isoladamente têm pouca atuação. Os antioxidantes sinérgicos agem de forma a regenerar o antioxidante primánio.

Omura (1995) elucidou o mecanismo de sinergismo existente numa mistura de BHA com BHT, que pode ser afetado por base ou ácido. Em princípio, a desidrogenação de um fenol por um radical fenoxi é um processo reversivel e existe reação reversa de desidrogenação de $\mathrm{BHT}$ com radical-BHA.

Avaliações sensoriais e físico-químicas em óleo de canola refinado adicionado de $\mathrm{BHA} / \mathrm{BHT}$ ou de TBHQ (terc-butil hidroquinona) submetido a procedimentos domésticos de aquecimento (frituras: 12 e 60 min a $185^{\circ} \mathrm{C}$ ) foram conduzidas por Hawrysh 
et al. (1990). Os resultados físico-químicos (valor de p-anisidina, absortividade em 234 e $268 \mathrm{~nm}, \%$ de ácidos graxos livres, ponto de fumaça e viscosidade) mostraram que os antioxidantes (BHA/BHT - $200 \mathrm{mg} \mathrm{kg}^{-1}$ e TBHQ - $200 \mathrm{mg} \mathrm{kg}^{-1}$ ) apresentaram um pequeno, mas estatisticamente significativo, efeito em retardar a degradação térmica.

Sinergismo também pode ser obtido utilizando-se substâncias não antioxidantes, como, por exemplo, alguns quelantes como o ácido cítrico. Estas substâncias são chamadas agentes seqüestrantes, pois possuem capacidade de ligar ions metálicos (ferro e cobre) para que estes não catalisem processos de oxidação (Rovellini et al., 1997; Lauridsen \& Schultz, 1994).

Segundo Cort (1974), o ácido ascórbico e o palmitato de ascorbila funcionam como seqüestrantes de oxjgênio e por isso são utilizados com a função de remover o oxigênio do espaço superior de sistemas de embalagens já fechados. McMullen et al. (1991) estudaram o efeito de vários niveis de palmitato de ascorbila (AP) e de BHA/BHT no óleo refinado de canola, a fim de elevar a estabilidade do óleo durante o periodo de armazenamento. Foi conduzido o teste acelerado em estufa $\left(65^{\circ} \mathrm{C}\right.$, por 16 dias) acompanhado por análises quimicas e sensoriais. Comparando-se o efeito da adição de $100 \mathrm{mg} \mathrm{kg}^{-1}$ de BHA/BHT e de $200 \mathrm{mg} \mathrm{kg}^{-1}$ de AP ao óleo de canola, concluiu-se que 200 $\mathrm{mg} \mathrm{kg}^{-1}$ de AP foi o melhor tratamento para manter a estabilidade do óleo após 12 dias de teste acelerado.

Estudos têm demonstrado que a adição do AP aos óleos de soja e de milho é efetiva para protegê-los da autoxidação (Cort, 1974). Apesar do seu poder antioxidante, o AP apresenta um inconveniente: é pouco solúvel em óleos e deve ser incorporado na forma de uma solução em etanol a 5\%, o que traz dificuldades para a difusão do seu uso.

Wamer et al. (1989) avaliaram o efeito de $100 \mathrm{mg} \mathrm{kg}^{-1}$ de ácido citrico sobre a estabilidade oxidativa de óleos refinados de soja, girassol e canola. Foram realizados testes acelerados em estufa (Schaal oven test modificado) a $60^{\circ} \mathrm{C}$, no escuro, e sob luz fluorescente (7350 lux) e o ácido citrico se mostrou eficiente nas duas condições e em todos os óleos. 


\subsection{Embalagens e fotoxidação}

Além da adição de antioxidantes, o sistema embalagem utilizado influencia a instalação ou não do ranço em óleos vegetais. A função principal de uma embalagem é oferecer proteção a fim de aumentar a vida de prateleira do alimento, devendo apresentar uma boa barreira ao oxigênio, à umidade e às radiações luminosas (Faria, 1991; Faria, 1994).

No entanto, se durante muito tempo a embalagem foi apenas utilizada como uma proteção ao seu produto, atualmente assume importância como instrumento de "marketing" e principal elo de ligação entre o consumidor e o produto. Essa ligação entre consumidor e embalagem passou a exigir cuidados maiores na criação e desenvolvimento de sistemas de embalagens (Leme, 1994).

Sabe-se que a luz determina um papel importante não apenas na estabilidade do aroma dos óleos vegetais e outras gorduras insaturadas, mas também na destruição de pigmentos e vitaminas (Faria \& Espinoza-Atencia, 1993). Segundo Bekbölet (1990) o efeito deteriorativo da luz em óleos, gorduras e alimentos contendo gorduras é conhecido desde 1899. O mecanismo de fotoxidação é diferente do mecanismo que ocorre na autoxidação clássica, com formação de radicais livres. Na presença de radiação ocorre a formação do oxigênio "singlet", 1500 vezes mais reativo que o oxigênio normal ("triplet") (Rovellini et al., 1997). O singleto é formado pela ação do UV e, portanto, óleos em embalagens transparentes que ficam expostos à luz têm na fotoxidação a principal reação e uma vida de prateleira menor (Lugasi et al., 1995). A luz também atua na degradação dos hidroperóxidos, mediante a fotólise, originando compostos voláteis tais como aldeídos, cetonas e álcoois (Espinoza-Atencia \& Faria, 1994). A parte do espectromagnético denominada luz visivel está na faixa de 400 a $700 \mathrm{~nm}$. As fontes de luz visivel podem ser naturais (solar) e artificiais (fluorescente e incandescente), contendo espectros com teores de radiação UV que induzirão a fotoxidação dos alimentos fotossensiveis (Gachter \& Muller, 1987). O oxigênio "singlet", segundo Kanner (1992), também pode ser gerado por descargas de microondas e por reações químicas e fotoquimicas.

Lugasi et al. (1995) expuseram óleos de soja, girassol, oliva, margarina e banha à luz ultravioleta por periodos de 20 minutos a 6 horas e verificaram a peroxidação lipídica, composição em ácidos graxos e quantidades de tocoferol e colesterol após cada 
tratamento. $O$ indice de peróxido e valor de TBA (ácido tiobarbitúrico) aumentaram significativamente após a exposição, principalmente após 6 horas.

Sattar \& deMan (1975) observaram um decréscimo nas taxas de oxidação com o aumento dos comprimentos de onda da luz incidente. A questão sobre quais comprimentos de onda são responsáveis pelos danos atribuidos à luz ainda não têm solução mas para Bekbölet (1990), embalagens de materiais que transmitem comprimentos de onda entre $490 \mathrm{~nm}$ e $589,5 \mathrm{~nm}$, que correspondem ao azul-esverdeado, verde e amarelo, podem proteger os óleos contra o desenvolvimento do ranço. Dai a importância da proteção do sistema de embalagem utilizado para óleos vegetais.

Dentre as embalagens plásticas, o PET (polietileno tereftalato) se destaca por apresentar resistência química e não reagir com ácidos, bases e vários solventes (Leme, 1994). O vidro, apesar de seu alto custo e peso elevado, é uma altemativa de embalagem para óleos comestiveis, para mercados que exigem condições menos artificiais e conservação ecológica, por ser reciclável (Espinoza-Atencia \& Faria, 1994). As embalagens plásticas, no entanto, apresentam uma tendência de substituir o vidro por razões econômicas (peso) e práticas (resistência a choques) e de substituir o metal, igualmente por razões econômicas e práticas (transparência e conservação depois de aberta) (Leme, 1994).

\subsection{Avaliação da estabilidade oxidativa de óleos e gorduras}

Existem vários métodos para avaliação da oxidação lipídica em alimentos. Alterações químicas, físicas ou nas propriedades organolépticas do óleo durante a oxidação podem ser acompanhadas. Entretanto, não há um esquema padrão para detecção de todas as alterações oxidativas em todos os tipos de alimentos. Os métodos para acompanhamento de oxidação lipídica em alimentos podem ser divididos em aqueles que medem as alterações primárias e aqueles que medem as alterações secundárias (Shahidi, 1995; Dutton, 1978).

As alterações primárias geralmente são medidas pela (a) diminuição dos ácidos graxos insaturados, (b) utilização de oxigênio ou ganho de peso, (c) índice de peróxido e (d) valor de dienos conjugados. As alterações secundárias são 
monitoradas por quantificação de (a) carbonilas, determinada por cromatografia gasosa ou como dinitrofenil hidrozona, (b) equivalente em malonaldeido e outros aldeídos (tesste de ácido tiobarbitúrico - TBA e de p-anisidina), (c) hidrocarbonetos (conteúdo de pentano ou etano) e (d) produtos fluorescentes (conteúdo de 1-amino-3iminopropano). $\dot{E}$ recomendado que se use uma combinação de métodos para verificação das alterações primárias e secundárias do óleo (Shahidi, 1995).

$\mathrm{Na}$ oxidação de óleos e gorduras, a taxa inicial de formação de hidroperóxidos excede sua taxa de decomposição, mas isso é revertido nos estágios posteriores. Determinar a quantidade de hidroperóxidos em função do tempo para obtenção de uma curva de concentração de hidroperóxido pode ser uma informaçãoguia para aceitação de produtos. Pelo ganho de peso durante um período de incubação, seguido pela quantificação de hidroperóxidos, pode-se determinar o efeito de antioxidantes na estabilidade de óleos e gorduras. O método clássico para quantificação de hidroperóxidos é a determinação do índice de peróxido (Shahidi, 1995). No entanto, os hidroperóxidos são produtos intermediários na formação de carbonilas e hidroxi-compostos. Um teste acelerado a $100^{\circ} \mathrm{C}$ mostrou que o índice de peróxido passa por um valor máximo e é muito sensível à variações de temperatura (Gray, 1978).

A oxidação de ácidos graxos polinsaturados é acompanhada do aumento da absortividade do lipídio na faixa do espectro ultravioleta. Lipídios contendo dienos ou polienos apresentam uma alteração na posição de suas duplas ligações durante a oxidação, resultado de isomerização e conjugação. Os dienos conjugados exibem uma intensa absorção em $234 \mathrm{~nm}$, da mesma forma que trienos conjugados absorvem em 268 nm (Shahidi, 1995). A Tabela 1 apresenta os comprimentos de onda em que outros compostos formados durante a oxidação lipídica apresentam máxima absorção.

St. Angelo et al. (1975) estudaram a autoxidação de manteiga de amendoim através da avaliação do índice de peróxido e aumento na absortividade em $234 \mathrm{~nm}$. Shahidi (1995) ressaltou que dienos conjugados e índice de peróxido são bem correlacionados durante a oxidação de óleos marinhos (baleia e bacalhau) e vegetais (canola e soja). Também concluiu que o método de dienos conjugados pode 
ser utilizado como um índice de estabilidade de lipídios. O método de dienos conjugados é mais rápido que a determinação do indice de peróxido e muito simples, pois não depende de reações químicas ou desenvolvimento de coloração e requer uma pequena quantidade de amostra (Gray, 1978).

Tabela 1. Máxima absorção dos principais grupos cromóforos dos produtos da oxidação.

\begin{tabular}{ll}
\hline Composto & UV (máximo nm) \\
\hline monoeno & 190 \\
dieno & $220-230$ \\
trieno & $265-270$ \\
tetraeno & $310-320$ \\
aldeido cetônico & $265-280$ \\
aldeido cetônico $\alpha, \beta$ etilênico & $220-250$ \\
& $310-330$ \\
$\alpha$-dicetona & 280 \\
$\alpha$-cetoaldeído & 282 \\
$\beta$-dicetona & 274 \\
ácido $\alpha$-cetônico & 210 \\
\hline
\end{tabular}

Fonte: Rovellini et al. (1997)

A indústria de óleos comestiveis tem procurado um teste analítico rápido para predizer quantitativamente a susceptibilidade de um óleo quanto à deterioração autoxidativa. Há alguns anos, começaram a ser comercializados o Rancimat e o Oil Stability Instrument (OSI), ambos baseados no método condutimétrico desenvolvido por Hadorn \& Zürcher (1975) ${ }^{\uparrow}$ (citados em Uma Comparação, 1995).

O OSI e o Rancimat são utilizados como métodos para escolha de gorduras e estudos de estabilidade pelas indústrias (Shahidi, 1995), mas não servem para

\footnotetext{
'HADORN, H. \& ZÜRCHER, K. Disch. Lebensmittel Rdsch. v. 70, p.57, 1974 Apud UMA COMPARAÇÃO entre instrumentos modernos para a análise de estabilidade oxidativa de óleos, gorduras e alimentos. Óleos e Grāos, n.26, p. 47-51, set.out. 1995.
} 
predizer a vida-de-prateleira de óleos. O teste acelerado em estufa também é bastante utilizado e muitos ensaios para a verificação do efeito de antioxidantes são baseados nesse teste. Hawrysh et al. (1988) compararam o efeito de $200 \mathrm{mg} \mathrm{kg}^{-1}$ de TBHQ ao efeito de $200 \mathrm{mg} \mathrm{kg}^{-1}$ de BHA/BHT, combinados ou não com ácido citrico, utilizando o "Schaal oven test" (frascos com $75 \mathrm{~mL}$ de óleo em estufa a $65^{\circ} \mathrm{C}$ ) por até 16 dias. $O$ indice de peróxido aumentou de 0,67 meq $\mathrm{kg}^{-1}$ para 61,71 , no controle, após os 16 dias de armazenamento. O óleo com BHA/BHT sofreu um aumento para 40,00 e o com TBHQ, para 3,40. A eficácia do TBHQ não foi melhorada com a adição de ácido cítrico.

Os efeitos de galato de propila (PG) com e sem palmitato de ascorbila (AP) e monoglicerídeo citrato (MGC) também foram avaliados por Hawrysh et al. (1992) em um teste em estufa com óleo refinado de canola. Após 12 dias na estufa, as análises indicaram que a adição de $P G+A P\left(200+200 \mathrm{mg} \mathrm{kg}^{-1}\right.$ ou $\left.100+200 \mathrm{mg} \mathrm{kg}{ }^{-1}\right)$ foi efetiva em retardar a oxidação.

Wanasundara \& Shahidi (1994) realizaram um teste acelerado em estufa a $65^{\circ} \mathrm{C}$ utilizando amostras de $25 \mathrm{~mL}$ de óleo de canola, acondicionadas em frascos abertos, por até 17 dias. Foram avaliados vários antioxidantes sintéticos e um extrato etanólico de canola. $O$ índice de peróxido e a absortividade em $234 \mathrm{~nm}$ mostraram que o BHA/BHT (200 mg kg-1) e o extrato de canola (500 e $1000 \mathrm{mg} \mathrm{kg}^{-1}$ ) apresentaram efeito protetor, mas não tão eficiente quanto o TBHQ (200 mg kg $\left.{ }^{-1}\right)$.

O TBHQ (200 mg kg $\left.{ }^{-1}\right)$ também foi muito eficiente em proteger o óleo bruto de castanha do Pará da oxidação durante um ensaio acelerado em estufa a $63^{\circ} \mathrm{C}$ e a adição do antioxidante ao óleo também retardou a degradação oxidativa durante o armazenamento em condições ambientes (em frascos de vidro) por 180 dias (Regitano-d'Arce \& Vieira, 1996).

\subsection{Efeito do aquecimento por microondas em lipídios}

A maioria dos trabalhos iniciais sobre o uso da energia de microondas foi direcionada para o desenvolvimento de radar para fins militares durante a segunda guerra mundial. Em 1947, o primeiro forno tornou-se disponivel para empresas de 
alimentos e, em 1955, foi lançado no mercado o forno de microondas doméstico, nos Estados Unidos (Mermelstein, 1997; Schiffmann, 1992; Decareau, 1985; Thuery, 1983).

As microondas são ondas eletromagnéticas de freqüência entre $300 \mathrm{MHz}$ e $300 \mathrm{GHz}$ que podem ser absorvidas, transmitidas ou refletidas, dependendo da natureza do material sobre o qual incidem (Giese, 1992; Rosén, 1972). A energia de microondas é gerada por um campo elétrico alternado e considerada não-ionizante (Buffler, 1992; Decareau \& Peterson, 1986). A constante dielétrica (medida da capacidade de um material em armazenar energia elétrica) e o fator de perda dielétrica (capacidade do material em dissipar energia elétrica) são características importantes na determinação do aquecimento por microondas (Datta \& Hu, 1992; Mudgett, 1982).

O aquecimento por microondas é influenciado por características do equipamento (freqüência e potência) e do alimento (massa, umidade, estado físico, densidade, temperatura, geometria, tamanho, condutividade elétrica, condutividade térmica e calor específico). Moléculas que possuem momentos dipolares, como a água, movem-se em resposta ao campo elétrico alternado (geralmente 915 ou 2450 $\mathrm{MHz}$ ) e o calor é gerado como resultado da rotação das moléculas. No gelo o movimento da água é restrito e por isso ele é um pobre absorvedor de microondas (requer alta energia para o descongetamento). f́ons fluem na direção dos pótos do campo dielétrico altemado, contribuindo para geração de calor de fricção (Fellows, 1989; Decareau \& Peterson, 1986; Mudgett et al., 1974).

Alimentos de baixa polaridade elétrica, como os lipídios, apresentam pouca perda dielétrica. No entanto, os baixos niveis de calor gerados por lipídios são compensados pelo seu baixo calor específico, o que faz com que sejam aquecidos rapidamente, apesar do seu baixo fator de perda dielétrica (Loupy, 1994; Buffler, 1992; Fellows, 1989; Copson, 1975).

A existência de um grande interesse sobre o efeito fisiológico potencial dos ácidos graxos trans levou Mai et al. (1980) a estudarem o efeito de tratamento por microondas $(2.450 \mathrm{MHz}, 600 \mathrm{~W})$ sobre a composição em ácidos graxos de vários alimentos lipidicos (gordura de frango, sebo bovino, toucinho, truta arco-íris, óleo de 
amendoim). Concluiram que o uso de microondas no preparo de tais alimentos não promoveu alterações na composição de ácidos graxos e nem isomerizações nos ácidos graxos insaturados. $O$ óleo de amendoim (amostras de $100 \mathrm{~g}$ ) foi exposto ao aquecimento $(675 \mathrm{~W}$ ) por $5,7,10$ e 15 min e avaliou-se a composição em ácidos de cada amostra por cromatografia gasosa. Nenhum ácido graxo trans foi detectado após os 15 min de exposição (Mai et al., 1980).

A estabilidade de óleos de peixes, ricos em ácidos graxos polinsaturados (PUFA), extraidos de espécies frescas com baixo ( $<5 \%)$, médio e alto $(>10 \%)$ teor de gordura, frente à cocção por microondas foi investigada por Thomas et al. (1987). Após 6 min de aquecimento por microondas, verificou-se que não houve destruição de PUFA, confirmando as conclusões de Mai et al. (1980).

O aquecimento de grãos de soja por $5 \min \left(150^{\circ} \mathrm{C}\right)$ não promoveu alterações moleculares nos triacilgliceróis e não causou diminuição nos ácidos graxos insaturados. Entretanto, o aquecimento por $8 \mathrm{~min}\left(170^{\circ} \mathrm{C}\right)$ promoveu um significativo decréscimo no conteúdo de triacilgliceróis e acréscimos no conteúdo de 1,2diacilgliceróis e ácidos graxos livres (Yoshida \& Kajimoto; 1986). Os mesmos autores realizaram um estudo sobre a estabilidade de tocoferóis em grãos de soja aquecidos por microondas e verificaram que $40 \%$ do tocoferol original foi perdido após $12 \mathrm{~min}$ de exposição (Yoshida \& Kajimoto, 1989).

Grãos de gergelim (5,83 g em cada placa de Petri, 5 placas aquecidas simultaneamente) também foram submetidos ao tratamento com microondas por periodos de 2 a $30 \mathrm{~min}$ para verificação das perdas de sesamina, sesamolina, sesamol e tocoferóis. $O$ indice de peróxido do óleo extraido das sementes tratadas por 25 min aumentou de 1,02 para 4,60 meq $\mathrm{kg}^{-1}$ (Yoshida \& Kajimoto, 1994).

Em outro estudo, Yoshida et al. (1990) verificaram o efeito do aquecimento por microondas sobre os tocoferóis de óleos refinados de linhaça, soja, milho, oliva e palma, utilizando amostras de $10 \mathrm{~g}$ em 3 repetições aquecidas simultaneamente. Verificaram que após 8-10 min de aquecimento em microondas as quantidades de tocoferóis dos óleos decresceram substancialmente. Valores de indice de peróxido aumentaram de cerca de 3,0 e 4,0 meq $\mathrm{kg}^{-1}$ para 7,0 e 8,0 , respectivamente, nos óleos de milho e soja, após 20 min de exposição. A estabilidade dos tocoferóis 
também foi investigada em gorduras de origem animal. Perdas consideráveis em sebo bovino e banha foram verificadas após 12-20 min de aquecimento por microondas (Yoshida et al., 1992).

A avaliação de alguns parâmetros físicos e químicos em dois óleos vegetais, refinado de girassol e de oliva virgem, aquecidos por microondas foi realizada por Albi et al. (1995). Amostras de $100 \mathrm{~mL}$ de óleo foram submetidas ao aquecimento convencional em forno elétrico $\left(170^{\circ} \mathrm{C}, 120 \mathrm{~min}\right)$ e ao aquecimento em forno de microondas $\left(40^{\circ} \mathrm{C}, 60 \mathrm{~min}\right.$ e $\left.170^{\circ} \mathrm{C}, 120 \mathrm{~min}, 500 \mathrm{~W}\right)$. As alterações na fração polar dos triacilgliceróis e sua distribuição e a absortividade faixa do ultravioleta e na faixa do visivel foram determinadas. Após o tratamento em forno de microondas em baixa temperatura não foram observadas alterações significativas nos parâmetros avaliados, ao contrário do ocorrido nos tratamentos em altas temperaturas.

Albi et al. (1997a) também verificaram o efeito dos mesmos tratamentos em forno de microondas sobre a degradação termoxidativa de cinco óleos e gorduras comestiveis (girassol, girassol com alto teor de ácido oléico, oliva virgem, oliva refinado e banha). Houve pequenas variações no indice de peróxido em todas as amostras após $120 \mathrm{~min}$ de exposição às microondas com aquecimento (temperatura de $170^{\circ} \mathrm{C}$ - índice de peróxido do óleo de girassol passou de $6,1 \mathrm{meq}^{-1}$ para 8,0) e nenhum parâmetro foi alterado nas amostras submetidas à exposição às microondas sem aquecimento.

Em um estudo complementar, Albi et al. (1997b) verificaram que os valores da absortividade em 232 e $270 \mathrm{~nm}$ para as mesmas amostras citadas anteriormente sofreram acréscimos bastante significativos após os 120 min de aquecimento (de 4,70 para 17,43 e de 3,15 para 5,16 , respectivamente para absortividade em $232 \mathrm{~nm}$ e em $270 \mathrm{~nm}$ do óleo de girassol).

O efeito do aquecimento por microondas sobre óleo de oliva virgem foi comparado ao efeito de uma fritura por Ruiz-Lopez et al. (1995), visando avaliar a perda de $\alpha$-tocoferol. $200 \mathrm{~mL}$ de óleo foram aquecidos por 8 min na potência máxima (não revelada), atingindo $250^{\circ} \mathrm{C}$. $O$ indice de peróxido subiu de 10,4 meq $\mathrm{kg}^{-1}$ para 18,0 e o indice de acidez manteve-se o mesmo $\left(0,42-0,47 \mathrm{mg} \mathrm{KOH} \mathrm{g}^{-1}\right)$. 
Óleos vegetais refinados comerciais (soja, milho, canola-e oliva) sem aditivos foram adicionados de tocoferóis $\left(2,510^{-7} \mathrm{~mol} \mathrm{~g}^{-1}\right)$ e expostos às microondas por intervalos de 4 a 20 min por Yoshida et al. (1991). Concluiram que os tocoferóis em óleos insaturados foram mais estáveis que em óleos mais saturados sob condições de aquecimento por microondas. No entanto, a oxidação nos óleos de soja e canola (mais insaturados) foi mais evidente, mostrando que as reduções na quantidade de tocoferóis não puderam ser diretamente relacionadas aos indices analíticos (valores de TBA, de $p$-anisidina e de carbonila).

O aquecimento por microondas promoveu aceleração na oxidação de óleos refinados purificados de canola, soja e palma (amostras de 5,0 g em duplicata aquecidas simultaneamente). $O$ indice de peróxido dos óleos de canola e soja passaram de cerca de 2,5 meq $\mathrm{kg}^{-1}$ para 30,0 após $20 \mathrm{~min}$ de exposição, sendo que o óleo de soja apresentou um valor máximo de 35,0 meq kg-1 aos $16 \mathrm{~min}$. Tocoferóis adicionados aos óleos mantiveram as amostras com índices de peróxido mais baixos (100 mg kg-1 de $\alpha$-tocoferol, $150-200 \mathrm{mg} \mathrm{kg}^{-1}$. de $\beta$ - ou $\gamma$-tocoferol e $500 \mathrm{mg} \mathrm{kg}^{-1}$ de $\delta$ tocoferol) (Yoshida et al., 1993).

Lie Ken Jie \& Yan-Kit (1988) estudaram as reações térmicas envolvendo ésteres de ácidos graxos de cadeia longa, que normalmente requerem muitas horas de aquecimento ou agitação à temperatura ambiente para sofrerem transformações. Quando amostras de oleato de metila foram aquecidas em forno de microondas (650 W) com meta-ácido cloroperbenzóico durante 3 e $5 \mathrm{~min}$, a análise por cromatografia gás-líquida (GLC) mostrou que houve 93,6 e 98,8\% de conversão de substrato insaturado em derivados de epóxido correspondentes. Os autores concluíram que as microondas como fonte de energia parecem ser adequadas para promover maior rapidez em várias reações que envolvem ácidos graxos de cadeia longa.

Farag et al. (1992) concluíram que radicais livres reativos podem ser formados por exposição à energia de microondas. A primeira etapa da peroxidação lipídica é a retirada do hidrogênio do grupo metilênico reativo do ácido graxo para formar um radical e isso pode ser acelerado por microondas. Os autores utilizaram $200 \mathrm{~g}$ de óleo refinado de algodão e de óleo hidrogenado de palma (índices de peróxido iniciais de $5,02 \mathrm{meq}^{-1}$ e 1,0 , respectivamente) aquecidos em um forno de 
microondas com potência de $1300 \mathrm{~W}$ e freqüência de $60 \mathrm{~Hz}$ por periodos de 2 a 8 min. $O$ indice de peróxido aumentou para 12,5 e 6,0 (nos óleos de algodão e palma) depois de $8 \mathrm{~min}$ de aquecimento (temperatura atingida de $230^{\circ} \mathrm{C}$ ).

A partir da análise dos ensaios acima citados, pode-se perceber que a comparação entre os resultados obtidos pelos diferentes autores é praticamente impossivel. Condições experimentais, tais como massa e quantidade de amostras expostas às microondas em cada periodo, não são comparáveis e muitas vezes nem foram descritas na metodologia. Este estudo visou a acompanhar as alterações que ocorrem no óleos refinados devido à ação do aquecimento por microondas, mantendo condições bem regulares e especificas. Paralelamente, ensaios em condições normais de armazenamento e em estufa foram realizados com os mesmos tratamentos utilizados no ensaio de aquecimento por microondas para que os resultados pudessem servir como referência. Foram utilizados óleos refinados de canola, milho e soja.

\subsection{Caracteristicas de óleos de canola, milho e soja}

\subsection{1 Óleo de canola}

Ao longo das duas décadas passadas o aspecto comercial do óleo de colza (Brassica napus, B. rapa, B. campestris; crucifera) mudou drasticamente. No passado, o óleo de colza apresentava problemas devido ao seu alto teor de ácido erúcico. No entanto, com melhoramento genético foram obtidas variedades que apresentavam não somente baixos teores de ácido erúcico, mas também maior resistência a doenças, maior produtividade e baixos teores de glucosinolatos. A variedade desenvolvida através do melhoramento genético com baixo teor de ácido erúcico foi chamada de canola (Rakow \& McGregor, 1973).

As sementes de canola são pequenas e redondas $(0,1-0,2 \mathrm{~cm}$ de diâmetro), de cor amarela, marrom ou preta. O teor de óleo é de 40-60\% e o óleo pode ser obtido por prensagem, extração por solvente ou combinação das duas formas. As várias etapas do processamento que contribuem para a boa qualidade do óleo foram revisadas por Ohlson (1992). O óleo bruto é escuro e contém altos níveis de 
fosfatidios $(3,5 \%)$ e compostos sulfurados. Os principais pigmentos de óleo de canola são as clorofilas a e b dos grãos imaturos, que são decompostas em feofitina a e b. 0 óleo bruto degomado contém $40-300 \mathrm{mg} \mathrm{kg}^{-1}$ de fósforo, dependendo do tipo de degomagem realizada (ácida ou somente com água) (Mag, 1983). Os fosfolipídios de óleo de canola são a fosfatidilcolina (48\%), fosfatidilinositol (19,5\%) e fosfatidiletanolamina $(8,9 \%)$.

O óleo de canola refinado é amarelo claro e livre de ceras e fósforo. Até o início da década de 70 , a colza era utilizada em alguns paises para alimentação. Testes biológicos com animais mostraram o potencial de risco de cardiopatia em humanos e, como conseqüência, a FAO/WHO (Food and Agriculture Organization/ World Health Organization) recomendou o uso apenas da colza com baixo teor de ácido erúcico (canola) para fins comestiveis. Na Comunidade Européia e Canadá apenas óleos com menos de $5 \%$ de ácido erúcico são permitidos para uso comestivel (Padley et al., 1994).

\subsection{2 Óleo de milho}

O grão de milho (Zea mays L.; graminea) contém aproximadamente $5 \%$ de óleo, sendo que $80 \%$ está concentrado no germe. O óleo bruto, de coloração acentuadamente vermelha escura, é obtido do germe através da combinação de extração por prensagem e solvente. O óleo bruto normalmente contém 1-3\% de fosfolipídios e ácidos graxos livres. Esses componentes são removidos no refino convencional. Traços de cera $(0,05 \%)$ podem ser removidos por "winterização" (Padley et al., 1994).

O óleo de milho contém aproximadamente $1 \%$ de esteróis, que usualmente não se apresentam em altos teores em óleos vegetais e constituem-se de esteril e triterpenil ésteres (Trost, 1989). 


\subsection{3 Óleo de soja}

A soja (Glycine max; leguminosa) è uma das mais antigas culturas cultivadas pelo homem. A produção comercial de soja começou a se expandir significativamente no início dos anos 40 nos Estados Unidos e atualmente é a principal oleaginosa produzida no mundo, principalmente nos Estados Unidos, China, Brasil e Argentina (Padley et al., 1994).

Os grãos de soja, que apresentam teor de óleo de 18 a $22 \%$, podem ser armazenados com umidade de $12 \%$ sem qualquer incremento na quantidade de ácidos graxos livres no óleo, embora a estocagem por períodos muitos longos promova alterações lentas, mas perceptíveis, na composição do óleo, principalmente a formação de ácidos graxos oxigenados pela ação da lipoxigenase (Barger, 1981). O óleo bruto de soja é obtido dos grãos por extração com solvente (hexano). Um óleo bruto de boa qualidade deve apresentar coloração âmbar e teor de ácidos graxos livres de $0,5 \%$. O óleo de grãos danificados é escuro, apresenta alto índice de acidez e lipidios modificados, o que limita a eficiência das etapas de refino. $O$ farelo residual é uma das fontes protéicas mais importantes para a alimentação animal (Padley et al., 1994).

Quanto aos componentes minoritários, os mais importantes são os fosfolipídios (400-700 $\mathrm{mg} \mathrm{kg}^{-1}$ de fósforo em óleo bruto). Os fosfatídios hidratáveis são removidos pela degomagem com água ( $2 \%)$, mas o óleo ainda mantém quantidades residuais de fosfatidios. Os fosfolipidios não hidratáveis complexam-se com ions metálicos, especialmente ferro e cobre. Estes normalmente são removidos por tratamento com ácido fosfórico diluído. Os fosfolipidios do óleo de soja são ácido fosfatídico $(5 \%)$, fosfatidilinositol $(20 \%)$, fosfatidil etanolamina $(23 \%)$ e fosfatidilcolina $(39 \%)$.

A Tabela 2 apresenta a distribuição padrão de ácidos graxos que os óleos de canola, milho e soja devem apresentar, segundo o Codex Alimentarius (1992). A Tabela 3 apresenta a quantificação de tocóis presentes nos óleos de canola, milho e soja. As formas $\alpha, \beta, \gamma, e \delta$ de tocoferóis diferem entre si quanto à posição e número de grupos metílicos no anel fenólico. Existe também a série correspondente de 
tocotrienóis, que apresentam a cadeia de 16 carbonos insaturada. Os oito compostos são chamados tocóis. Os tocóis são antioxidantes naturais, sendo que os tocotrienóis apresentam um poder antioxidante maior que os tocoferóis, enquanto $0 \delta$-tocoferol é mais potente que o $\alpha$-tocoferol (Rossel, 1991).

Tabela 2. Composição padrão em ácidos graxos de óleos de canola, milho e soja.

\begin{tabular}{lrrr}
\hline Ácido Graxo & \multicolumn{3}{c}{ Óleo } \\
\cline { 2 - 4 } f(GL) & Canola & \multicolumn{1}{c}{ Milho } & \multicolumn{1}{c}{ Soja } \\
\hline C16:0 & $2,5-6,0$ & $9,0-14,0$ & $7,0-14,0$ \\
C16:1 & $<0,6$ & $<0,5$ & $<0,5$ \\
C18:0 & $0,8-2,5$ & $0,5-4,0$ & $1,4-5,5$ \\
C18:1 & $50,0-66,0$ & $24,0-42,0$ & $19,0-30,0$ \\
C18:2 & $18,0-20,0$ & $34,0-62,0$ & $44,0-62,0$ \\
C18:3 & $6,0-14,0$ & $<2,0$ & $4,0-11,0$ \\
C20:0 & $0,1-1,2$ & $<1,0$ & $<1,0$ \\
C20:1 & $0,1-4,3$ & $<0,5$ & $<1,0$ \\
C22:0 & $<0,6$ & $<0,5$ & $<0,5$ \\
C22:1 & $<5,0$ & - & - \\
\hline
\end{tabular}

Fonte: Codex Alimentarius (1992) 
Tabela 3. Faixas de variação e médias $\left(\mathrm{mg} \mathrm{kg}^{-1}\right)$ de teores de tocoferóis $(T)$ e tocotrienóis $\left(T_{3}\right)$ em óleos de canola, milho e soja.

\begin{tabular}{lrrr}
\hline Tocol & \multicolumn{3}{c}{ Óleos } \\
\cline { 2 - 4 } & \multicolumn{1}{c}{ Canota } & \multicolumn{1}{c}{ Milho } & \multicolumn{1}{c}{ Soja } \\
\hline$\alpha T$ & $100-320(202)$ & $23-573(282)$ & $9-352(99)$ \\
$\beta T$ & $16-140(65)$ & nd - 356(54) & nd - 36 (7) \\
$\gamma T$ & $287-753(490)$ & $268-2468(1034)$ & $409-2397(1021)$ \\
$\delta T$ & $4-22(9)$ & $23-75(54)$ & $154-932(421)$ \\
$\alpha T_{3}$ & - & $n d-239(49)$ & - \\
$\beta T_{3}$ & - & $n d-52(8)$ & - \\
$\gamma T_{3}$ & - & nd - $450(161)$ & - \\
$\delta T_{3}$ & - & nd - 20 (6) & - \\
Total & $424-1054(766)$ & $331-3402(1647)$ & $575-3320(1549)$ \\
\hline
\end{tabular}

Fonte: Rossel (1991)

as médias são apresentadas entre parênteses

nd $=$ não detectado 


\section{MATERIAL E MÉTODOS}

\subsection{Material}

Os óleos selecionados para o estudo foram de canola, milho e soja, devido às diferenças existentes quanto à composição em ácidos graxos, presença de antioxidantes naturais (tocóis) e pelo destaque no mercado. Foram fornecidos por indústrias de óleo brasileiras em tambores ou latas, recém refinados, sem adição de qualquer antioxidante e nem ácido citrico, aptos a serem embalados em frascos de transparentes, conforme o procedimento industrial. Após a caracterização físicoquímica inicial, parte do óleo foi congelada aguardando os ensaios acelerados 1 e 2 por 6 meses e parte foi acondicionada em frascos de PET (polietileno tereftalato) de $500 \mathrm{~mL}$ com tampas rosqueáveis fornecidos por empresa produtora de frascos para comercialização de óleos vegetais. Foi obedecida a relação superfície:volume de 0,52 existente na embalagem comercial de $900 \mathrm{~mL}$.

Os antioxidantes BHA (butilhidroxi anisol) e BHT (butilhidroxi tolueno), da marca Sigma, e o ácido cítrico ( $A C$ ), da marca Cinética Quimica, foram adicionados diretamente aos óleos e homogeneizados durante 5 min antes do inicio de cada ensaio. Os antioxidantes BHA e BHT foram utilizados na forma de uma mistura de proporção 1:1 em todos os ensaios.

\subsection{Métodos}

A estabilidade oxidativa dos óleos de canola, milho e soja foi avaliada sob condições de aquecimento por microondas e comparada aos resultados obtidos em um teste em estufa e no armazenamento em condições normais de comercialização. 


\subsubsection{Ensaio 1: teste acelerado em estufa}

Os antioxidantes BHA/BHT (200 mg kg-1), BHA/BHT $\left(200 \mathrm{mg} \mathrm{kg}^{-1}\right)+\mathrm{AC}$ (100 $\mathrm{mg} \mathrm{kg}^{-1}$ ) e $\mathrm{AC}\left(100 \mathrm{mg} \mathrm{kg}^{-1}\right)$ foram adicionados diretamente a cada óleo, sendo mantidas amostras sem adição de antioxidante como controle. Foram, portanto, 4 tratamentos para cada óleo. Amostras de óleo $(20 \mathrm{~g})$ acondicionado em béqueres de $50 \mathrm{~mL}$ foram avaliadas em ensaio acelerado em estufa a $63 \pm 1^{\circ} \mathrm{C} .12$ amostras, referentes às 3 repetições dos 4 tratamentos, foram colocadas na estufa e retiradas após um periodo de 24 horas para a determinação da absortividade em $232 \mathrm{~nm}$ e em $270 \mathrm{~nm}$, espectro de absortividade entre 220 e $320 \mathrm{~nm}$, indice de peróxido e indice de acidez. O mesmo procedimento foi seguido para a avaliação de amostras submetidas aos periodos de 48, 72, 96, 120 e 144 horas (2, 3, 4, 5 e 6 dias). Foram conduzidos ensaios separadamente para cada um dos três óleos.

\subsubsection{Ensaio 2: teste acelerado - aquecimento por microondas}

Amostras de $20 \mathrm{~g}$ de óleo acondicionado em béqueres com capacidade de $50 \mathrm{~mL}$ selados com filme de cloreto de polivinila, adicionado dos mesmos antioxidantes do ensaio 1, foram aquecidas em forno de microondas (marca Sanyo, modelo EM - 804 T GR, potência efetiva de $800 \mathrm{~W}$, freqüência de $2.450 \mathrm{MHz}$ ) por periodos de $0,2,4,6,8,10,12,16,20,24,28,32$ e $36 \mathrm{~min}$. Foram conduzidos ensaios para cada óleo separadamente. Em cada periodo de exposição foram aquecidas 12 amostras (3 repetições, 4 tratamentos), dispostas eqüidistantemente ao longo de uma circunferência de $25 \mathrm{~cm}$ de diâmetro sobre o prato giratório. A temperatura das amostras foi determinada, imediatamente após cada periodo de exposição, com um termopar (K-termocouple Hanna instruments, modelo $\mathrm{H} l$ 93530). As amostras foram resfriadas em temperatura ambiente até $23 \pm 1^{\circ} \mathrm{C}$ para a realização das mesmas análises realizadas no ensaio 1. 


\subsubsection{Ensaio 3: armazenamento em condições normais de temperatura e luminosidade}

Os óleos refinados comerciais foram embalados em frascos de PET (500 $\mathrm{mL}$ ), fechados com tampas plásticas rosqueáveis, e armazenados durante o período de 6 meses. A cada 15 dias, no primeiro, segundo e terceiro mês de armazenamento, 3 amostras de cada tratamento (ensaio realizado em triplicata) foram analisadas quanto a absortividade em $232 \mathrm{~nm}$ e $270 \mathrm{~nm}$, índice de peróxido e índice de acidez. A partir do terceiro mês de armazenamento, as análises foram realizadas a cada 30 dias. $O$ indice de iodo e o espectro de absortividade no UV foram determinados no tempo inicial, após 90 dias e após 180 dias de armazenamento. A iluminação com lâmpadas fluorescentes foi intermitente (12 horas de claro e 12 horas de escuro). Todas as análises foram realizadas em duplicata, exceto $o$ indice de acidez.

\subsection{Determinações analíticas}

\subsubsection{Determinações físicas}

\subsubsection{Absortividade em $232 \mathrm{~nm}$ e em $270 \mathrm{~nm}$}

Foi determinada espectrofotometricamente conforme a NDG C-40 (SSOG, 1976). Foram feitas diluições de óleo em isoctano, de forma que a leitura de absorbância registrada estivesse entre 0,2 e 0,8 . Foram utilizados, portanto, balões volumétricos com $25 \mathrm{~mL}$ ou $50 \mathrm{~mL}$ de capacidade, dependendo do estado oxidativo do óleo. Foi utilizado o espectrofotômetro Shimadzu, modelo UV 1203. Os resultados nos comprimentos de onda expressos em absortividade foram dados pela fórmula:

Absortividade $=A /(c \times e)$

Sendo: $A$ = absorbância registrada no comprimento de onda utilizado

$c=$ concentração $\left(\mathrm{g} 100 \mathrm{~mL}^{-1}\right)$ da solução amostrada

$\mathrm{e}=$ largura da cubeta utilizada $(\mathrm{cm})$ 


\subsubsection{Espectro de absortividade na faixa do espectro ultravioleta - $220 \mathrm{~nm}$ a} $320 \mathrm{~nm}$

Realizado segundo IUPAC (1979), método II.D.23, com as mesmas diluições em isoctano utilizadas na determinação da absortividade em 232 nm e 270 nm. Foi utilizado o espectrofotômetro Shimadzu, modelo UV 1203 e a varredura foi realizada através do programa "Personal Spectroscopy" versão 1.1. As curvas fornecidas foram multiplicadas pelo fator de concentração para que os valores representassem os valores de absortividade em cada comprimento de onda.

\subsubsection{Determinações químicas}

\subsubsection{1 indice de peróxido}

Verificado segundo as normas da AOCS - Cd 8-53 (1983), através da dissolução de amostra de $5 \mathrm{~g}$ de óleo em solução de ácido acético e clorofórmio (3:2) e adição de solução de iodeto de potássio saturada, seguida de titulação com solução de tiossulfato de sódio 0,01 N. O volume gasto, após adição de goma de amido, indicou a concentração em peróxidos em meq $\mathrm{kg}^{-1}$, através da fórmuta:

$$
\begin{aligned}
& \text { IP }=[N \times(m L \text { de tiossulfato amostra }-m L \text { tiossulfato branco }) \times 1000] / p \\
& \text { Sendo: } N=\text { normalidade da solução de tiossulfato de sódio } \\
& \qquad P=\text { massa da amostra }(g)
\end{aligned}
$$

\subsubsection{2 Índice de acidez}

Realizado segundo as normas da AOCS - Ca 5a-40 (1983), com a dissolução de amostras de $5 \mathrm{~g}$ de óleo em álcool etílico a quente $\left(60-65^{\circ} \mathrm{C}\right)$ e titulação com solução de hidróxido de sódio $0,1 \mathrm{~N}$. O volume gasto indicou a porcentagem de ácidos graxos livres (em ácido oléico) através da fórmula:

$$
\% A G L=(m L \text { gastos } \times 28,2 \times N) / p
$$

Sendo: $N$ = normalidade da solução de hidróxido de sódio.

$$
p=\text { massa da amostra }(g)
$$




\subsubsection{3 Índice de iodo}

Realizado segundo Wijs (AOCS - Cd 1-25, 1983), através da dissolução de amostra de 0,2-0,22 g de óleo em tetracloreto de carbono e em solução de Wijs, permanência por 30 minutos no escuro e titulação com solução de tiossulfato de sódio $0,1 \mathrm{~N}$ após a adição de $\mathrm{Kl} 15 \%$ e água destilada. A viragem foi verificada adicionando-se goma de amido. A insaturação é conhecida pela quantidade de iodo, em mg, absorvidos por $100 \mathrm{mg}$ de amostra, conforme a fórmula:

$$
\|=[(B-A) \times 12,69 \times N] / p
$$

Sendo: $B=m L$ de tiossulfato de sódio gastos com o branco

$A=m L$ de tiossulfato de sódio gastos com amostra

$N=$ normalidade da solução de tiossulfato de sódio

$p=$ massa da amostra $(g)$

\subsubsection{Análise estatística}

Todos os ensaios foram conduzidos em triplicata no esquema fatorial modelo inteiramente casualizado, considerando os fatores antioxidante e período de amostragem. Foi aplicado teste de Tukey para médias do fator antioxidante, médias do fator periodo de amostragem e para médias da interação entre antioxidante e periodo de amostragem, para cada óleo separadamente, considerando o nivel de significância de $5 \%$. Utilizou-se o programa de análise estatística Sanest. 


\section{RESULTADOS E DISCUSSÃO}

A Tabela 4 apresenta a caracterização inicial dos óleos de canola, milho e soja e os espectros de absortividade entre $220 \mathrm{~nm}$ e $320 \mathrm{~nm}$ dos óleos são apresentados na Figura 1. Alguns produtos da oxidação apresentam valores máximos de absorção em determinado comprimento de onda. Compostos primários da oxidação apresentam valores máximos de absortividade na faixa entre 220 e $234 \mathrm{~nm}$. A partir de $265 \mathrm{~nm}$ são os compostos secundários da oxidação (trienos, aldeídos e cetonas) que apresentam maior absorção, como pode ser verificado através da Tabela 1. O acompanhamento das alterações no espectro de absortividade de amostras de óleo fornece uma boa indicação da ocorrência do processo oxidativo.

Tabela 4. Caracterização inicial dos óleos de canola, milho e soja.

\begin{tabular}{lccc}
\hline & \multicolumn{3}{c}{ Óleos } \\
\cline { 2 - 4 } & Canola & Milho & Soja \\
\hline Absortividade em $232 \mathrm{~nm}$ & 4,738 & 3,377 & 4,260 \\
Absortividade em $270 \mathrm{~nm}$ & 0,734 & 1,404 & 3,130 \\
Índice de peróxido (meq kg ${ }^{-1}$ ) & 0,80 & 1,40 & 2,29 \\
Índice de acidez (\% AGL) & 0,050 & 0,025 & 0,050 \\
Índice de iodo segundo Wijs (mg iodo $100 \mathrm{mg}^{-1}$ ) & 116,15 & 116,18 & 129,56 \\
\hline
\end{tabular}




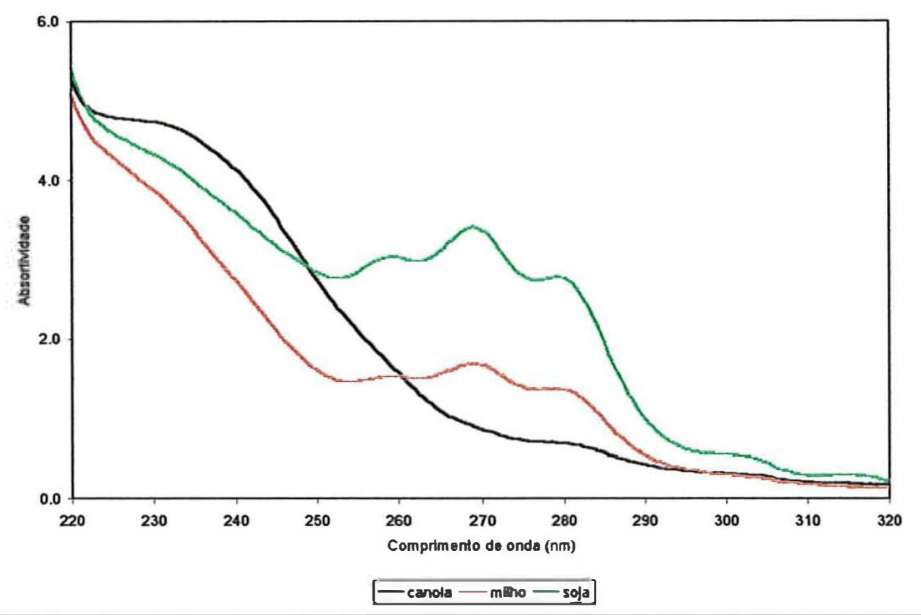

Figura 1 - Espectros de absortividade iniciais dos óleos de canola, milho e soja.

\subsection{Teste acelerado em estufa}

A adição de $200 \mathrm{mg} \mathrm{kg}^{-1}$ de BHA/BHT e de $200 \mathrm{mg} \mathrm{kg}^{-1}$ de BHA/BHT + 100 $\mathrm{mg} \mathrm{kg}^{-1}$ de $A C$ retardou a ocorrência das alterações oxidativas nos óleos de canola, milho e soja submetidos ao teste acelerado em estufa $\left(63^{\circ} \pm 1^{\circ} \mathrm{C}\right)$. Os valores de índice de peróxido e de absortividade em $232 \mathrm{~nm}$ apresentaram aumentos proporcionais em todas as amostras.

Não houve diferenças significativas entre os tratamentos aplicados ao óleo de canola para a variável índice de peróxido até os 2 dias a $63^{\circ} \mathrm{C}$. No entanto, o teste de Tukey aplicado para médias de antioxidantes dentro de cada nível do fator período de amostragem indicou que o índice de peróxido das amostras adicionadas de $\mathrm{BHA} / \mathrm{BHT}$ e de BHA/BHT + AC diferiu do controle e das amostras adicionadas somente de $A C$ aos 3, 4, 5 e 6 dias, no nível de $5 \%$ de significância. $O$ índice de peróxido manteve-se sem alterações estatisticamente significativas até 2 dias de estocagem nas amostras adicionadas de BHA/BHT e BHA/BHT + AC, sofrendo então aumentos gradativos (3, 4 e 5 dias) e estabilizando-se aos 6 dias. As alterações no índice de peróxido com o tempo de exposição ao calor foram mais intensas nos tratamentos com $\mathrm{AC}$ e no controle. $\mathrm{O}$ índice de peróxido nestes tratamentos manteve- 
se sem alterações significativas somente até o primeiro dia a $63^{\circ} \mathrm{C}$, sofrendo aumentos gradativos a partir deste período (Figura 2).

McMullen et al. (1991) verificaram que $200 \mathrm{mg} \mathrm{kg}^{-1}$ de BHA/BHT, adicionados ou não de citrato de monoglicerídeo (contendo $50 \mathrm{mg} \mathrm{kg}^{-1}$ de ácido citrico) foram ineficientes em inibir a degradação do óleo de canola durante um teste em estufa a $65^{\circ} \mathrm{C}$. No entanto, Wanasundara \& Shahidi (1994) verificaram que 200 $\mathrm{mg} \mathrm{kg}^{-1}$ de BHA ou de BHT retardaram o aumento do índice de peróxido e da absortividade em $234 \mathrm{~nm}$ do óleo neutralizado e clarificado de canola por até 16 dias de teste acelerado em estufa $\left(65^{\circ} \mathrm{C}\right)$. Um teste acelerado em estufa realizado por Hawrysh et al. (1988) também demonstrou que amostras de óleo de canola adicionadas de $100 \mathrm{mg} \mathrm{kg}^{-1}$ de BHA/BHT apresentaram valores de indice de peróxido e de TBA mais baixos que os do controle ao final de 16 dias a $65^{\circ} \mathrm{C}$.

A absortividade em $232 \mathrm{~nm}$ apresentou comportamento semelhante ao observado para o índice de peróxido. As amostras de o óleo de canola adicionado de $\mathrm{BHA} / \mathrm{BHT}$ e de $\mathrm{BHA} / \mathrm{BHT}+\mathrm{AC}$ diferiram do controle e do tratamento com AC em nivel de $5 \%$ de significancia, segundo o teste de Tukey aplicado para médias de antioxidantes. Os valores de absortividade em $232 \mathrm{~nm}$ mantiveram-se estáveis até dois dias a $63^{\circ} \mathrm{C}$ nos tratamentos com BHA/BHT e BHA/BHT + AC e apenas por um dia no controle e no tratamento com AC. Somente a partir de 3 dias de estufa foram verificadas diferenças significativas entre os tratamentos (Figura 3).

O teste de Tukey aplicado para médias de antioxidantes indicou que o indice de peróxido e a absortividade em $232 \mathrm{~nm}$ do óleo de canola adicionado de 100 $\mathrm{mg} \mathrm{kg}^{-1}$ de $\mathrm{AC}$ não diferiram do controle, apesar da diferença apresentada entre os dois tratamentos aos 5 dias de estufa (o tratamento com AC diferiu do controle e dos tratamentos restantes quanto ao indice de peróxido e absortividade em $232 \mathrm{~nm}$ somente no quinto dia de estufa, segundo o teste de Tukey). 


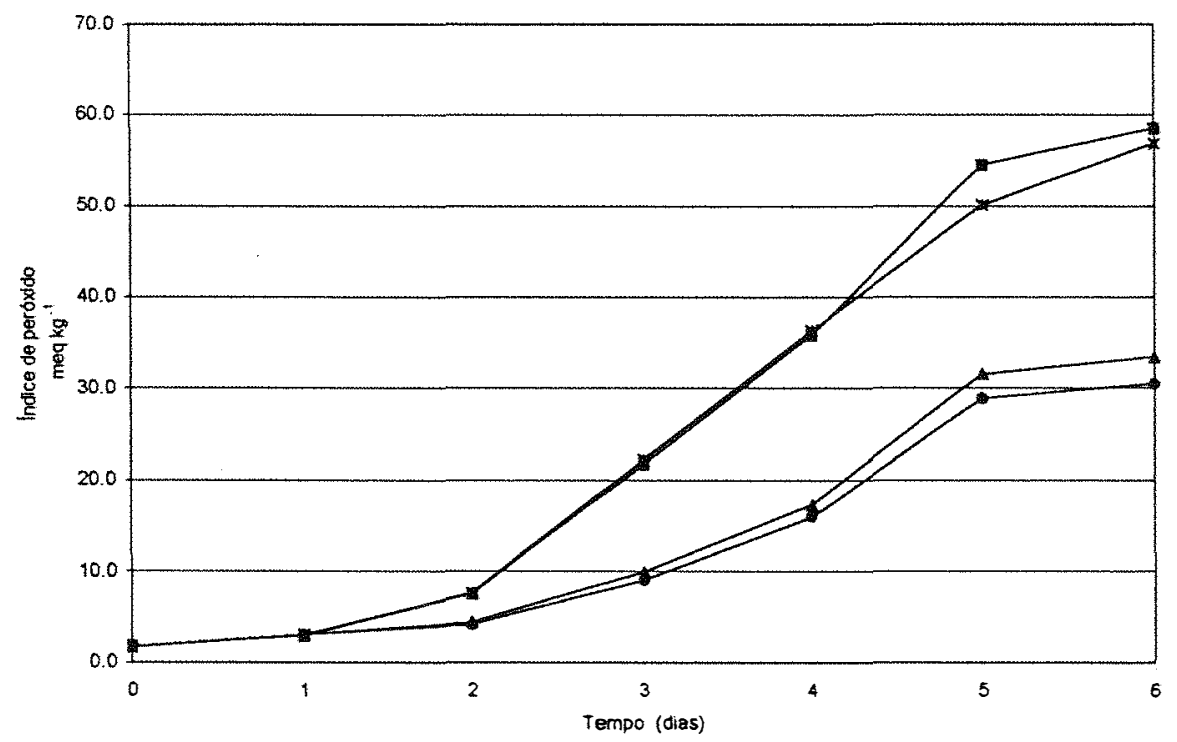

Figura 2 - Índice de peróxido (meq $\mathrm{kg}^{-1}$ ) de óleo de canola submetido ao teste em estufa a $63^{\circ} \mathrm{C}$.

(C.V. $=8,322 \%)$

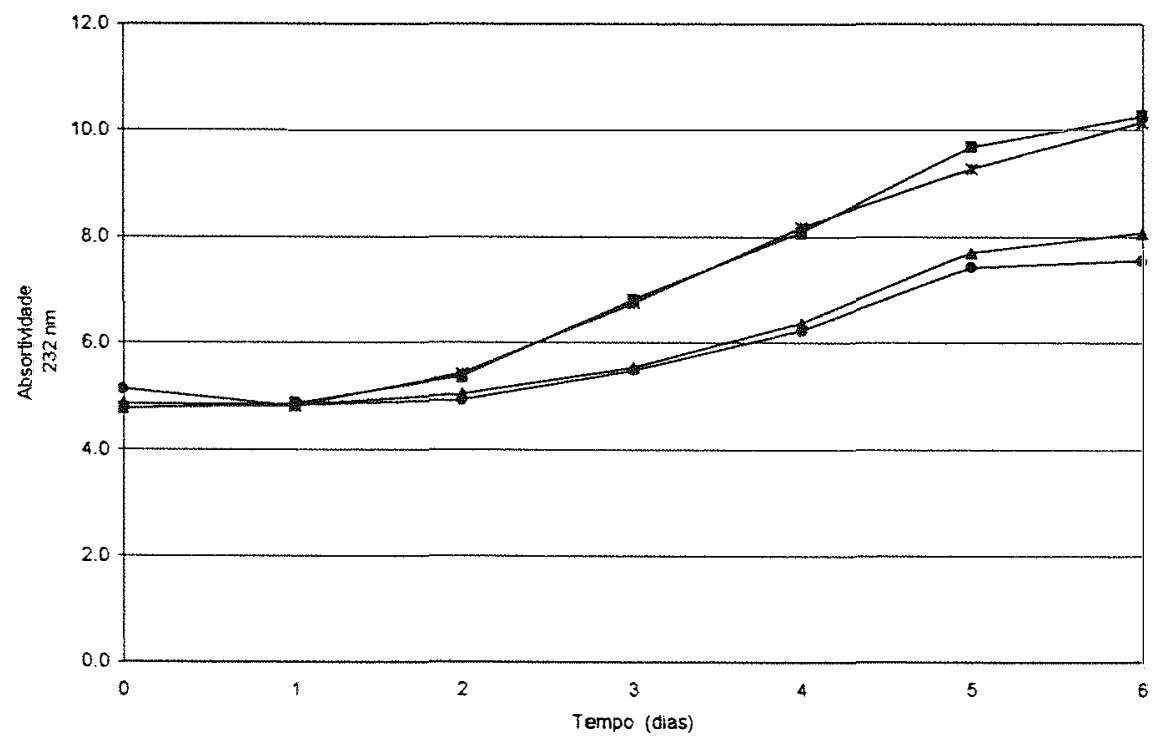

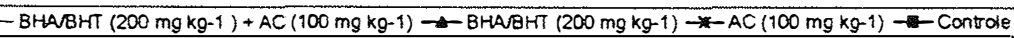

Figura 3 - Absortividade em $232 \mathrm{~nm}$ de óleo de canola submetido ao teste em estufa a $63^{\circ} \mathrm{C}$.

(C.V. $=2,759 \%$ ) 
No entanto, a adição do ácido cítrico foi eficiente em retardar a oxidação do óleo de milho durante $o$ teste acelerado. As médias do fator antioxidante para a variável de índice de peróxido em função do periodo de amostragem diferiram entre si no nivel de $5 \%$ de significância. Da mesma maneira, os tratamentos foram diferentes entre si quanto à absortividade em $232 \mathrm{~nm}$. Nas duas variáveis citadas, somente a partir de 4 dias de estocagem foram verificadas diferenças entre os tratamentos (segundo o teste de Tukey aplicado para médias do fator antioxidante dentro de cada nível do fator período de amostragem). O teste de Tukey aplicado para médias de periodos de amostragem indicou que os valores de índice de peróxido e de absortividade em $232 \mathrm{~nm}$ mantiveram-se sem alterações significativas até 3 dias de estocagem, sofrendo um aumento aos 4 e 5 dias e estabilizando-se até o sexto dia, em todas as amostras (Figuras 4 e 5).

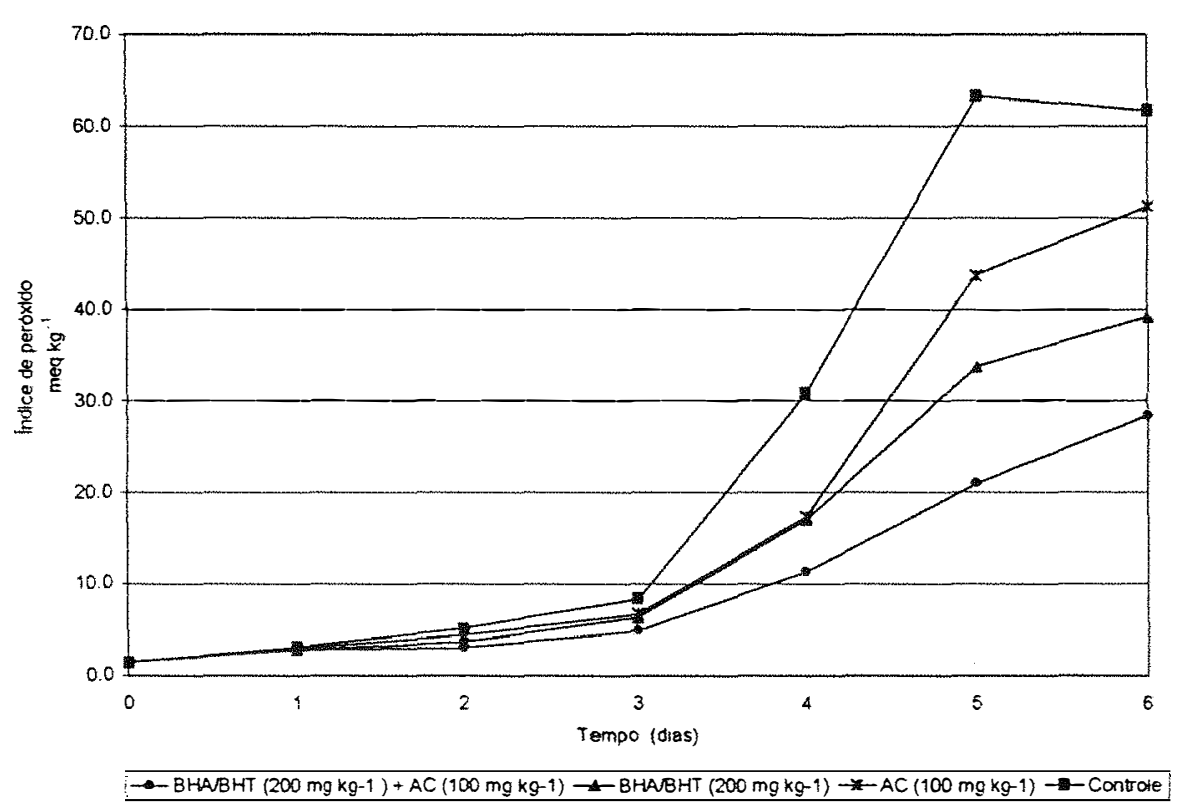

Figura 4 - Índice de peróxido (meq $\mathrm{kg}^{-1}$ ) de óleo de milho submetido ao teste em estufa a $63^{\circ} \mathrm{C}$.

(C. V. $=20,952 \%$ ) 


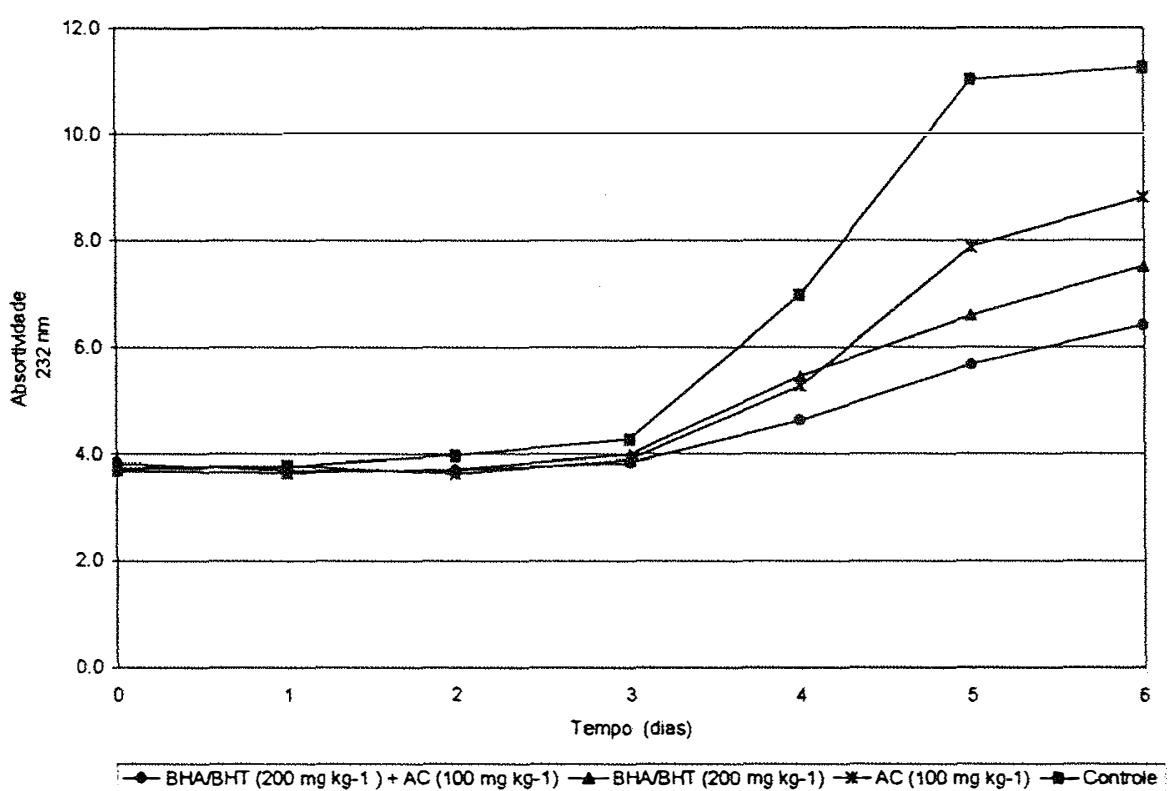

Figura 5 - Absortividade em $232 \mathrm{~nm}$ de óleo de milho submetido ao teste em estufa a $63^{\circ} \mathrm{C}$.

(C.V. $=7,299 \%)$

O ácido cítrico é considerado um agente seqüestrante, pois possui a capacidade de ligar íons metálicos (ferro e cobre) para que estes não catalisem os processos de oxidação (Rovellini et al., 1997; Lauridsen \& Schultz, 1994). Wamer et al. (1989) observaram o efeito de $100 \mathrm{mg} \mathrm{kg}^{-1}$ de ácido cítrico adicionados aos óleos de canola, girassol e soja submetidos a teste acelerado em estufa $\left(60^{\circ} \mathrm{C}\right)$ e concluiram que a composição em ácidos graxos e presença de metais contaminantes e pigmentos são características que definem a estabilidade oxidativa de óleos. Provavelmente, devido à presença de traços de metais, o ácido citrico retardou o desenvolvimento da oxidação do óleo de milho durante o teste em estufa quando utilizado isoladamente e agiu de forma a melhorar a eficiência do BHA/BHT.

O óleo de soja, por ser mais insaturado (Tabelas 2 e 4) e consequentemente mais suscetível à oxidação, apresentou valores de índice de peróxido e de absortividade em $232 \mathrm{~nm}$ mais altos que aqueles apresentados pelos óleos de canola e milho ao final dos 6 dias a $63^{\circ} \mathrm{C}$ (Figuras 6 e 7). 


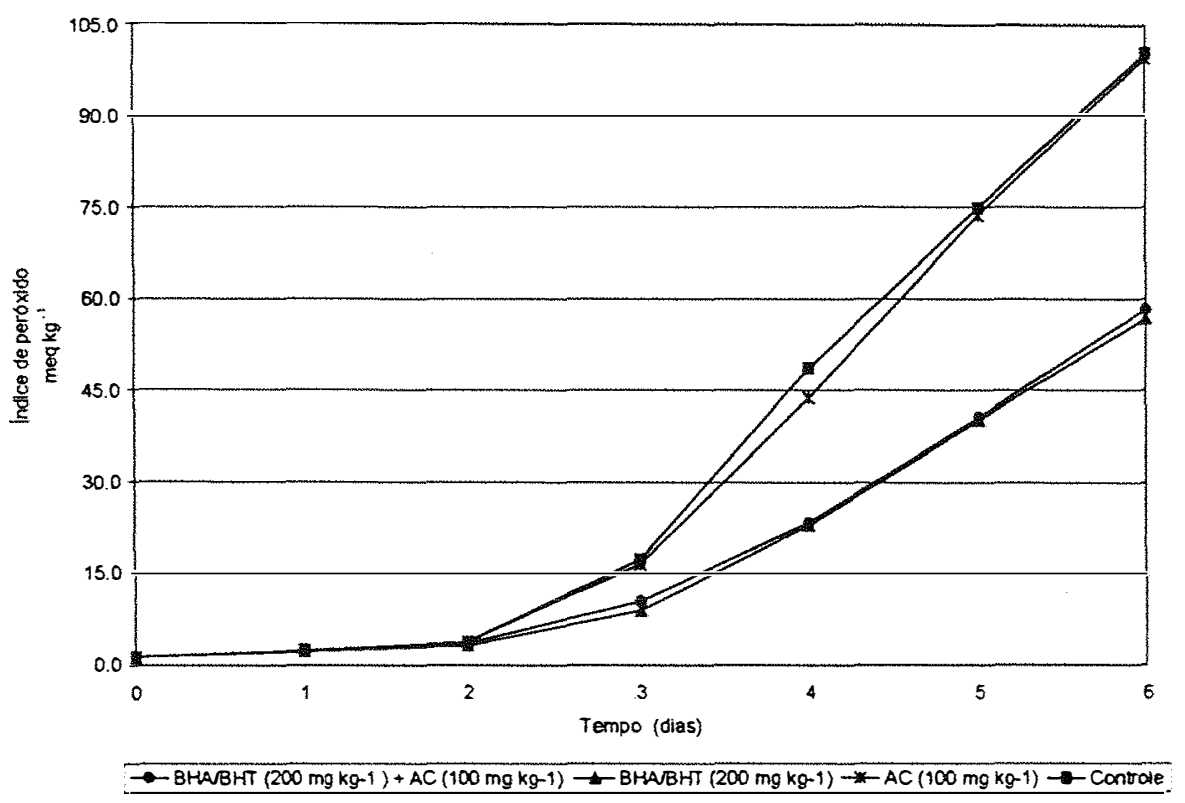

Figura 6 - Índice de peróxido $\left(m e q \mathrm{~kg}^{-1}\right.$ ) de óleo de soja submetido ao teste em estufa a $63^{\circ} \mathrm{C}$.

(C.V. $=16,635 \%)$

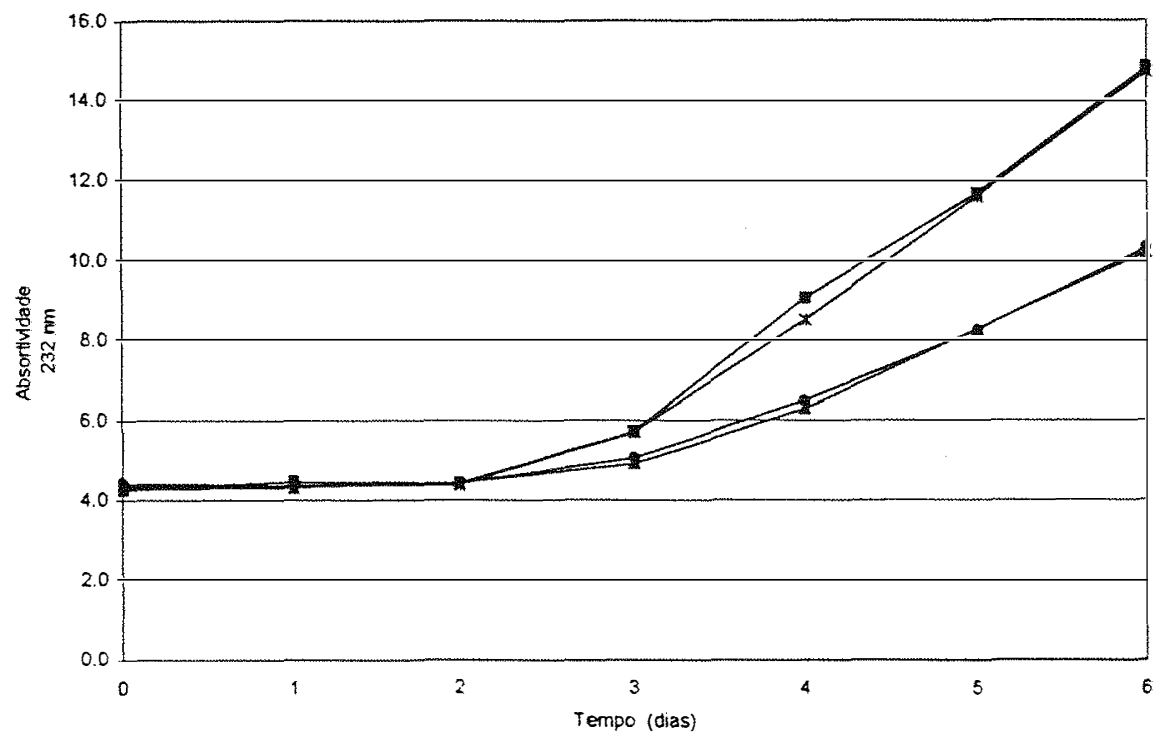

$\Rightarrow-B H A B H T(200 \mathrm{mg} \mathrm{kg-1})+A C(100 \mathrm{mg} \mathrm{kg}-1) \rightarrow-8 H A B H T(200 \mathrm{mg} \mathrm{kg}-1) \rightarrow-A C(100 \mathrm{mg} \mathrm{kg}-1) \rightarrow$ Controle

Figura 7 - Absortividade em $232 \mathrm{~nm}$ de óleo de soja submetido ao teste em estufa a $63^{\circ} \mathrm{C}$.

(C.V. $=6,510 \%)$ 
Os tratamentos com os antioxidantes BHA/BHT e BHA/BHT + AC diferiram em nivel de $5 \%$ de significância do controle e do tratamento com AC para as variáveis indice de peróxido e absortividade em $232 \mathrm{~nm}$, segundo o teste de Tukey aplicado para médias do fator antioxidante.

Diferenças significativas entre os tratamentos aplicados foram verificadas a partir de 4 dias de estocagem a $63^{\circ} \mathrm{C}$, tanto para o indice de peróxido quanto para a absortividade em $232 \mathrm{~nm}$. O teste de Tukey aplicado para médias de periodos de amostragem indicou que as duas variáveis mantiveram-se sem alterações significativas por 3 dias (BHA/BHT e BHA/BHT +AC) e 2 dias (AC e controle) de estufa, sofrendo a partir daí aumentos significativamente gradativos até o término dos 6 dias. $\bigcirc$ óleo de soja não apresentou a tendência à estabilização após os 5 dias de teste acelerado em estufa verificada para os óleos de canola e milho. Todos os tratamentos aplicados ao óleo de soja apresentaram acréscimos significativos nos valores de indice de peróxido e de absortividade em $232 \mathrm{~nm}$ entre 5 e 6 dias de estocagem. Da mesma maneira que para o óleo de canola, a adição de ácido cítrico não melhorou a eficiência da mistura de BHA/BHT em proteger o óleo de soja da oxidação.

O teste acelerado em estufa não promoveu grandes alterações nos valores de absortividade em $270 \mathrm{~nm}$. O teste de Tukey aplicado para médias de antioxidantes acusou que os tratamentos não diferiram entre si, em nivel de $5 \%$ de significância, em nenhum dos três óleos. As Tabelas 5, 6 e 7 apresentam os valores de absortividade em $270 \mathrm{~nm}$ determinados para os óleos de canola, milho e soja. Apesar do teste de Tukey aplicado para médias de periodos de amostragem ter indicado a existência de diferenças entre os resultados ao longo do tempo, as alterações não foram relacionadas à oxidação lipídica, conforme pode ser observado pela análise estatistica. 
Tabela 5. Absortividade em $270 \mathrm{~nm}^{1}$ de óleo de canola submetido ao teste em estufa a $63^{\circ} \mathrm{C}$.

\begin{tabular}{|c|c|c|c|c|}
\hline \multirow{2}{*}{$\begin{array}{l}\text { Tempo } \\
\text { (dias) }\end{array}$} & \multicolumn{3}{|c|}{ Tratamentos $^{2}$} & \multirow{3}{*}{ Controle } \\
\hline & $B H A / B H T+A C$ & $\mathrm{BHA} / \mathrm{BHT}$ & $A C$ & \\
\hline & $\left(200+100 \mathrm{mg} \mathrm{kg}^{-1}\right)$ & $\left(200 \mathrm{mg} \mathrm{kg}^{-1}\right)$ & $\left(100 \mathrm{mg} \mathrm{kg}^{-1}\right)$ & \\
\hline 0 & $0,812^{a b}$ & $0,771^{\text {abcd }}$ & $0,751^{\text {cd }}$ & $0,740^{b}$ \\
\hline 1 & $0,712^{b c d}$ & $0,714^{\text {bcd }}$ & $0,702^{\text {cd }}$ & $0,733^{b}$ \\
\hline 2 & $0,666^{d}$ & $0,668 \quad d$ & $0,673^{d}$ & $0,685^{b}$ \\
\hline 3 & $0,690^{\text {cd }}$ & 0,680 cd & $0,698^{c d}$ & $0,720^{\circ}$ \\
\hline 4 & $0,821^{a b}$ & 0,821 ab & $0,808^{b c}$ & $0,875^{a}$ \\
\hline 5 & $0,780^{a b c}$ & 0,791 abc & $0,874^{a b}$ & $0,891^{a}$ \\
\hline 6 & $0,843^{a}$ & $0,863 \quad a$ & $0,942^{2}$ & $0,908^{a}$ \\
\hline
\end{tabular}

' médias de 3 repetiçōes $\quad{ }^{2}$ C.V. $=5,776 \%$ d.m.s. $5 \%=0,056$

Valores seguidos por letras distintas na coluna diferem entre si ao nivel de $5 \%$ de significância, segundo o teste de Tukey aplicado para as médias de periodo de amostragem.

Tabela 6. Absortividade em $270 \mathrm{~nm}^{1}$ de óleo de milho submetido ao teste em estufa a $63^{\circ} \mathrm{C}$

\begin{tabular}{ccccc}
$\begin{array}{c}\text { Tempo } \\
\text { (dias) }\end{array}$ & $\begin{array}{c}\text { Tratamentos }^{2} \\
\text { BHA/BHT + AC } \\
\left(200+100 \mathrm{mg} \mathrm{kg}^{-1}\right)\end{array}$ & $\begin{array}{c}\text { BHA/BHT } \\
\left(200 \mathrm{mg} \mathrm{kg}^{-1}\right)\end{array}$ & $\begin{array}{c}\text { AC } \\
\left(100 \mathrm{mg} \mathrm{kg}^{-1}\right)\end{array}$ & Controle \\
\hline 0 & $1,726^{\mathrm{a}}$ & $1,642^{\mathrm{a}}$ & $1,675^{\mathrm{ab}}$ & $1,675^{\mathrm{ab}}$ \\
1 & $1,653^{\mathrm{a}}$ & $1,633^{\mathrm{a}}$ & $1,740^{\mathrm{a}}$ & $1,726^{\mathrm{a}}$ \\
2 & $1,635^{\mathrm{a}}$ & $1,614^{\mathrm{a}}$ & $1,595^{\mathrm{b}}$ & $1,602^{\mathrm{b}}$ \\
3 & $1,642^{\mathrm{a}}$ & $1,630^{\mathrm{a}}$ & $1,640^{\mathrm{ab}}$ & $1,642^{\mathrm{ab}}$ \\
4 & $1,665^{\mathrm{a}}$ & $1,661^{\mathrm{a}}$ & $1,684^{\mathrm{ab}}$ & $1,670^{\mathrm{ab}}$ \\
5 & $1,653^{\mathrm{a}}$ & $1,638^{\mathrm{a}}$ & $1,612^{\mathrm{b}}$ & $1,684^{\mathrm{ab}}$ \\
6 & $1,663^{\mathrm{a}}$ & $1,707^{\mathrm{a}}$ & $1,646^{\mathrm{ab}}$ & $1,646^{\mathrm{ab}}$ \\
\hline
\end{tabular}

${ }^{1}$ médias de 3 repetiçōes ${ }^{2}$ C.V. $=2,427 \%$ d.m.s. $5 \%=0,050$

Valores seguidos por letras distintas na coluna diferem entre si ao nivel de $5 \%$ de significância, segundo o teste de Tukey aplicado para as médias de periodo de amostragem. 
Tabela 7. Absortividade em $270 \mathrm{~nm}^{1}$ de óleos de soja submetido ao teste em estufa a $63^{\circ} \mathrm{C}$.

\begin{tabular}{|c|c|c|c|c|}
\hline \multirow{2}{*}{$\begin{array}{l}\text { Tempo } \\
\text { (dias) }\end{array}$} & \multicolumn{4}{|c|}{ Tratamentos $^{2}$} \\
\hline & $\begin{array}{c}\text { BHAVBHT + AC } \\
\left(200+100 \mathrm{mg} \mathrm{kg}^{-1}\right)\end{array}$ & $\begin{array}{c}\text { BHAVBHT } \\
\left(200 \mathrm{mg} \mathrm{kg}^{-1}\right)\end{array}$ & $\begin{array}{c}\mathrm{AC} \\
\left(100 \mathrm{mg} \mathrm{kg}^{-1}\right)\end{array}$ & Controle \\
\hline 0 & $3,524^{a}$ & $3,395^{a}$ & $3,456^{a}$ & $3,424^{a b}$ \\
\hline 1 & $3,457^{a b}$ & $3,423^{a}$ & $3,449^{a}$ & $3,489^{a}$ \\
\hline 2 & $3,430^{a b}$ & $3,454^{a}$ & $3,415^{a}$ & $3,468^{a b}$ \\
\hline 3 & $3,433^{a b}$ & $3,419^{a}$ & $3,450^{a}$ & $3,404^{a b}$ \\
\hline 4 & $3,443^{a b}$ & $3,394^{a}$ & $3,383^{a}$ & $3,371^{\circ}$ \\
\hline 5 & $3,415^{a b}$ & $3,448^{a}$ & $3,406^{a}$ & $3,425^{a b}$ \\
\hline 6 & $3,400^{b}$ & $3,393^{a}$ & $3,353^{a}$ & $3,387^{a b}$ \\
\hline
\end{tabular}

${ }^{1}$ médias de 3 repetiçōes ${ }^{2}$ C.V. $=1,332 \%$ d.m.s. $5 \%=0,057$

Valores seguidos por letras distintas na coluna diferem entre si ao nivel de $5 \%$ de significância, segundo o teste de Tukey aplicado para as médias de período de amostragem.

Os espectros de absortividade apresentados nas Figuras 8, 9 e 10 indicam que o teste acelerado em estufa $\left(63^{\circ} \mathrm{C}\right)$ não promoveu aumentos nos valores de absortividade na faixa de 265 a $320 \mathrm{~nm}$ em função do periodo de amostragem. Os gráficos de varredura, no entanto, apresentam variações ocorridas na faixa de 220 a $260 \mathrm{~nm}$ e o efeito dos antioxidantes adicionados pode ser verificado através da análise das curvas. 

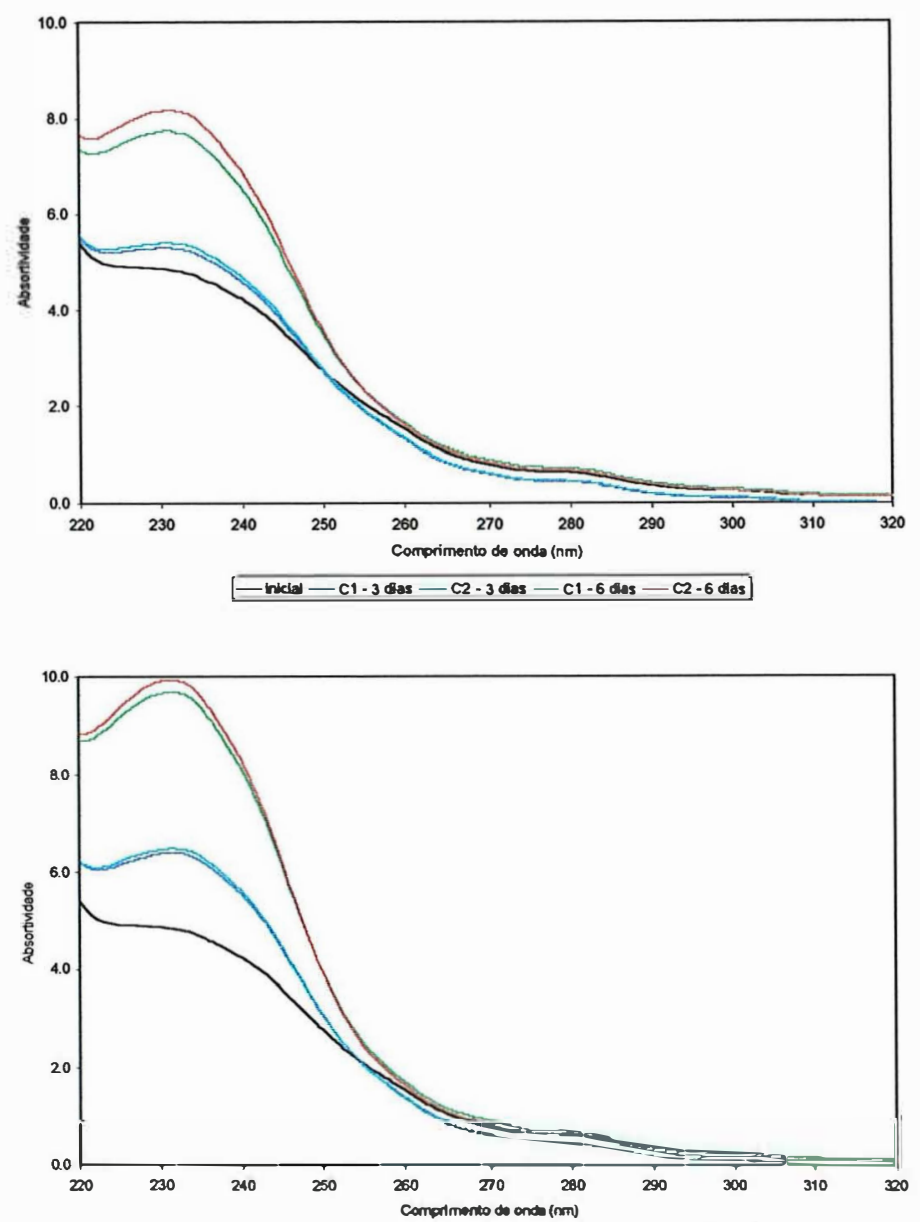

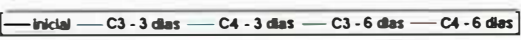

Figura 8 - Espectros de absortividade entre 220 e $320 \mathrm{~nm}$ de óleo de canola submetido ao teste em estufa a $63^{\circ} \mathrm{C}$.

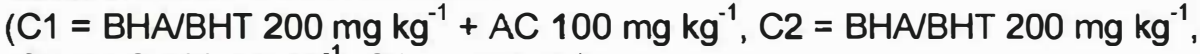

$\mathrm{C} 3=\mathrm{AC} 100 \mathrm{mg} \mathrm{kg}^{-1}, \mathrm{C} 4=$ controle) 


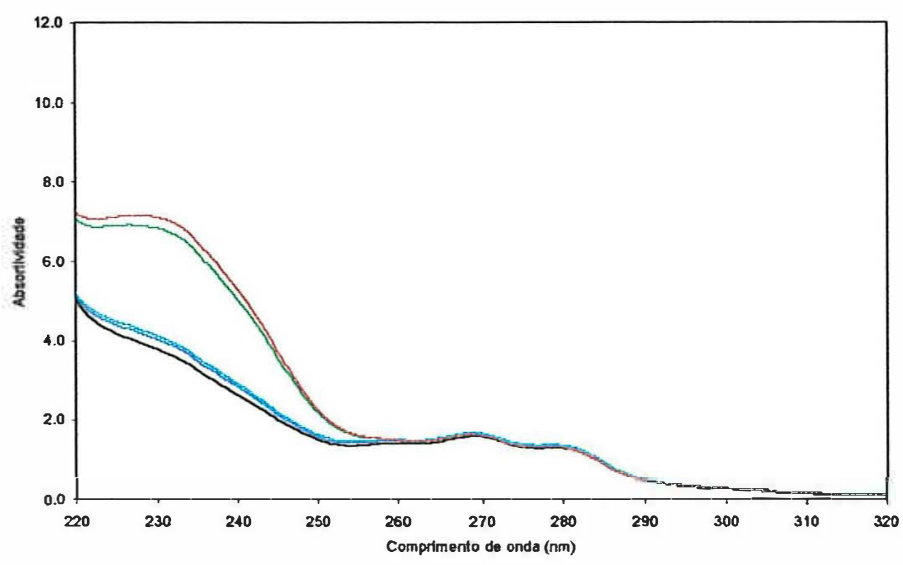

- Inkial - M1 - 3 dias - $M R-3$ dlas - M1 -6 dias - MR - 6 dlas

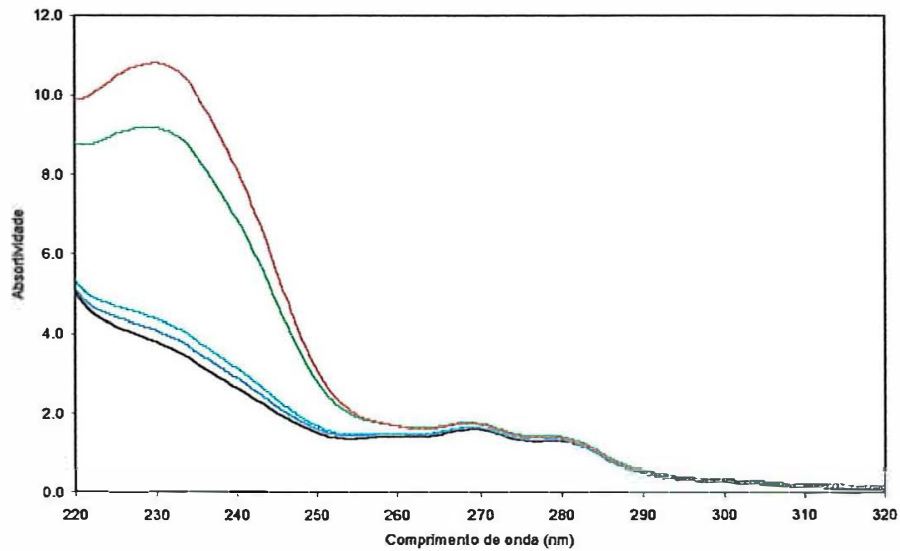

[- mikial - MB - 3 dias - M4 - 3 dias - M3 - 6 dias - M44-6 dias ]

Figura 9 - Espectros de absortividade entre 220 e 320 nm de óleo de milho submetido ao teste em estufa a $63^{\circ} \mathrm{C}$.

$\left(M 1=B H A / B H T 200 \mathrm{mg} \mathrm{kg}^{-1}+\mathrm{AC} 100 \mathrm{mg} \mathrm{kg}^{-1}, M 2=\mathrm{BHA} / \mathrm{BHT} 200 \mathrm{mg} \mathrm{kg}^{-1}\right.$, $M 3=A C 100 \mathrm{mg} \mathrm{kg}^{-1}, \mathrm{M} 4=$ controle) 


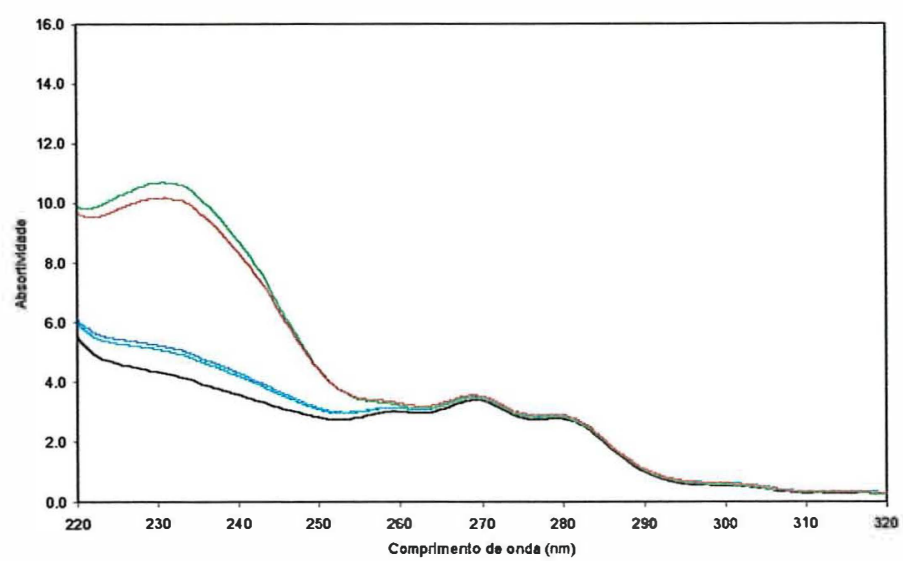

-inkial - $s 1-3$ das - $52-3$ das - $51-6$ das - $52-6$ das

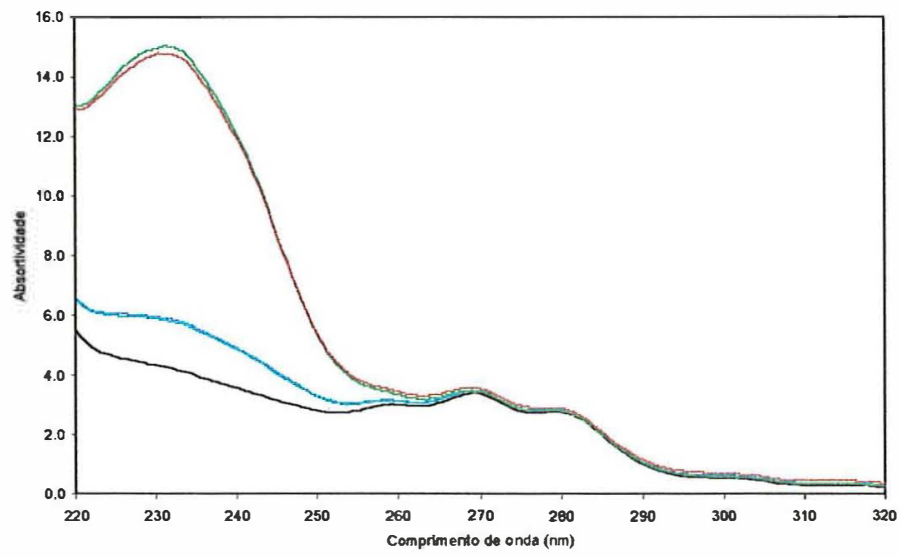

- tricial - S3-3 das - S4 - 3 dias - S3-6 das - $54-6$ dias

Figura 10 - Espectros de absortividade entre 220 e 320 nm de óleo de soja submetido ao teste em estufa a $63^{\circ} \mathrm{C}$.

( $\mathrm{S} 1=\mathrm{BHA} / \mathrm{BHT} 200 \mathrm{mg} \mathrm{kg}^{-1}+\mathrm{AC} 100 \mathrm{mg} \mathrm{kg}^{-1}, \mathrm{~S} 2=\mathrm{BHA} / \mathrm{BHT} 200 \mathrm{mg} \mathrm{kg}^{-1}$, $\mathrm{S} 3=\mathrm{AC} 100 \mathrm{mg} \mathrm{kg}^{-1}, \mathrm{~S} 4=$ controle)

O índice de acidez dos óleos do ensaio em estufa manteve-se inalterado até o final do período de estocagem. Não houve alterações entre tratamentos e nem durante o período de exposição a $63^{\circ} \mathrm{C}$. Os óleos de canola e milho mantiveram-se com índice de acidez (\% AGL) de 0,075 e o de soja com 0,080. 


\subsection{Teste acelerado - aquecimento por microondas}

O aquecimento por microondas promoveu a oxidação dos óleos de canola, milho e soja e a absortividade na faixa do espectro UV se mostrou um índice analítico bastante prático para o acompanhamento das alterações oxidativas. Como $\circ$ teste acelerado em estufa é um instrumento utilizado para a seleção de antioxidantes eficientes em proteger óleos da instalação do ranço, os mesmos tratamentos usados no teste em estufa foram utilizados para a verificação do efeito do aquecimento por microondas.

A Figura 11 apresenta o aumento da temperatura em função do tempo de exposição das amostras de óleo às microondas. As alterações na temperatura foram similares para os óleos de canola, milho e soja.

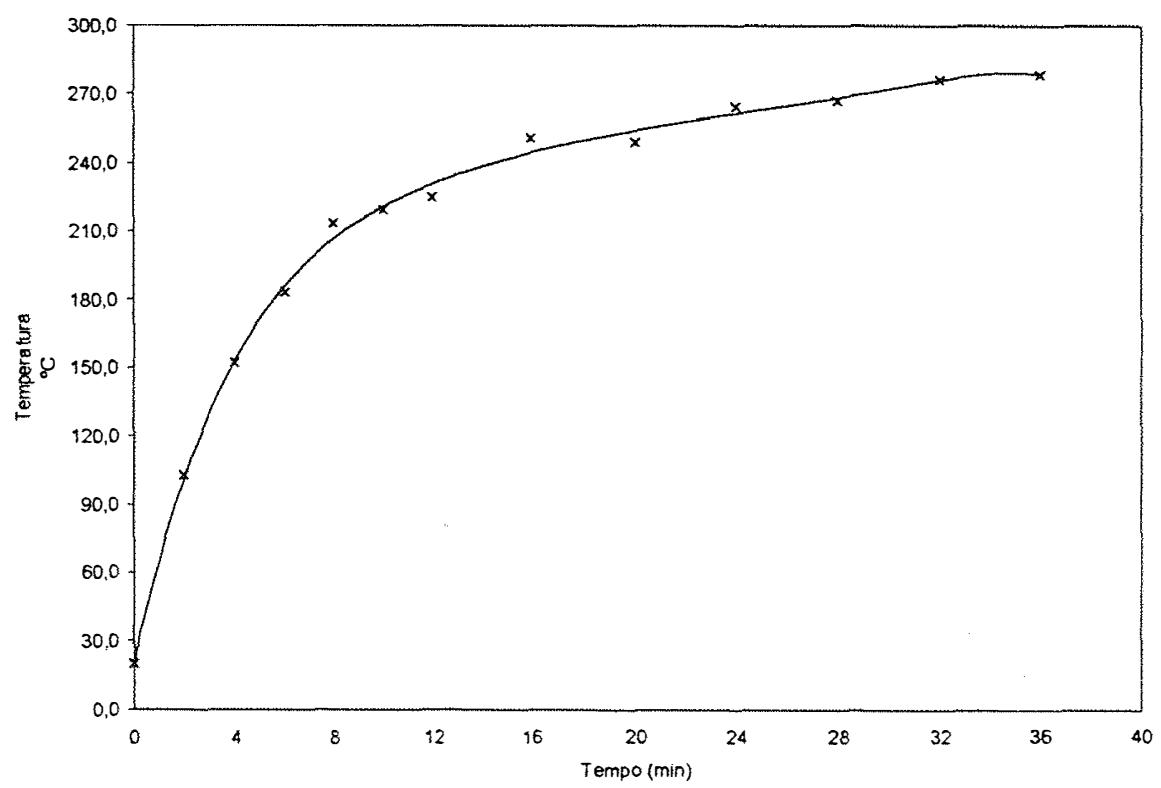

Figura 11 - Tempo de exposição e temperatura média dos óleos aquecidos em forno de microondas.

Os resultados obtidos para valores de absortividade em $232 \mathrm{~nm}$ e em 270 $\mathrm{nm}$, apresentados nas Figuras 12 a 17, indicam que o aquecimento por microondas induz a oxidação lipídica. A absortividade em $232 \mathrm{~nm}$ dos óleos de canola, milho e 
soja manteve-se sem alterações significativas estatisticamente até 8 min de exposição às microondas, sofrendo acréscimos gradativos a partir deste periodo, evidenciando a ocorrência do processo oxidativo devido à formação de dienos conjugados (Figuras 12, 13 e 14). Da mesma maneira, valores de absortividade em $270 \mathrm{~nm}$ sofreram aumentos significativos a partir de 4 min de aquecimento. Durante o aquecimento por microondas ocorre fricção molecular, o que poderia estar contribuindo para a formação de trienos e cetonas ou aldeidos insaturados, compostos secundários da oxidação, avaliados pela absortividade em 270 nm (Figuras 15, 16 e 17), confirmando os resultados obtidos por Albi et al. (1997a), que observaram aumentos do valor da absortividade em $270 \mathrm{~nm}$ de óleo de girassol de 3,15 para 5,16 após 120 minutos de aquecimento em fomo de microondas com potência de $500 \mathrm{~W}$ (temperatura atingida de $\left.170 \pm 10^{\circ} \mathrm{C}\right)$.

Os valores de absortividade em $232 \mathrm{~nm}$ apresentados pelo controle dos três óleos ao final dos 6 dias em estufa a $63^{\circ} \mathrm{C}$ foram correspondentes aos valores apresentados pelas amostras aquecidas e m forno de microondas durante 36, 32 e 3236 min, respectivamente para os óleos de canola, milho e soja.

O teste de Tukey aplicado para médias de antioxidantes, ao contrário do teste aplicado para médias de periodos de amostragem, indicou que não houve diferenças entre os tratamentos em nivel de $5 \%$ de significância para as variáveis absortividade em $232 \mathrm{~nm}$ e em $270 \mathrm{~nm}$ em nenhum periodo de amostragem. Os valores de diferença minima significativa (d.m.s) apresentados juntamente com as figuras são, portanto, referentes às médias de periodos de amostragem. 


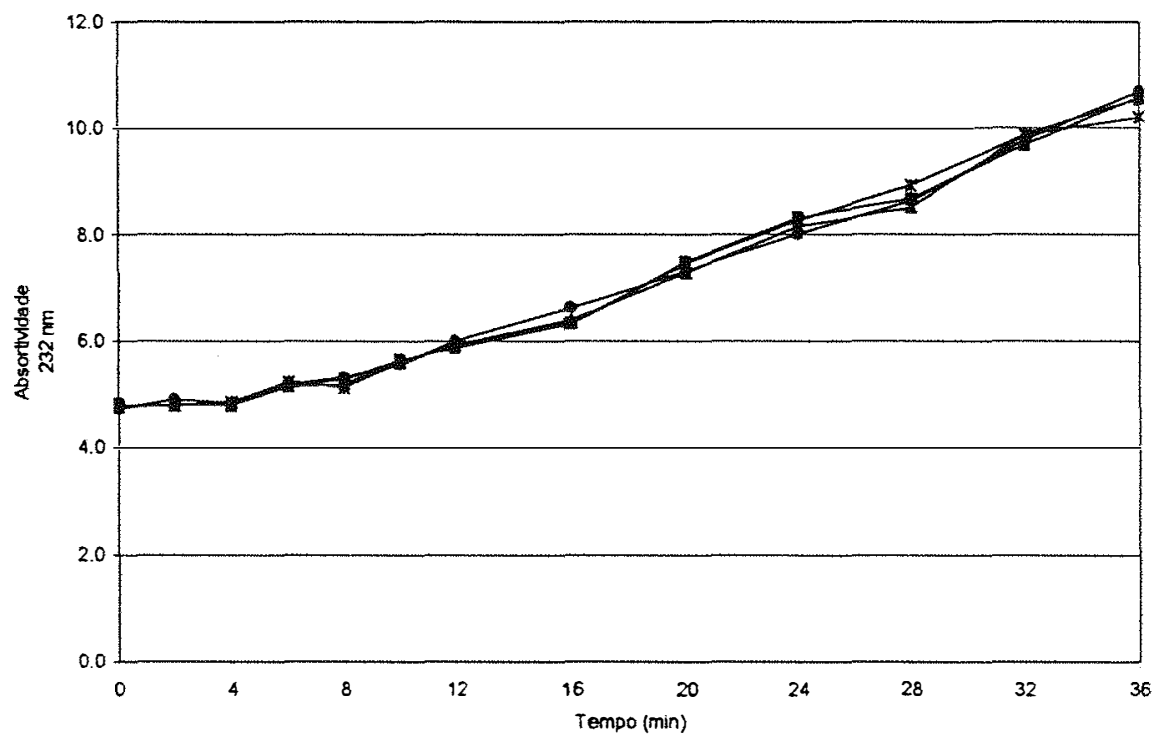

BHA BHT $(200 \mathrm{mg} \mathrm{kg}-1)+A C(100 \mathrm{mg} \mathrm{kg-1}) \rightarrow-B H A B H T(200 \mathrm{mg} \mathrm{kg-1}) \rightarrow-A C(100 \mathrm{mg} \mathrm{kg}-1) \rightarrow-$ Controle

Figura 12 - Absortividade em $232 \mathrm{~nm}$ de óleo de canola aquecido em forno de microondas.

(C.V. $=6,103 \%$, d.m.s. $5 \%=0,563)$

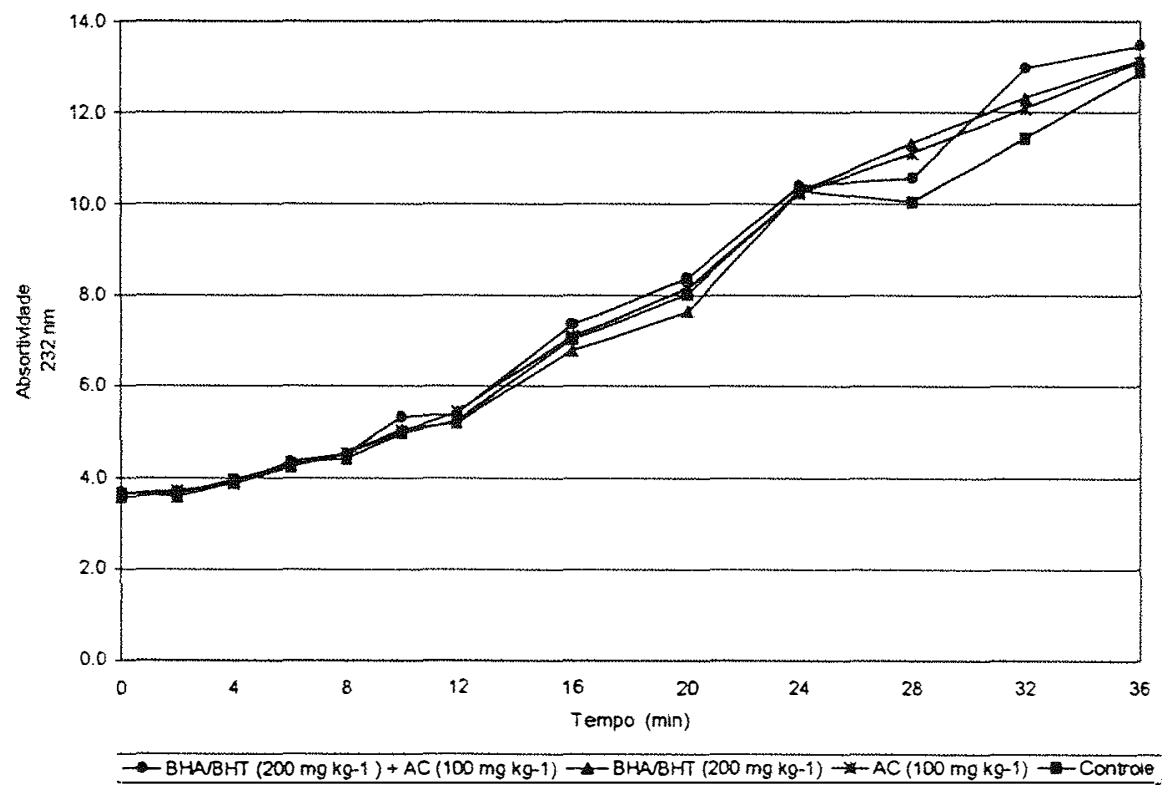

Figura 13 - Absortividade em $232 \mathrm{~nm}$ de óleo de milho aquecido em forno de microondas.

(C.V. $=8,797 \%$, d.m.s. $5 \%=0,856)$ 


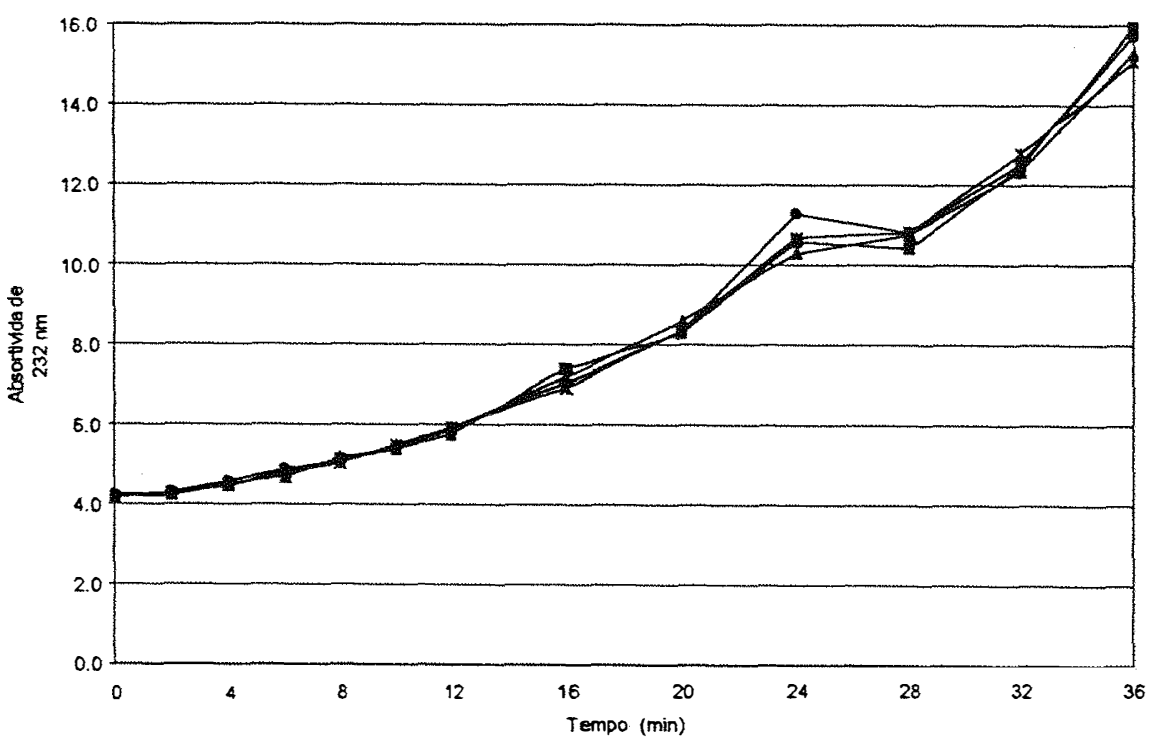

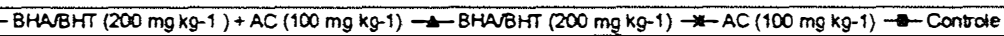

Figura 14 - Absortividade em $232 \mathrm{~nm}$ de óleo de soja aquecido em forno de microondas.

(C.V. $=10,284 \%$, d.m.s. $5 \%=1,079$ )

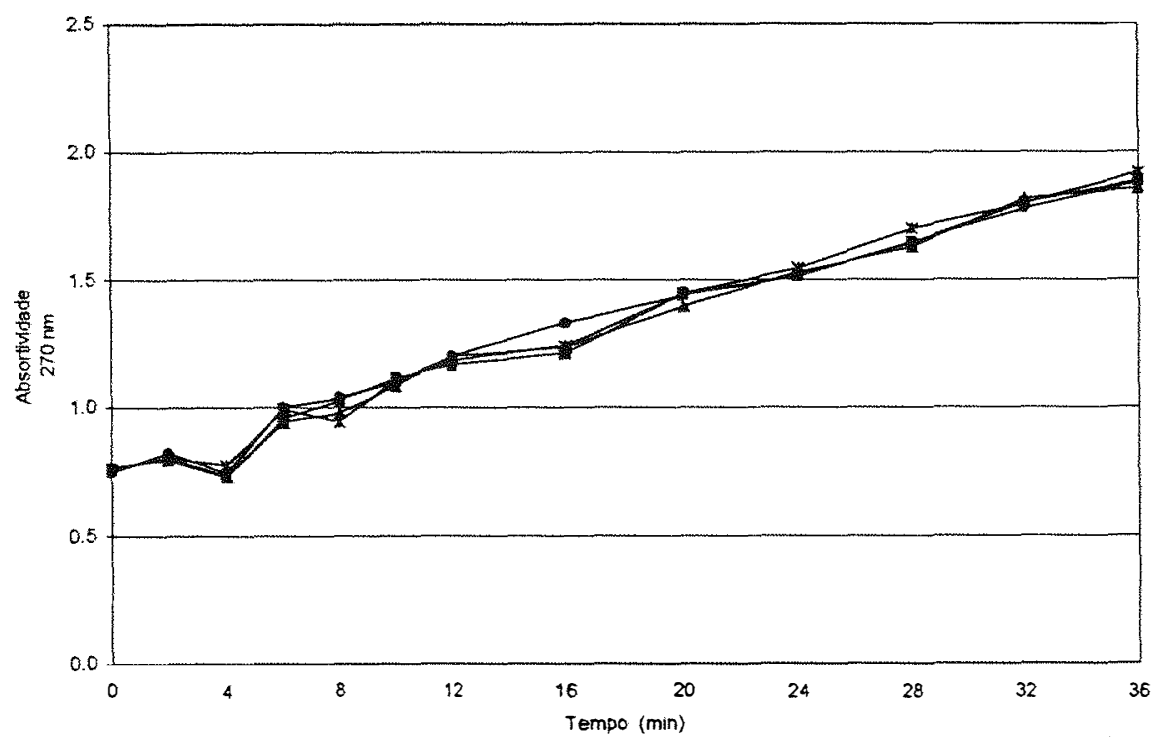

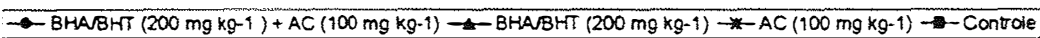

Figura 15 - Absortividade em $270 \mathrm{~nm}$ de óleo de canola aquecido em forno de microondas.

(C.V. $=4,026 \%$, d.m.s. $5 \%=0,069)$ 


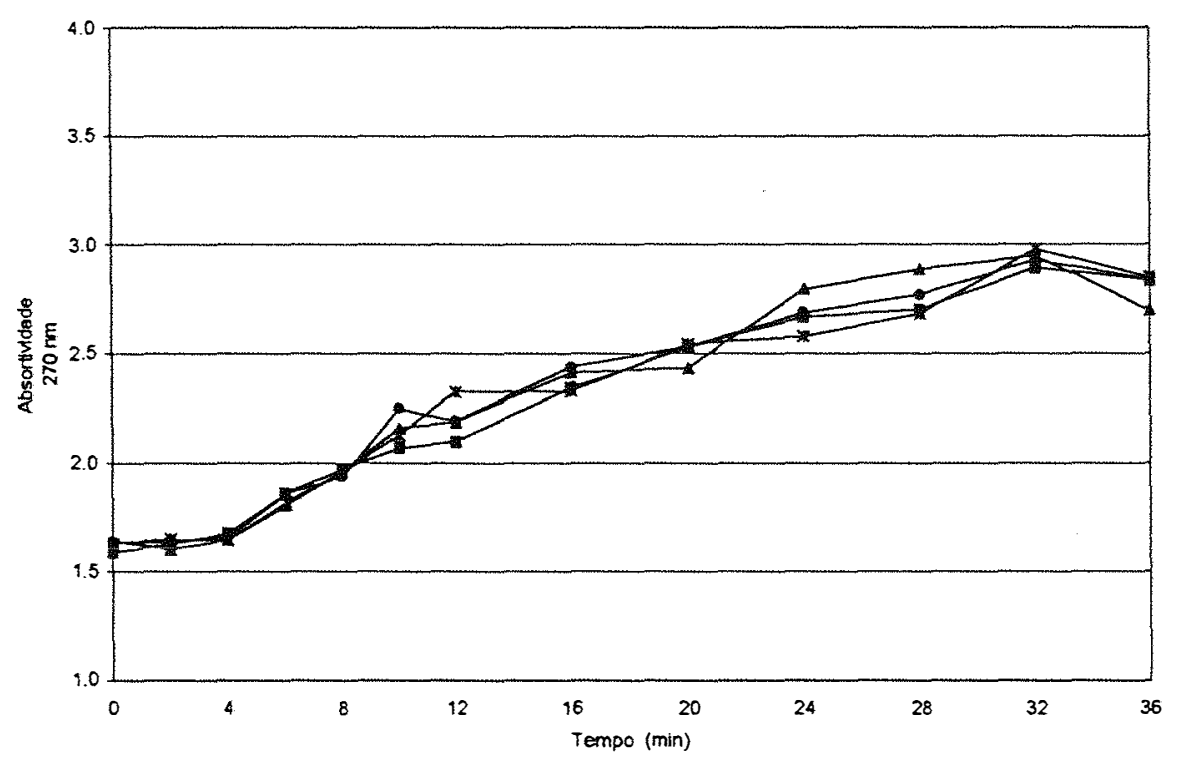

$-B H A B H T(200 \mathrm{mg} \mathrm{kg}-1)+A C(100 \mathrm{mg} \mathrm{kg-1})-\mathrm{BHABBHT}(200 \mathrm{mg} \mathrm{kg-1}) \rightarrow-\mathrm{AC}(100 \mathrm{mg} \mathrm{kg-1}) \rightarrow$ Contoole

Figura 16 - Absortividade em $270 \mathrm{~nm}$ de óleo de milho aquecido em forno de microondas.

(C.V. $=3,743 \%$, d.m.s. $5 \%=0,115)$

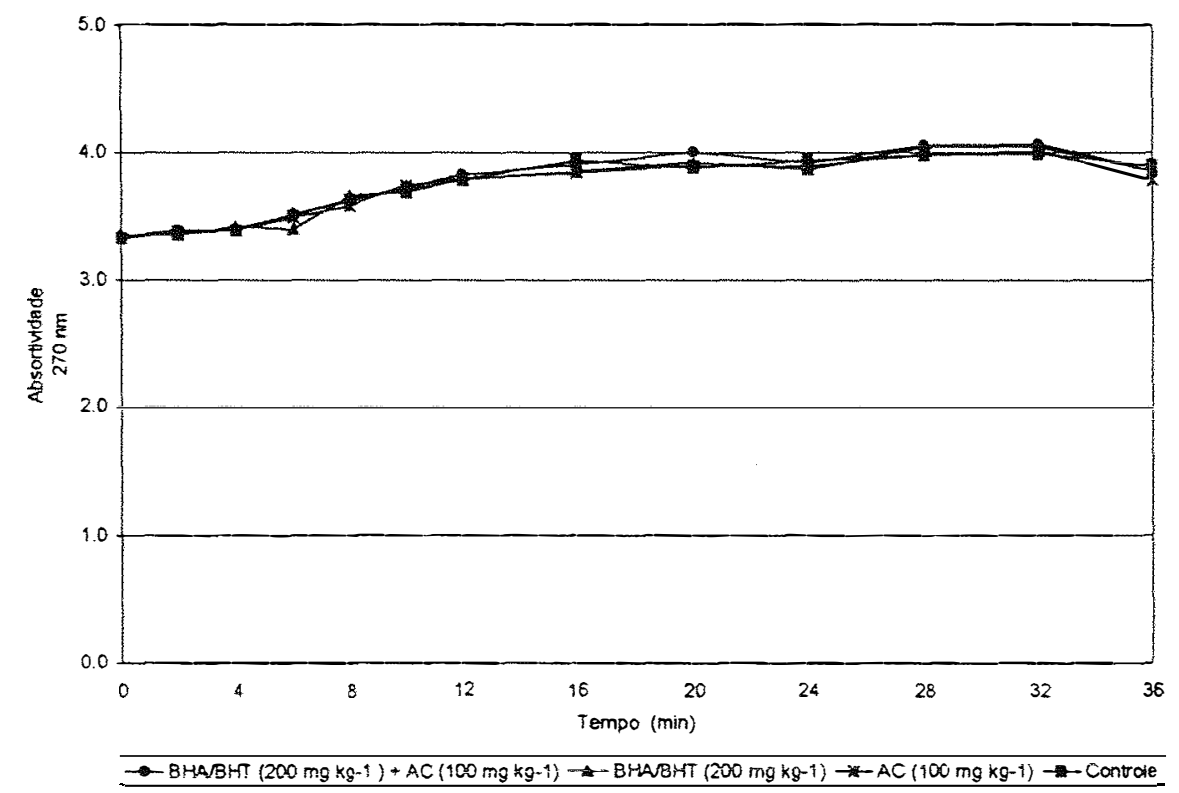

Figura 17 - Absortividade em 270 nm de óleo de soja aquecido em forno de microondas.

(C.V. $=1,857 \%$, d.m.s. $5 \%=0,095)$ 
Os antioxidantes BHA/BHT (100 mg kg-1), combinados a $50 \mathrm{mg} \mathrm{kg}^{-1}$ de $\mathrm{AC}$ não melhoraram a estabilidade do óleo de canola submetido ao aquecimento a $185^{\circ} \mathrm{C}$ durante 12 min (condições de fritura) em um estudo desenvolvido por Hawrysh et al. (1990). Os autores verificaram um aumento nos valores de absortividade em $234 \mathrm{~nm}$ de 4,32 e 4,29 para 6,06 e 5,72, respectivamente para o controle e para o óleo com antioxidante adicionado. A absortividade em $268 \mathrm{~nm}$ aumentou de 0,75 e 0,74 para 1,70 e 1,57 , respectivamente no controle e na amostra com BHA/BHT.

Como nenhum dos antioxidantes foi eficiente, somente os espectros de absortividade dos controles são apresentados na Figura 18. As Figuras 19, 20 e 21 apresentam as variações ocorridas no indice de peróxido dos óleos durante 0 aquecimento por microondas. $O$ indice de peróxido do óleo de canola manteve-se estável até $2 \mathrm{~min}$, apresentando um valor máximo aos $20 \mathrm{~min}\left(5,74 \mathrm{meq} \mathrm{kg}^{-1}\right.$ no controle), decrescendo a partir dai e mantendo-se sem diferenças até o final dos 36 min. Os óleos de milho e de soja apresentaram valores máximos aos 4 e 6 min, mas a tendência à redução observada no óleo de milho não ocorreu com a mesma velocidade no óleo de soja. Aos $36 \mathrm{~min}$, o óleo de milho apresentou um índice de peróxido estatisticamente igual ao inicial. Albi et al. (1997b) verificaram somente um pequeno aumento no indice de peróxido de óleo de oliva e de girassol aquecidos por microondas durante $120 \mathrm{~min}\left(170^{\circ} \mathrm{C}\right)$, contrastando com os resultados obtidos por Yoshida et al. (1993), que apresentaram curvas crescentes para 0 indice de peróxido dos óleos de canola, soja e palma em função do tempo.

Os hidroperóxidos são compostos instáveis às altas temperaturas. Durante o aquecimento por microondas, a taxa de degradação desses compostos é alta e, portanto, o acompanhamento das alterações no indice de peróxido é um parâmetro questionável para as investigações sobre estabilidade oxidativa de óleos expostos à ação de microondas. No entanto, as variações no índice de peróxido em função do tempo de aquecimento por microondas puderam ser associadas às alterações de absortividade que ocorreram em $270 \mathrm{~nm}$ e na faixa entre 265 e $280 \mathrm{~nm}$. A partir de 6 min de aquecimento (temperatura atingida de $183,1^{\circ} \mathrm{C}$ ) $\circ$ indice de peróxido dos óleos de canola, milho e soja apresentou uma tendência à redução, enquanto que os valores de absortividade em $270 \mathrm{~nm}$ apresentaram tendência a aumentar. 


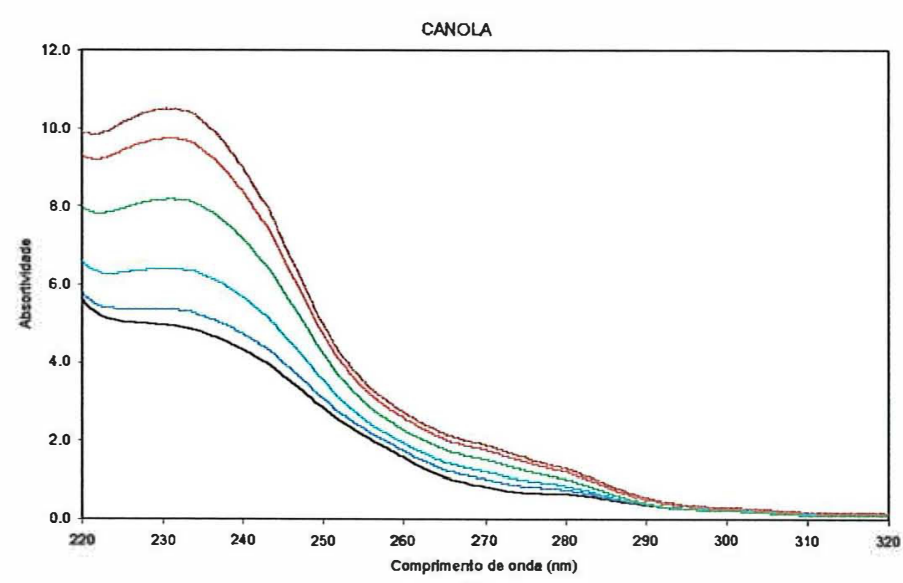

- niclal $-8 \mathrm{mln}-16 \mathrm{mln}-24 \mathrm{mln}-32 \mathrm{~min}=36 \mathrm{mln}$

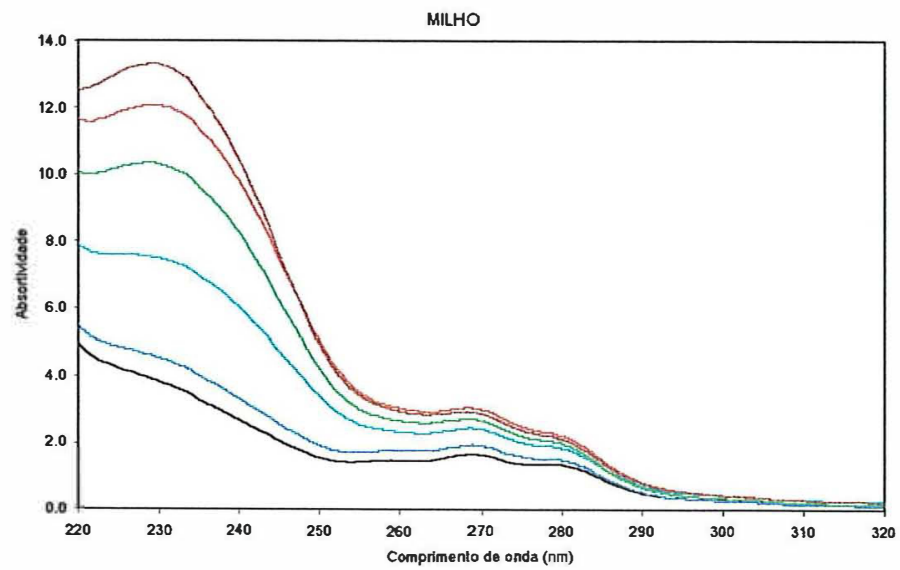

- incial $-8 \mathrm{~min}-16 \mathrm{~min}-24 \mathrm{mln}-32 \mathrm{~min}-36 \mathrm{~min}$

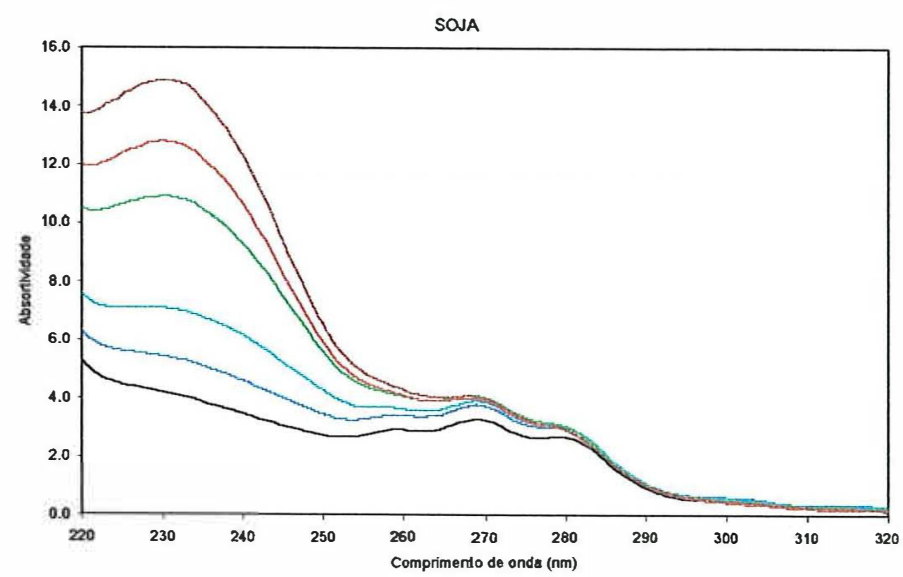

-

Figura 18 - Espectros de absortividade entre 220 e 320 nm dos óleos de canola, milho e soja aquecidos em forno de microondas. 


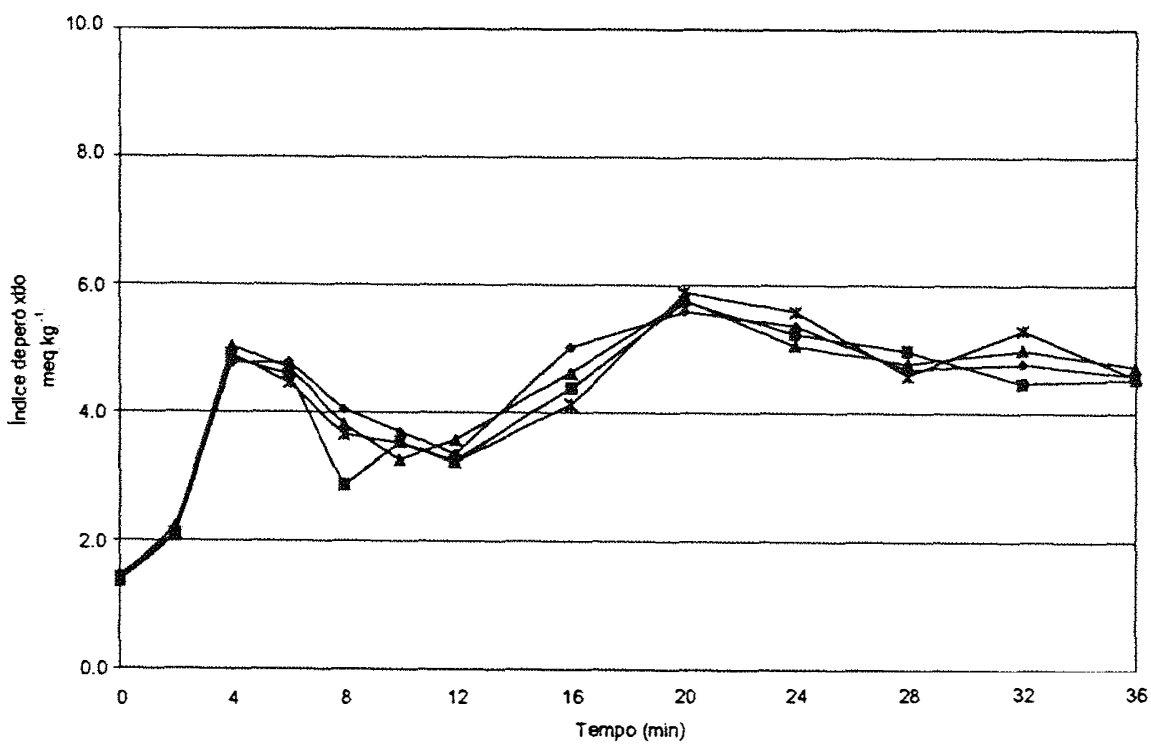

$-\mathrm{AHAVBHT}(200 \mathrm{mg} \mathrm{kg}-1)+A C(100 \mathrm{mg} \mathrm{kg}-1) \rightarrow$ BHABHT $(200 \mathrm{mg} \mathrm{kg}-1) \rightarrow-\mathrm{AC}(100 \mathrm{mg} \mathrm{kg}-1) \rightarrow$ Contode

Figura 19 - Índice de peróxido $\left(m e q \mathrm{~kg}^{-1}\right)$ de óleo de canola aquecido em forno de microondas.

(C.V. $=13,188 \%$, d.m.s. $5 \%=0,744)$

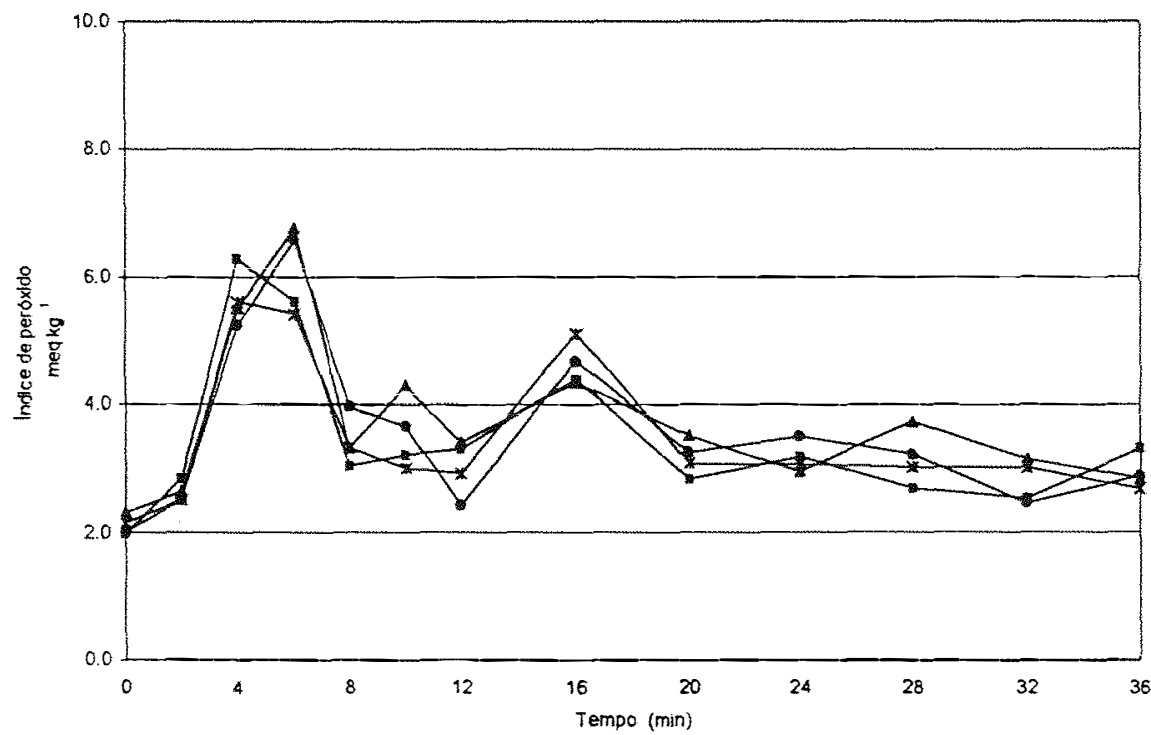

$\rightarrow$ BHAVBHT $(200 \mathrm{mgkg}-1)+\mathrm{AC}(100 \mathrm{mg} \mathrm{kg}-1) \rightarrow-B H A B H T(200 \mathrm{mg} \mathrm{kg}-1) \rightarrow-\mathrm{AC}(100 \mathrm{mg} \mathrm{kg}-1) \rightarrow$ Contole

Figura 20 - Índice de peróxido (meq $\mathrm{kg}^{-1}$ ) de óleo de milho aquecido em forno de microondas.

(C.V. $=19,984 \%$, d.m.s. $5 \%=0,980)$ 


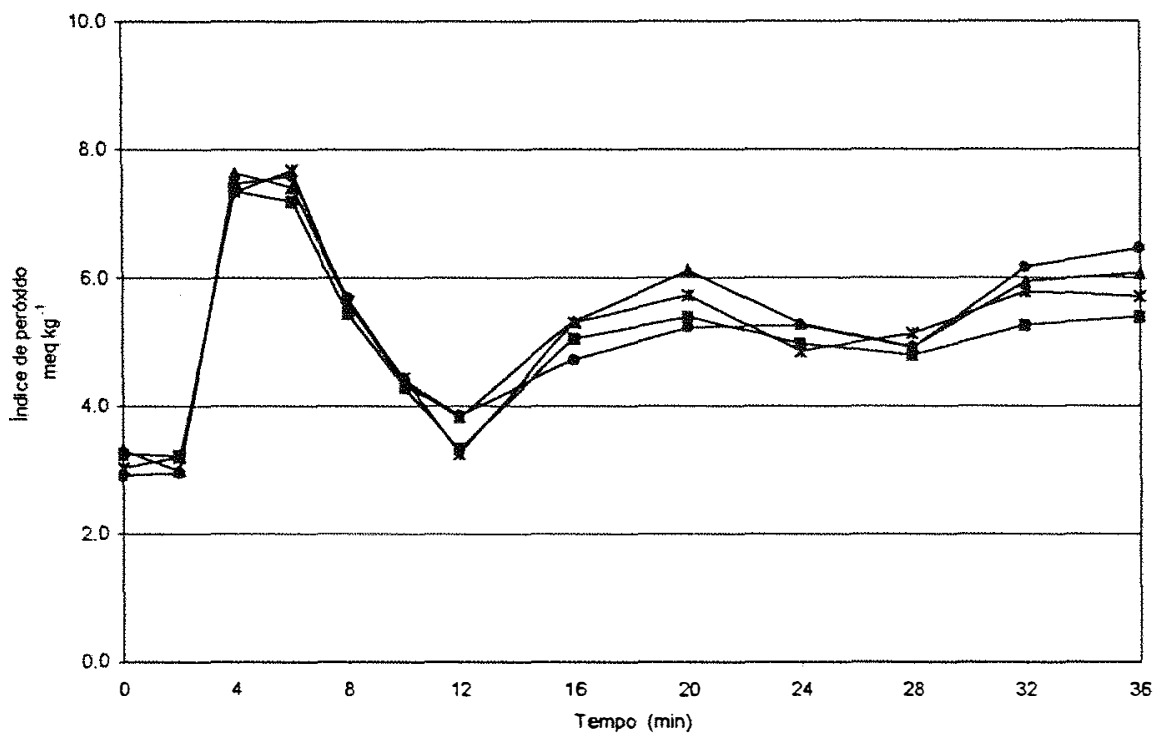

$\rightarrow$ BHABHT $(200 \mathrm{mgkg}-1)+A C(100 \mathrm{mg} \mathrm{kg}-1) \rightarrow$ BHABHT $(200 \mathrm{mg} \mathrm{kg}-1) \rightarrow$ - $-\mathrm{AC}(100 \mathrm{mg} \mathrm{kg}-1) \rightarrow-$ Controle

Figura 21 - Índice de peróxido $\left(m e q \mathrm{~kg}^{-1}\right.$ ) de óleo de soja aquecido em forno de microondas.

(C.V. $=10,164 \%$, d.m.s. $5 \%=0,721$ )

O teste de Tukey aplicado para médias de antioxidantes da variável indice de peróxido dos três óleos indicou que nenhum antioxidante foi efetivo em proteger as amostras da degradação oxidativa, em nível de $5 \%$ de significância. Os valores de diferença mínima significativa (d.m.s.) indicados nas figuras são, portanto, referentes às médias de períodos de amostragem.

$O$ indice de acidez sofreu pequenos, mas significativos, acréscimos ao longo do período estudado, indicando que houve alterações hidrolíticas durante 0 aquecimento por microondas nos três óleos (Tabela 8). Os antioxidantes não tiveram efeito. 
Tabela 8. Índice de acidez (\% AGL $)^{1}$ de óleos de canola, milho e soja aquecidos em forno de microondas.

\begin{tabular}{cccc}
\hline Tempo & \multicolumn{3}{c}{ Óleos } \\
\cline { 2 - 4 } (min) & Canola $^{2}$ & Milho $^{3}$ & Soja $^{4}$ \\
\hline 0 & $0,075^{\mathrm{e}}$ & $0,077^{\mathrm{e}}$ & $0,075^{\mathrm{g}}$ \\
2 & $0,080^{\mathrm{d}}$ & $0,075^{\mathrm{e}}$ & $0,079^{\mathrm{g}}$ \\
4 & $0,080^{\mathrm{d}}$ & $0,101^{\mathrm{d}}$ & $0,079^{\mathrm{g}}$ \\
6 & $0,075^{\mathrm{d}}$ & $0,104^{\mathrm{d}}$ & $0,079^{\mathrm{g}}$ \\
8 & $0,080^{\mathrm{d}}$ & $0,104^{\mathrm{d}}$ & $0,102^{\mathrm{f}}$ \\
10 & $0,080^{\mathrm{d}}$ & $0,127^{\mathrm{c}}$ & $0,102^{\mathrm{d}}$ \\
12 & $0,080^{\mathrm{d}}$ & $0,127^{\mathrm{c}}$ & $0,107^{\mathrm{e}}$ \\
16 & $0,080^{\mathrm{d}}$ & $0,127^{\mathrm{c}}$ & $0,132^{\mathrm{d}}$ \\
20 & $0,080^{\mathrm{d}}$ & $0,129^{\mathrm{bc}}$ & $0,132^{\mathrm{d}}$ \\
24 & $0,101^{\mathrm{c}}$ & $0,132^{\mathrm{b}}$ & $0,157^{\mathrm{c}}$ \\
28 & $0,106^{\mathrm{b}}$ & $0,132^{\mathrm{b}}$ & $0,157^{\mathrm{c}}$ \\
32 & $0,156^{\mathrm{a}}$ & $0,154^{\mathrm{a}}$ & $0,208^{\mathrm{b}}$ \\
36 & $0,156^{\mathrm{a}}$ & $0,154^{\mathrm{a}}$ & $0,233^{\mathrm{a}}$ \\
\hline
\end{tabular}

média de 3 repetiçōes (controle)

${ }^{2}$ C.V. $=2,443 \%$ d.m.s. $5 \%=0,00317,{ }^{3}$ C.V. $=2,304 \%$ d.m.s. $5 \%=0,00378,{ }^{4}$ C.V. $=2,170 \%$ d.m.s. $5 \%=0,00378$ Valores seguidos por letras distintas nas colunas diferem entre si ao nivel de $5 \%$ de significancia.

\subsection{Armazenamento em condições normais de temperatura e luminosidade}

Assim como no ensaio acelerado de aquecimento das amostras em forno de microondas, os antioxidantes adicionados aos óleos de canola, milho e soja não apresentaram efeito em retardar o desenvolvimento da rancidez durante 180 dias de armazenamento em condições de comercialização. As variações de temperatura e de umidade relativa registradas durante o armazenamento dos óleos são apresentadas na Tabela 9. 
Tabela 9. Temperatura e de umidade relativa ambientes durante 0 armazenamento em condições normais de comercialização de óleos de canola, milho e soja embalados em frascos de PET.

\begin{tabular}{lcccccc}
\hline Período de & \multicolumn{3}{c}{ Temperatura $\left({ }^{\circ} \mathrm{C}\right)$} & \multicolumn{3}{c}{ Umidade Relativa (\%) } \\
\cline { 2 - 7 } armazenamento (dias) & média & máxima & mínima & média & máxima & mínima \\
\hline $0-15$ & 27,9 & 29,0 & 26,0 & 64,7 & 74,0 & 51,0 \\
$15-30$ & 28,3 & 29,0 & 26,0 & 57,8 & 76,0 & 47,0 \\
$30-45$ & 27,4 & 28,0 & 26,0 & 60,4 & 73,0 & 50,0 \\
$45-60$ & 27,8 & 28,0 & 23,0 & 59,9 & 77,0 & 47,0 \\
$60-75$ & 27,3 & 28,0 & 24,0 & 57,4 & 71,0 & 45,0 \\
$75-90$ & 26,8 & 28,0 & 25,0 & 57,1 & 70,0 & 46,0 \\
$90-120$ & 25,4 & 27,0 & 21,0 & 59,7 & 80,0 & 42,0 \\
$120-150$ & 25,4 & 27,0 & 23,0 & 58,4 & 76,0 & 42,0 \\
$150-180$ & 25,3 & 27,0 & 19,0 & 56,5 & 79,0 & 41,0 \\
\hline
\end{tabular}

Foram verificados aumentos nos valores de índice de peróxido em função do periodo de armazenamento nos três óleos. O óleo de canola apresentou valores máximos de índice de peróxido aos 120 e 180 dias (Figura 22). Tais valores corresponderam ao valor atingido pelas amostras submetidas a 2 dias em estufa (média de 5,90 meq $\mathrm{kg}^{-1}$ ). Até 2 dias de teste acelerado em estufa não houve diferença estatisticamente significativa entre os tratamentos aplicados ao óleo de canola, apesar do controle e do tratamento com AC mostrarem valores médios de indices de peróxido mais altos que aqueles apresentados pelos tratamentos com BHA/BHT e BHA/BHT +AC. 


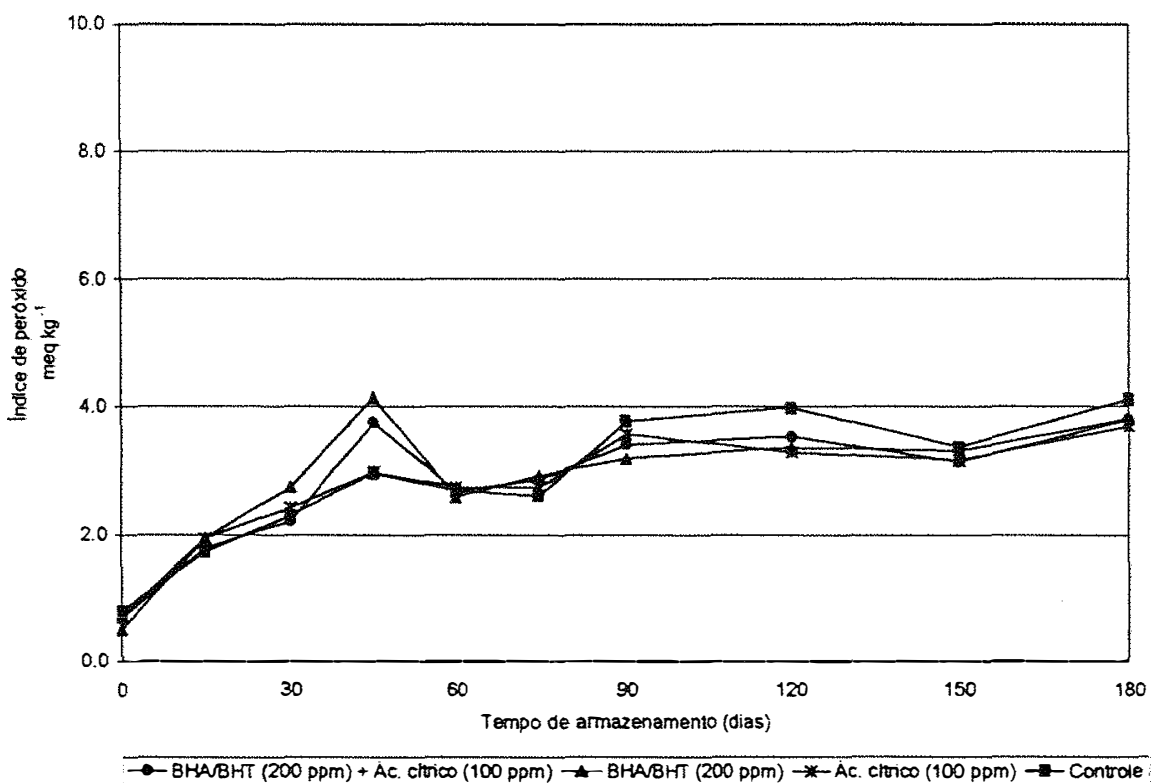

Figura 22 - Índice de peróxido (meq $\mathrm{kg}^{-1}$ ) de óleo de canola armazenado em frascos de PET em condições de comercialização.

(C.V. $=8,947 \%$, d.m.s. $5 \%=0,322$ )

Os óleos de milho e de soja apresentaram aumentos no índice de peróxido ao longo dos 6 meses de armazenamento. Os valores máximos, apresentados aos 180 dias, corresponderam àqueles observados aos 2 dias em estufa a $63^{\circ} \mathrm{C}$ (Figuras 23 e 24). Tanto o óleo de milho quanto o de soja somente apresentaram diferenças estatisticamente significativas entre os tratamentos depois de 3 dias em estufa. 0 tempo de armazenamento em temperatura ambiente foi, portanto, insuficiente para que $o$ efeito dos antioxidantes pudesse ser comparado aos resultados obtidos no teste acelerado em estufa $\left(63^{\circ} \mathrm{C}\right)$. Todavia, como o período máximo de conservação de óleos refinados em embalagem de PET normalmente estabelecido pelos fabricantes é de 6 meses, a adição dos antioxidantes testados seria desnecessária para manter a estabilidade oxidativa dos óleos de canola, milho e soja em condições normais de armazenamento. 


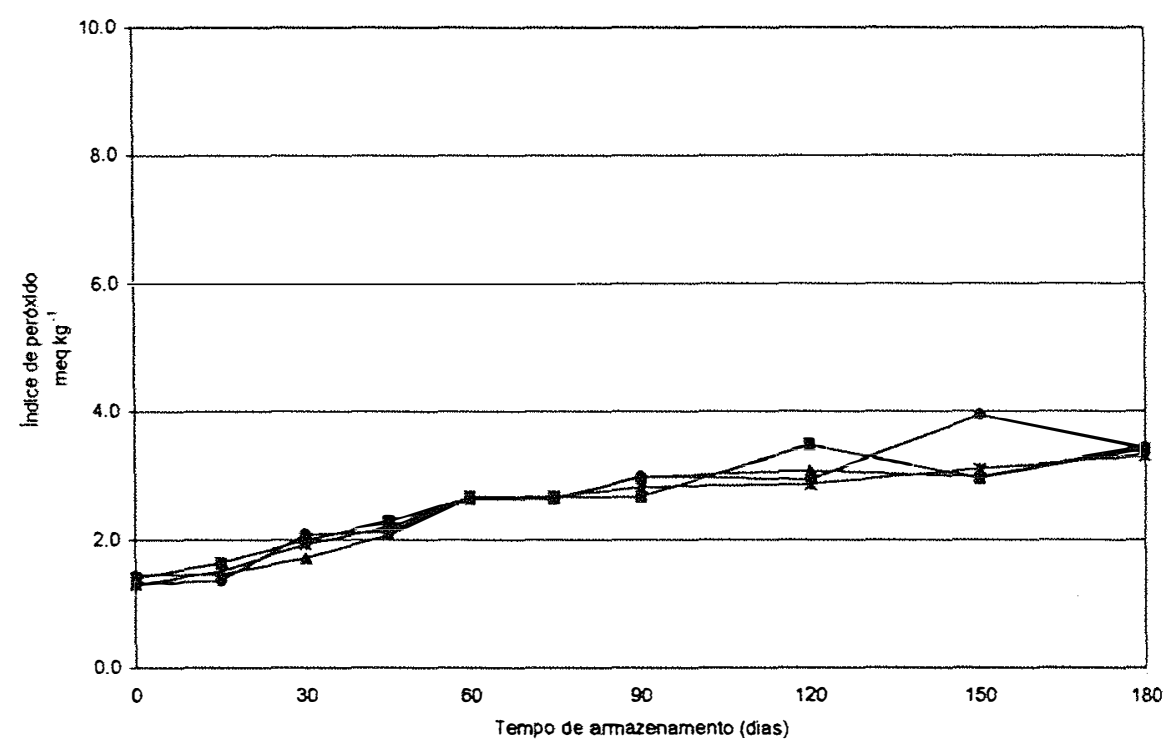

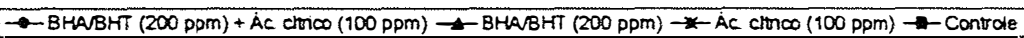

Figura 23 - Índice de peróxido (meq $\mathrm{kg}^{-1}$ ) de óleo de milho armazenado em frascos de PET em condições de comercialização.

(C.V. $=14,487 \%$, d.m.s. $5 \%=0,478$ )

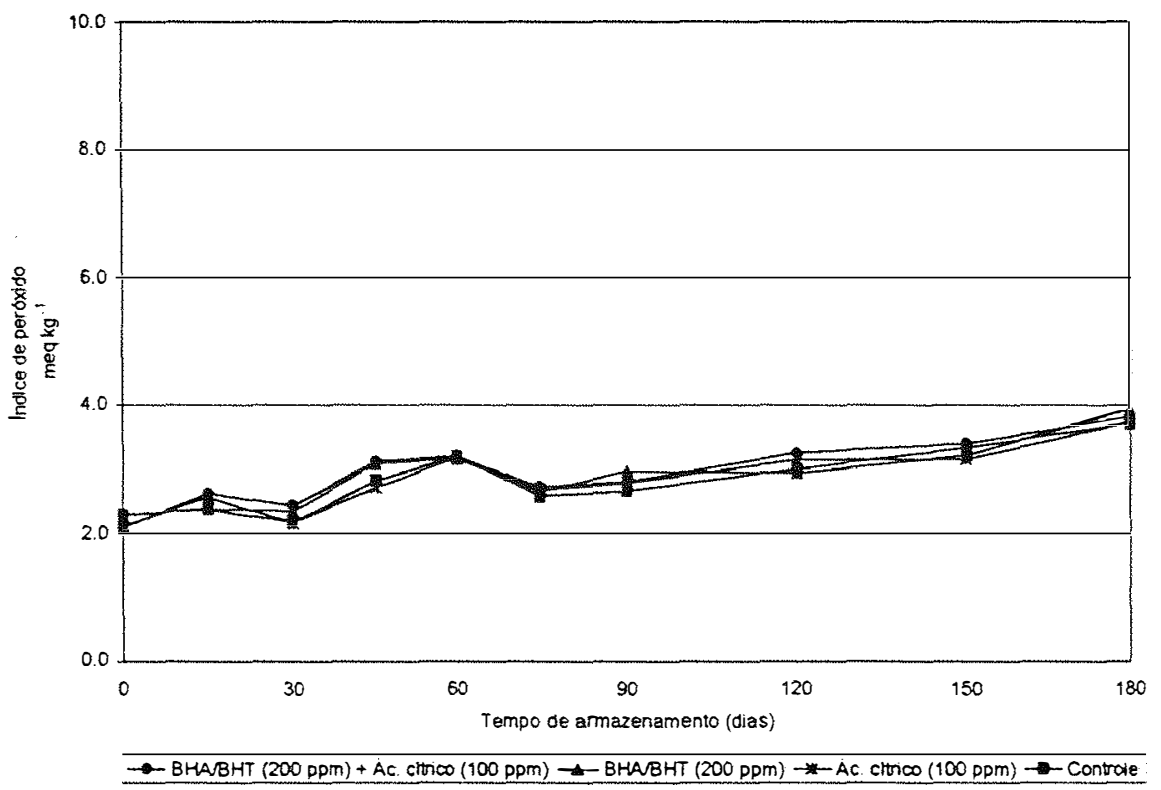

Figura 24 - Índice de peróxido $\left(m e \mathrm{~kg}^{-1}\right.$ ) de óleo de soja armazenado em frascos de PET em condições de comercialização.

(C.V. $=7,363 \%$, d.m.s. $5 \%=0,284)$ 
A absortividade em $232 \mathrm{~nm}$ sofreu variações durante os 6 meses de armazenamento, mas não foi verificada diferença entre o controle e as amostras adicionadas de antioxidantes em nenhum dos três óleos. No entanto, o teste de Tukey aplicado para médias de tempo de armazenamento acusou diferenças significativas entre os resultados obtidos (Tabelas 10, 11 e 12). No óleo de soja observaram-se aumentos crescentes nos valores de absortividade em $232 \mathrm{~nm}$ até 90 dias de armazenamento. A partir daí, os valores de absortividade em $232 \mathrm{~nm}$ mantiveram-se sem alterações significativas. Esses Valores corresponderam a 2 dias de teste acelerado em estufa e a 4 min de aquecimento em forno de microondas. Os óleos de canola e milho não apresentaram a mesma tendência de sofrer acréscimos apresentada pelo óleo de soja, apesar da verificação de diferenças significativas na absortividade em $232 \mathrm{~nm}$ em função do tempo de armazenamento.

Tabela 10. Absortividade em $232 \mathrm{~nm}{ }^{1}$ de óleo de canola armazenado em frascos de PET em condições de comercialização.

\begin{tabular}{ccccc}
\hline \multirow{2}{*}{$\begin{array}{l}\text { Tempo de } \\
\text { armazenamento }\end{array}$} & \multicolumn{4}{c}{ Tratamentos $^{2}$} \\
\cline { 2 - 5 } (dias) & $\begin{array}{c}\text { BHA/BHT }+ \text { AC } \\
\left(200+10 \mathrm{mg} \mathrm{kg}^{-1}\right)\end{array}$ & $\begin{array}{c}\text { BHA/BHT } \\
\left(200 \mathrm{mg} \mathrm{kg}^{-1}\right)\end{array}$ & $\begin{array}{c}\text { AC } \\
\left(100 \mathrm{mg} \mathrm{kg}^{-1}\right)\end{array}$ \\
\hline 0 & $4,928^{\mathrm{abc}}$ & $4,677^{\mathrm{b}}$ & $4,747^{\mathrm{b}}$ & $4,738^{\mathrm{ab}}$ \\
15 & $5,147^{\mathrm{abc}}$ & $5,021^{\mathrm{a}}$ & $4,821^{\mathrm{b}}$ & $4,995^{\mathrm{ab}}$ \\
30 & $5,444^{\mathrm{a}}$ & $5,554^{\mathrm{b}}$ & $5,420^{\mathrm{a}}$ & $5,195^{\mathrm{a}}$ \\
45 & $4,935^{\mathrm{abc}}$ & $4,640^{\mathrm{b}}$ & $4,611^{\mathrm{b}}$ & $4,715^{\mathrm{ab}}$ \\
60 & $4,687^{\mathrm{c}}$ & $4,651^{\mathrm{b}}$ & $4,642^{\mathrm{b}}$ & $4,634^{\mathrm{b}}$ \\
75 & $5,235^{\mathrm{ab}}$ & $4,987^{\mathrm{b}}$ & $4,941^{\mathrm{ab}}$ & $5,002^{\mathrm{ab}}$ \\
90 & $5,114^{\mathrm{abc}}$ & $4,929^{\mathrm{b}}$ & $4,935^{\mathrm{ab}}$ & $5,137^{\mathrm{ab}}$ \\
120 & $4,730^{\mathrm{bc}}$ & $5,068^{\mathrm{ab}}$ & $4,877^{\mathrm{b}}$ & $4,695^{\mathrm{ab}}$ \\
150 & $5,002^{\mathrm{abc}}$ & $4,977^{\mathrm{b}}$ & $5,076^{\mathrm{ab}}$ & $4,963^{\mathrm{ab}}$ \\
180 & $5,011^{\mathrm{abc}}$ & $4,945^{\mathrm{b}}$ & $5,080^{\mathrm{ab}}$ & $5,107^{\mathrm{ab}}$ \\
\hline
\end{tabular}

${ }^{1}$ médias de 3 repetiçōes $\quad{ }^{2}$ C.V. $=3,944 \%$ d.m.S. $5 \%=0,259$

Valores seguidos por letras distintas na coluna diferem entre si ao nivel de $5 \%$ de significância, segundo o teste de Tukey aplicado para as médias de tempo de armazenamento. 
Tabela 11. Absortividade em $232 \mathrm{~nm}{ }^{1}$ de óleo de milho armazenado em frascos de PET em condições de comercialização.

\begin{tabular}{|c|c|c|c|c|}
\hline \multirow{2}{*}{$\begin{array}{l}\text { Tempo de } \\
\text { armazenamento } \\
\text { (dias) }\end{array}$} & \multicolumn{4}{|c|}{ Tratamentos $^{2}$} \\
\hline & $\begin{array}{c}\text { BHAVBHT + AC } \\
\left(200+100 \mathrm{mg} \mathrm{kg}^{-1}\right)\end{array}$ & $\begin{array}{c}\text { BHA/BHT } \\
\left(200 \mathrm{mg} \mathrm{kg}^{-1}\right) \\
\end{array}$ & $\begin{array}{c}\mathrm{AC} \\
\left(100 \mathrm{mg} \mathrm{kg}^{-1}\right) \\
\end{array}$ & Controle \\
\hline 0 & $3,303^{b}$ & 3,542 bc & $3,243^{b}$ & $3,377^{c}$ \\
\hline 15 & $3,284^{b}$ & $3,336^{c}$ & $3,289^{b}$ & $3,248^{\circ}$ \\
\hline 30 & $3,264^{b}$ & $3,168 \quad c$ & $3,335^{b}$ & $3,119^{\circ}$ \\
\hline 45 & $3,979^{a}$ & 4,224 & $3,792^{a b}$ & $4,038^{a b}$ \\
\hline 60 & $3,492^{a b}$ & 3,483 bc & $3,356^{b}$ & $2,971^{\mathrm{c}}$ \\
\hline 75 & $3,842^{a b}$ & $4,086^{a b}$ & $4,118^{a}$ & $4,193^{a}$ \\
\hline 90 & $3,419^{a b}$ & $3,391 \quad c$ & $3,318^{b}$ & $3,411^{b c}$ \\
\hline 120 & $3,295^{a}$ & $3,321 \quad c$ & $3,346^{b}$ & $3,317^{c}$ \\
\hline 150 & $3,406^{a b}$ & 3,542 bc & $3,358^{b}$ & $3,332^{\circ}$ \\
\hline 180 & $3,555^{a b}$ & $3,659^{a b c}$ & $3,480^{a b}$ & $3,413^{b c}$ \\
\hline
\end{tabular}

${ }^{1}$ médias de 3 repetiçōes ${ }^{2}$ C.V. $=6,919 \%$ d.m.s. $5 \%=0,321$

Valores seguidos por letras distintas na coluna diferem entre si ao nivel de $5 \%$ de significancia, segundo o teste de Tukey aplicado para as médias de tempo de armazenamento. 
Tabela 12. Absortividade em $232 \mathrm{~nm}^{1}$ de óleo de soja armazenado em frascos de PET em condições de comercialização.

\begin{tabular}{|c|c|c|c|c|}
\hline \multirow{2}{*}{$\begin{array}{l}\text { Tempo de } \\
\text { armazenamento } \\
\text { (dias) }\end{array}$} & \multicolumn{4}{|c|}{ Tratamentos $^{2}$} \\
\hline & $\begin{array}{c}\text { BHAVBHT + AC } \\
\left(200+100 \mathrm{mg} \mathrm{kg}^{-1}\right)\end{array}$ & $\begin{array}{c}\text { BHA/BHT } \\
\left(200 \mathrm{mg} \mathrm{kg}^{-1}\right)\end{array}$ & $\begin{array}{c}\mathrm{AC} \\
\left(100 \mathrm{mg} \mathrm{kg}^{-1}\right)\end{array}$ & Controle \\
\hline 0 & $4,257^{\text {bed }}$ & $4,396^{a b c}$ & $4,453^{a b}$ & $4,260^{\text {bed }}$ \\
\hline 15 & $3,986 d$ & $4,111^{c}$ & $4,102^{b}$ & $3,939 d$ \\
\hline 30 & $4,292^{\text {bcd }}$ & $4,712^{a}$ & $4,090^{b}$ & 4,093 cd \\
\hline 45 & $4,027^{c d}$ & 4,180 bc & $4,264^{a b}$ & $4,215^{\mathrm{bcd}}$ \\
\hline 60 & $4,260^{\text {bcd }}$ & $4,095^{c}$ & $4,288^{a b}$ & $4,234^{\mathrm{bcd}}$ \\
\hline 75 & $4,236^{\text {bed }}$ & $4,176^{b c}$ & $4,196^{a b}$ & 4,079 cd \\
\hline 90 & $4,415^{b}$ & $4,441^{a b c}$ & $4,555^{a}$ & $4,385^{a b c}$ \\
\hline 120 & $4,801^{a}$ & $4,583^{a}$ & $4,543^{a}$ & $4,413^{a b c}$ \\
\hline 150 & $4,392^{b c}$ & $4,469^{a b c}$ & $4,513^{a}$ & $4,650^{a}$ \\
\hline 180 & $4,505^{a b}$ & $4,522^{a b}$ & $4,504^{a}$ & $4,474^{a b}$ \\
\hline
\end{tabular}

A absortividade em $270 \mathrm{~nm}$ também só sofreu aumentos gradativos no óleo de soja. Apesar de serem verificadas alterações significativas nos valores de absortividade em $270 \mathrm{~nm}$ registrados para os óleos de canola e milho ao longo do tempo, as variações não puderam ser relacionadas à oxidação lipídica (Tabelas 13 , 14 e 15). Como nenhum tratamento apresentou-se estatisticamente diferente do controle, a Figura 25 apresenta os espectros de absortividade traçados para as amostras controle dos óleos de canola, milho e soja. O tempo de armazenamento não promoveu alterações nos espectros de absortividade em nenhum dos três óleos, indicando a baixa velocidade de formação de produtos da oxidação durante 0 armazenamento por 6 meses. 
Tabela 13. Absortividade em $270 \mathrm{~nm}^{1}$ de óleo de canola armazenado em frascos de PET em condições de comercialização.

\begin{tabular}{|c|c|c|c|c|}
\hline \multirow{2}{*}{$\begin{array}{l}\text { Tempo de } \\
\text { armazenamento } \\
\text { (dias) }\end{array}$} & \multicolumn{4}{|c|}{ Tratamentos $^{2}$} \\
\hline & $\begin{array}{c}\text { BHAVBHT + AC } \\
\left(200+100 \mathrm{mg} \mathrm{kg}^{-1}\right)\end{array}$ & $\begin{array}{c}\text { BHA/BHT } \\
\left(200 \mathrm{mg} \mathrm{kg}^{-1}\right)\end{array}$ & $\begin{array}{c}\mathrm{AC} \\
\left(100 \mathrm{mg} \mathrm{kg}^{-1}\right)\end{array}$ & Controle \\
\hline 0 & $0,812^{\text {abcd }}$ & $0,827^{a b}$ & $0,734^{b c}$ & $0,734^{a b c}$ \\
\hline 15 & 0,836 abc & $0,792^{a b}$ & $0,769^{b c}$ & $0,768^{a b}$ \\
\hline 30 & $0,914 \quad a$ & $0,934^{a}$ & $0,925^{a}$ & $0,831^{a}$ \\
\hline 45 & 0,640 & $0,603^{\circ}$ & $0,599^{c}$ & $0,572^{c}$ \\
\hline 60 & 0,677 cde & $0,663^{b c}$ & $0,646^{b c}$ & $0,632^{b c}$ \\
\hline 75 & $0,856 \quad a b$ & $0,754^{b c}$ & $0,771^{a b}$ & 0,826 \\
\hline 90 & $0,741^{\text {bcde }}$ & $0,726^{b c}$ & $0,701^{b c}$ & $0,774^{a b}$ \\
\hline 120 & 0,649 de & $0,709^{b c}$ & $0,651^{b c}$ & 0,626 bc \\
\hline 150 & $0,799^{\text {abcde }}$ & $0,797^{a b}$ & $0,772^{a b}$ & $0,783^{a b}$ \\
\hline 180 & $0,758^{\text {abcde }}$ & $0,741^{b c}$ & $0,776^{a b}$ & $0,785^{a b}$ \\
\hline
\end{tabular}

${ }^{1}$ médias de 3 repetições ${ }^{2}$ C.V. $=8,261 \%$ d.m.s. $5 \%=0,082$

Valores seguidos por letras distintas na coluna diferem entre si ao nivel de $5 \%$ de significancia, segundo o teste de Tukey aplicado para as médias de tempo de armazenamento. 
Tabela 14. Absortividade em $270 \mathrm{~nm}{ }^{1}$ de óleo de milho armazenado em frascos de PET em condições de comercialização.

\begin{tabular}{|c|c|c|c|c|}
\hline \multirow{2}{*}{$\begin{array}{l}\text { Tempo de } \\
\text { armazenamento } \\
\text { (dias) }\end{array}$} & \multicolumn{4}{|c|}{ Tratamentos $^{2}$} \\
\hline & $\begin{array}{c}\text { BHAVBHT + AC } \\
\left(200+100 \mathrm{mg} \mathrm{kg}^{-1}\right)\end{array}$ & $\begin{array}{c}\text { BHA/BHT } \\
\left(200 \mathrm{mg} \mathrm{kg}^{-1}\right)\end{array}$ & $\begin{array}{c}\mathrm{AC} \\
\left(100 \mathrm{mg} \mathrm{kg}^{-1}\right)\end{array}$ & Controle \\
\hline 0 & $1,431^{\circ}$ & $1,524^{b c}$ & $1,582^{a b c}$ & $1,404^{b c}$ \\
\hline 15 & $1,349^{c}$ & $1,391^{\mathrm{cd}}$ & 1,389 cd & $1,351^{b c}$ \\
\hline 30 & $1,268^{\circ}$ & $1,257^{d}$ & $1,348^{d}$ & $1,194^{\circ}$ \\
\hline 45 & $1,788^{a}$ & $1,773^{a}$ & $1,650^{a b}$ & $1,652^{a}$ \\
\hline 60 & $1,454^{\circ}$ & $1,457^{\text {cd }}$ & $1,407^{\text {cd }}$ & $1,354^{b c}$ \\
\hline 75 & $1,684^{a b}$ & $1,720^{a b}$ & $1,747^{a}$ & $1,812^{a}$ \\
\hline 90 & $1,426^{\circ}$ & $1,422^{c d}$ & $1,395^{c d}$ & $1,406^{b}$ \\
\hline 120 & $1,451^{\circ}$ & $1,451^{\text {cd }}$ & $1,432^{\text {bed }}$ & $1,406^{b c}$ \\
\hline 150 & $1,371^{\circ}$ & $1,434^{\mathrm{cd}}$ & $1,352^{d}$ & $1,350^{b c}$ \\
\hline 180 & $1,474^{b c}$ & $1,494^{\circ}$ & $1,435^{\text {bed }}$ & $1,403^{b c}$ \\
\hline
\end{tabular}

'médias de 3 repetiçōes ${ }^{2}$ C.V. $=5,797 \%$ d.m.s. $5 \%=0,113$

Valores seguidos por letras distintas na coluna diferem entre si ao nivel de $5 \%$ de significancia, segundo o teste de Tukey aplicado para as médias de tempo de armazenamento. 
Tabela 15. Absortividade em $270 \mathrm{~nm}^{1}$ de óleo de soja armazenado em frascos de PET em condições de comercialização.

\begin{tabular}{ccccc}
\hline \multirow{2}{*}{$\begin{array}{c}\text { Tempo de } \\
\text { armazenamento }\end{array}$} & $\begin{array}{c}\text { Tratamentos } \\
\text { (dias) }\end{array}$ & $\begin{array}{c}\text { BHA/BHT }+ \text { AC } \\
\left(200+100 \mathrm{mg} \mathrm{kg}^{-1}\right)\end{array}$ & $\begin{array}{c}\text { BHAHT } \\
\left(200 \mathrm{mg} \mathrm{kg}^{-1}\right)\end{array}$ & $\begin{array}{c}\text { AC } \\
\left(100 \mathrm{mg} \mathrm{kg}^{-1}\right)\end{array}$ \\
\hline 0 & $3,129^{b}$ & $3,212^{b}$ & $3,269^{\mathrm{ab}}$ & $3,130^{\mathrm{b}}$ \\
15 & $2,956^{\mathrm{b}}$ & $2,999^{\mathrm{b}}$ & $3,039^{\mathrm{c}}$ & $2,915^{\mathrm{b}}$ \\
30 & $3,058^{\mathrm{b}}$ & $3,190^{\mathrm{b}}$ & $2,975^{\mathrm{c}}$ & $2,970^{\mathrm{b}}$ \\
45 & $3,004^{\mathrm{b}}$ & $3,046^{\mathrm{b}}$ & $3,090^{\mathrm{bc}}$ & $3,091^{\mathrm{b}}$ \\
60 & $3,087^{\mathrm{b}}$ & $3,003^{\mathrm{b}}$ & $3,057^{\mathrm{c}}$ & $3,016^{\mathrm{b}}$ \\
75 & $3,092^{\mathrm{b}}$ & $3,068^{\mathrm{b}}$ & $3,053^{\mathrm{c}}$ & $3,005^{\mathrm{b}}$ \\
90 & $3,462^{\mathrm{a}}$ & $3,443^{\mathrm{a}}$ & $3,482^{\mathrm{a}}$ & $3,437^{\mathrm{a}}$ \\
120 & $3,573^{\mathrm{a}}$ & $3,542^{\mathrm{a}}$ & $3,508^{\mathrm{a}}$ & $3,439^{\mathrm{a}}$ \\
150 & $3,395^{\mathrm{a}}$ & $3,449^{\mathrm{a}}$ & $3,465^{\mathrm{a}}$ & $3,500^{\mathrm{a}}$ \\
180 & $3,450^{\mathrm{a}}$ & $3,457^{\mathrm{a}}$ & $3,475^{\mathrm{a}}$ & $3,475^{\mathrm{a}}$ \\
\hline
\end{tabular}

'médias de 3 repetições ${ }^{2}$ C.V. $=2,547 \%$ d.m.s. $5 \%=0,109$

Valores seguidos por letras distintas na coluna diferem entre si ao nivel de $5 \%$ de significância, segundo o teste de Tukey aplicado para as médias de tempo de armazenamento. 


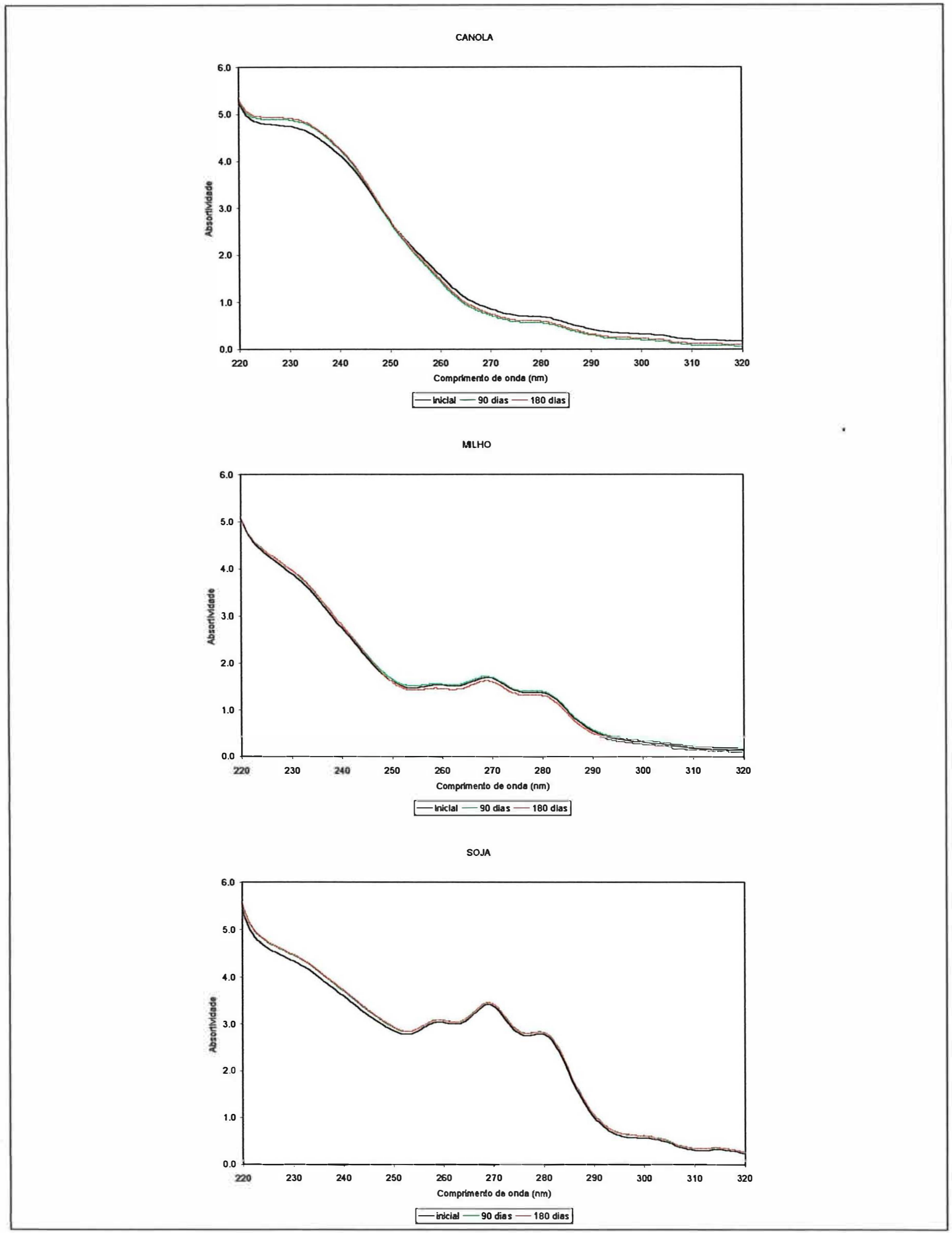

Figura 25 - Espectros de absortividade entre 220 e 320 nm dos óleos de canola, milho e soja armazenados em frascos de PET em condições de comercialização. 
$O$ indice de acidez sofreu aumentos gradativos e significativos ao longo do tempo nos óleos de canola e soja. Ao final dos 180 dias de armazenamento, o óleo de canola apresentou um índice de acidez proporcional ao apresentado depois de 32-36 min de aquecimento por microondas. O óleo de soja, depois de 180 dias de armazenamento ao ambiente, apresentou valores de índice de acidez correspondentes aos apresentados pelas amostras aquecidas durante $32 \mathrm{~min}$ em forno de microondas. O teste de Tukey aplicado para médias de tempo de armazenamento do óleo de milho acusou a existência de diferenças entre os valores de índice de acidez, mas o valor máximo foi verificado aos 120 dias de armazenamento e seguido por uma redução. $O$ teste de Tukey aplicado para médias de antioxidante indicou que não houve diferenças entre os tratamentos em nenhum dos três óleos. A Tabela 16 apresenta os valores de índice de acidez verificados no controle dos óleos de canola, milho e soja armazenados em frascos de PET por 180 dias e as letras nas colunas são referentes ao resultado do teste de Tukey aplicado para médias do fator tempo de armazenamento.

O grau de hidrólise observado nas amostras aquecidas por microondas por até 36 min e nas amostras conservadas em condições normais de armazenamento durante 180 dias foi proporcional. $O$ índice de iodo não sofreu grandes variações durante o ensaio de armazenamento, conforme indicado na Tabela 17. Também não houve variações entre os tratamentos aplicados. 
Tabela 16. Índice de acidez (\% AGL) ${ }^{1}$ de óleos de canola, milho e soja armazenados em frascos de PET em condições de comercialização.

\begin{tabular}{cccc}
\hline \multirow{2}{*}{$\begin{array}{c}\text { Tempo de } \\
\text { armazenamento (dias) }\end{array}$} & Canola $^{2}$ & Milho $^{3}$ & Soja $^{4}$ \\
\cline { 2 - 4 } & $0,050^{\mathrm{d}}$ & $0,025^{\mathrm{g}}$ & $0,050^{\mathrm{g}}$ \\
15 & $0,050^{\mathrm{d}}$ & $0,050^{\text {ef }}$ & $0,079^{\mathrm{f}}$ \\
30 & $0,050^{\mathrm{d}}$ & $0,050^{\mathrm{f}}$ & $0,089^{\mathrm{e}}$ \\
45 & $0,050^{\mathrm{d}}$ & $0,050^{\mathrm{f}}$ & $0,102^{\mathrm{e}}$ \\
60 & $0,050^{\mathrm{d}}$ & $0,050^{\mathrm{f}}$ & $0,095^{\mathrm{e}}$ \\
75 & $0,050^{\mathrm{d}}$ & $0,079^{\mathrm{de}}$ & $0,107^{\mathrm{cd}}$ \\
90 & $0,050^{\mathrm{d}}$ & $0,060^{\mathrm{dd}}$ & $0,104^{\mathrm{de}}$ \\
120 & $0,070^{\mathrm{c}}$ & $0,102^{\mathrm{a}}$ & $0,126^{\mathrm{c}}$ \\
150 & $0,080^{\mathrm{b}}$ & $0,079^{\mathrm{b}}$ & $0,151^{\mathrm{b}}$ \\
180 & $0,106^{\mathrm{a}}$ & $0,070^{\mathrm{bc}}$ & $0,211^{\mathrm{a}}$ \\
\hline
\end{tabular}

'média de 3 repetiçōes (controle)

${ }^{2} \mathrm{CV}=9,642 \%$ d.m.s. $5 \%=0,008{ }^{3} \mathrm{CV}=11,436$ d.m.s. $5 \%=0,009{ }^{4} \mathrm{CV}=7,454 \%$ d.m.s. $5 \%=0,011$

Valores seguidos por letras distintas nas colunas diferem entre si ao nivel de $5 \%$ de significância.

Tabela 17. Índice de iodo segundo Wijs (mg iodo $\left.100 \mathrm{mg}^{-1}\right)^{1}$ de óleos de canola, milho e soja armazenados em frascos de PET em condições de comercialização.

\begin{tabular}{cccc}
\hline Tempo de & \multicolumn{3}{c}{ Óleos } \\
\cline { 2 - 4 } armazenamento (dias) & Canola & Milho & Soja \\
\hline 0 & 116,66 & 116,07 & 129,66 \\
90 & 114,44 & 113,22 & 129,27 \\
180 & 114,62 & 116,45 & 131,83 \\
\hline
\end{tabular}

\footnotetext{
${ }^{1}$ média de 3 repetiçōes (controle)
} 
Através da análise dos resultados obtidos nos três ensaios percebeu-se que a oxidação de óleos refinados pode ser acelerada através do aquecimento por microondas. O óleo de soja, que apresenta grande proporção de ácidos linoléico e linolênico foi o mais suscetivel à oxidação durante o aquecimento em forno de microondas e no teste em estufa, seguido pelo óleo de milho. O óleo de canola foi o mais estável, devido à presença de ácido oléico (monoinsaturado) em grande proporção na composição em ácidos graxos (Tabela 2).

Os valores de absortividade em $232 \mathrm{~nm}$ atingidos após 32-36 min de aquecimento por microondas foram proporcionais aos observados aos 6 dias de estufa, indicando que a formação de dienos conjugados, compostos primários da oxidação, foi comparável nas duas condições.

No entanto, a formação de compostos secundários da oxidação ocorrida durante o aquecimento por microondas não foi verificada durante o teste em estufa e a ação dos antioxidantes em retardar a oxidação dos óleos somente foi observada no teste em estufa, indicando que o mecanismo de aquecimento e a diferença de temperatura influiu no desenvolvimento do processo oxidativo. Durante o armazenamento por 180 dias em condições de comercialização houve apenas pequenas alterações oxidativas nos óleos e a adição dos antioxidantes não melhorou a estabilidade de nenhum dos óleos.

O tempo de armazenamento ambiente se mostrou insuficiente para a obtenção de resultados comparáveis aos dos testes acelerados. No entanto, foi possivel comprovar que as absortividades em $232 \mathrm{~nm}$ e em $270 \mathrm{~nm}$ apresentaram padrões de variação similares entre si durante o armazenamento, exibindo uma tendência à estabilidade (óleos de canola e milho) ou ao aumento (óleo de soja). Tal comportamento também foi observado durante o aquecimento por microondas, em que os valores de absortividade em $232 \mathrm{~nm}$ e em $270 \mathrm{~nm}$ sofreram acréscimos nos três óleos. No teste em estufa, no entanto, somente a absortividade em $232 \mathrm{~nm}$ sofreu aumentos.

O uso do aquecimento por microondas, portanto, dever servir como um instrumento para a comparação da estabilidade oxidativa de diferentes óleos através de análises de absortividade na faixa do espectro UV. 


\section{CONCLUSÕES}

- O aquecimento dos óleos refinados de canola, milho e soja por ação de microondas promoveu a oxidação lipidica. As análises espectrofotométricas na faixa UV evidenciaram claramente a ocorrência da degradação oxidativa.

- As variações irregulares do índice de peróxido em função do tempo de exposição às microondas foi associada à instabilidade dos hidroperóxidos às altas temperaturas e ao incremento da absortividade em $270 \mathrm{~nm}$, devido à formação de compostos secundários da oxidação.

- A absortividade em $232 \mathrm{~nm}$ foi um indice adequado para a avaliação das alterações oxidativas tanto no teste em estufa quanto no ensaio de aquecimento por microondas. Os valores de absortividade em $232 \mathrm{~nm}$ apresentados pelos óleos de canola, milho e soja depois de 32-36 min de aquecimento por microondas corresponderam àqueles apresentados pelos óleos após 6 dias de estufa a $63^{\circ} \mathrm{C}$.

- Os antioxidantes que apresentaram efeito em retardar a oxidação dos óleos submetidos ao teste em estufa a $63^{\circ} \mathrm{C}\left(200 \mathrm{mg} \mathrm{kg}^{-1}\right.$ de BHA/BHT e $200 \mathrm{mg} \mathrm{kg}^{-1}$ de $B H A / B H T+100 \mathrm{mg} \mathrm{kg}^{-1}$ de $\mathrm{AC}$ ) não foram eficientes em nenhum dos periodos de aquecimento por microondas e nem no armazenamento ambiente. Quanto maior o teor de ácido linolênico (C18:3) do óleo, menos visível foi a ação do ácido cítrico durante o teste em estufa a $63^{\circ} \mathrm{C}$.

- Os óleos apresentaram comportamentos diferentes em função do grau de insaturação nas diferentes condições de estudo. 
- O aquecimento por microondas associado às análises de absortividade na faixa do espectro UV deve servir como um instrumento para a comparação da estabilidade oxidativa de diferentes óleos. 


\section{REFERÊNCIAS BIBLIOGRÁFICAS}

ALBI, T.; LANZÓN, A.; GUINDA, A.; LEÓN, M; PÉREZ-CAMINO, M.C. Evaluation de algunos parametros fisico-quimicos en aceites calentados en horno microondas. In: LATIN AMERICAN CONGRESS AND EXHIBIT ON FATS AND OILS PROCESSINGS, 6, Campinas, 1995. Proceedings. Campinas: Sociedade Brasileira de Óleos e Gorduras, 1995. p.167-171.

ALBI, T.; LANZÓN, A.; GUINDA, A.; LEÓN, M; PÉREZ-CAMINO, M.C. Microwave and conventional heating effects on thermoxidative degradation of edible fats. Journal of Agricultural and Food Chemistry. v.45, n.10, p.3795-3798. Oct. 1997 a

ALBI, T.; LANZÓN, A.; GUINDA, A.; PÉREZ-CAMINO, M.C.; LEÓN, M. Microwave and conventional heating effects on some physical and chemical parameters of edible fats. Journal of Agricultural and Food Chemistry. v.45, n.8, p.30003003. Aug. 1997b

AMERICAN OIL CHEMISTS' SOCIETY. Official and tentative methods. 3. ed. Champaign, 1983.

BARGER, W.M. Handling, transport and preparation of soybeans. Journal of the American Oil Chemists' Society, v.58, n.3, p.154-156. Mar. 1981.

BEKBÖLET, M. Lights effects in food. Journal of Food Protection, v.53, n.5, p.430-440. May 1990. 
BRASIL. Ministério da Saúde. Comissão Nacional de Normas e Padrões para Alimentos. Resolução n. ${ }^{\circ} 22 / 77$ do decreto lei n. ${ }^{\circ} 986$ de 21 de abril de 1969. In: ASSOCIAÇÃO BRASILEIRA DAS INDÚSTRIAS DE ALIMENTAÇÃO. Compêndio da Legislação de Alimentos. São Paulo. 1991. v.1/A, pg. 7.107.11 .

BUFFLER, C.R. Microwave cooking and processing - engineering fundamentals for the food scientist. New York: Van Nostrand Reinhold, 1992. 169p.

COPSON, D.A. Microwave heating. 2. ed. Westport: The Avi Publishing Company, 1975. $615 p$.

CORT, W.M. Antioxidant activity of tocopherols, ascorbyl palmitate and ascoricic acid and their mode of action. Joumal of American Oil Chemists' Society, v.51, n.7, p.321. Jul. 1974.

DATTA, A.K.; HU, W. Optimization of quality in microwave heating. Food Technology, v. 46, n. 12, p.53-56. Dec. 1992.

DECAREAU, R.V. Microwaves in the food processing industry. Orlando: Academic Press, 1985. 234p.

DECAREAU, R.V.; PETERSON, R.A. Microwave processing and engineering. Chichester: Ellis Horwood, 1986. 224p.

DUTTON, H.J. Analysis of fats and oils. Journal of the American Oil Chemists' Society, v.55, p.806-808. Nov. 1978.

ESPINOZA-ATENCIA, E.J.; FARIA, J.A.F. Fotoxidação de óleos comestiveis em embalagens plásticas transparentes. Óleos e grãos, n.19, p.44-51. jul./ago. 1994.

FARAG, R.S.; HEWEDI, F.M.; ABU-RAIIA, S.H.; EL-BAROTY, G.S. Comparative study on deterioration of oils by microwave and conventional heating. Journal of Food Protection, v.55, n.9, p. 722-727. Sep. 1992.

FARIA, J.A.F. A função da embalagem na estabilidade de óleos vegetais. Óleos e Grãos, n.6, p.50-52. out./nov. 1991. 
FARIA, J.A.F. Antioxidantes e estabilidade de óleos comestíveis. Óleos e Grãos, n.20, p.32-34. set./out. 1994.

FARIA, J.A.F.; ESPINOSA-ATENCIA, E.J. Efeito da cor das garrafas de vinila (PVC) na fotoxidação de óleos de soja. Óleos e Grãos, n.11, p.40-44. mar./abr. 1993.

FELLOWS, P. Heating by irradiated energy. In: FELLOWS, P. Food processing technology - principles and practice. Cambridge: VCH, 1989. Cap. D-17, p.343356.

GATCHER, R.; MULLER, H. Plastics additives handbook. Munich: Hanser Publishers, 1987. p. 97-192.

GIESE, J. Advances in microwave food processing. Food Technology, v.46, n.9, p.118123. 1992.

GRAY, J.I. Measurement of lipid oxidation: a review. Journal of the American Oil Chemists' Society, v.55, n.6, p.539-546, Jun. 1978.

HAWRYSH, Z.J.; ERIN, M.K.; LIN, Y.C.; HARDIN, R.T. Propyl gallate and ascorbyl palmitate affect stability of canola oils in accelerated storage. Journal of Food Science, v.57, n.5, p.1324-1238, Sep./Oct. 1992.

HAWRYSH, Z.J.; MCMULLEN, L.M.; LIN, C.; TOKARSKA, B.; HARDIN, R.T. Effects of tertiary butylhydroquinone on canola oil thermal stability. Canadian Institute of Food Science and Technology Journal, v.23,.n.2/3, p.94-100, Jun. 1990.

HAWRYSH, Z.J.; SHAND, P.J.; TOKARSKA, B.; LIN, C. Effects of tertiary butylhydroquinone on the stability of canola oil. I. Accelerated storage. Canadian Institute of Food Science and Technology Journal, v.21, n.5, p.549-554, Dec. 1988.

INTERNATIONAL UNION OF PURE AND APPLIED CHEMISTRY. Standard methods for the analysis of oils, fats and derivatives. 6. ed. 1979.

JOHANSSON, G.M.R. Finished oil handling and storage in Europe. Journal of the American Oil Chemists' Society, v.53, n.6, p.410-413. Jun. 1976. 
KANNER, J. Mechanism of nonenzymic lipid peroxidation in muscle foods. In: St. ANGELO, A.J. Lipid Oxidation in Food. Washington: American Chemical Society, 1992. Cap. 4, p.55-73.

LAURIDSEN, J.B.; SCHULTZ, A.M. Antioxidantes: prolongando a vida de prateleira dos alimentos. Espuma, n.25, p.35-37, 1994.

LEME, C.C.M. Uso de embalagem adequada aumenta venda de óleos comestiveis. Óleos e Grãos, n.20, p.32-34, set./out. 1994.

LIE KEN JIE, M.S.F; YAN-KIT, C. The use of a microwave oven in the chemical transformation of long chain fatty acid esters. Lipids, v.23, n.4, p.367-369. Apr. 1988.

LOUPY, A. Les micro-ondes: leurs applications potencielles dans la chimie des corps gras. Oléagineux corps gras lipides. v.1, n.1, p.62-68. Août/Sept. 1994.

LUGASI, A.; HÓVÁRI, J.; DWORSCHÁK, E.; NESZLÉNYI, K.; LEBOVICS, V.; ZSINKA, Á.J.N. Effect of UV irradiation on lipid peroxidation in edible fats. Acta Alimentaria, v.24, n.3, p.269-276. Sep. 1995.

MAG, T.K. Canola oil processing in Canada. Journal of the American Oil Chemists' Society, v.60, n.2, p.380-384. Feb. 1983.

MAI, J.; TSAI, C.H.; ARMBRUSTER, G.; CHU, P.; KINSELLA, J.E. Effects of microwave cooking on food fatty acids: no evidence of chemical alteration or isomerization. Journal of Food Science, v.45, n.6, p.1753-1755. Nov./Dec. 1980.

MERMELSTEIN, N.H. How food technology covered microwaves over the years. Food Technology, v.51, n.5, p.82. May. 1997.

MCMULLEN, L.M.; HAWRYSH, Z.J.; LIN, C.; TOKARSKA, B. Ascorbyl palmitate efficacy in enhancing the accelerated storage stability of canola oil. Journal of Food Science, v.56, n.6, p.1651-1659. Nov./Dec. 1991.

MUDGETT, R.E. Electrical properties of foods in microwave processing. Food Technology, v.36, n.2, p. 109-115. Feb. 1982. 
MUDGETT, R.E.; WANG, D.I.C.; GOLDBLITH, S.A. Prediction of dielectric properties in oil-water and alcohol-water mixtures at $3,000 \mathrm{MHz}, 25^{\circ} \mathrm{C}$ based on pure component properties. Journal of Food Science, v.39, n.3, p.632-635. May/Jun. 1974.

OHLSON, R. Modem processing of rapeseed. Journal of the American Oil Chemists' Society, v.69, n.3, p.195-198. Mar. 1992.

OMURA, K. Antioxidant synergism between butylated hydroxyanisole and butylated hydroxytoluene. Journal of the American Oil Chemists' Society, v.72, n.12, p.1565-1570. Dec. 1995.

PADLEY, F.B.; GUNSTONE, F.D.; HARWOOD, J.L. Occurrence and characteristics of oils and fats. In: GUNSTONE, F.D.; HARWOOD, J.L.; PADLEY, F.B. The Lipid Handbook. 2.ed. London: Chapman \& Hall, 1994. Cap. 3, p.47-146.

PROGRAMA CONJUNTO FAOIOMS SOBRE NORMAS ALIMENTARIAS - COMISION DEL CODEX ALIMENTARIUS. Codex Alimetarius. Roma: FAO, 1992. p.11.5, $11.12,11.22$.

RAKOW, G.; McGREGOR, D.I. Opportunities and problems in modification of levels of rapeseed $C_{18}$ unsaturated fatty acids. Journal of the American Oil Chemists' Society, v.50, n.10, p.400-403. Oct. 1973.

REGITANO-d'ARCE, M.A.B. \& VIEIRA, T.M.F.S. Storability of Brazil nut (Bertholletia excelsa) crude oil. In: WORLD CONFERENCE ON OILSEED AND EDIBLE OILS PROCESSING S: EMERGING TECHNOLOGIES, CURRENT PRACTICES, QUALITY CONTROL, TECHNOLOGY TRANSFER AND ENVIRONMENTAL ISSUES, Istanbul, 1996. Proceedings. AOCS, 1996. p.174-176.

ROSEN, C.G. Effects of microwaves on food and related materials. Food Technology, v.26, n.7, p.36-40, 55. Jul. 1972.

ROSSEL, J.B. Vegetable oils and fats. In: ROSSEL, J.B.; PRITCHARD, J.L.R. Analysis of Oilseeds, Fats and Fatty Foods. New York: Elsevier Science Publishing, 1991. Cap. 7, p.261-327.

ROVELLINI, P.; CORTESI, N.; FEDELI, E. Ossidazioni dei lipidi. Nota 1. La Rivista Italiana delle Sostanze Grasse, v.74, n.5, p. 181-189. Mag. 1997. 
RUIZ-LOPEZ, M.D.; ARTACHO, R.; FERNANDEZ PINEDA, M.A.; LOPEZ GARCIA de la SERRANA, H.; LOPEZ MARTINEZ, M.C. Stability of $\alpha$-tocopherol in virgin olive oil during microwave heating. Lebensmittel-Wissenschaft \& Technology, v.28, n.6, p.644-646, 1995.

SATTAR, A.; deMAN, J.M. Photooxidation of milk and milk products: a review. Critical Reviews in Food Science and Nutrition, v.7, n. 1, p.13-37, 1975.

SHAHIDI, F. Stability of fats and oils. In: LATIN AMERICAN CONGRESS AND EXHIBIT ON FATS AND OILS PROCESSINGS, 6., Campinas, 1995. Proceedings. Campinas: Sociedade Brasileira de Óleos e Gorduras, 1995. p.4754.

SHERWIN, E.R. Oxidation and antioxidants in fat and oil processing. Journal of the American Oil Chemists' Society, v.55, p.809-814. Nov. 1978.

SHIFFMANN, R.F. Microwave processing in the U.S. food industry. Food Technology, v.46, n.12, p. 50-52, 56. Dec. 1992.

SIMIC, M.G.; JOVANIC, S.V.; NIKI, E. Mechanisms of lipid oxidative processes and their inhibition. In: St. ANGELO, A.J. Lipid Oxidation in Food. Washington: American Chemical Society, 1992. Cap. 2, p.14-32.

St. ANGELO, A.J.; ORY, R.L.; BROWN, L.E. Comparison of methods for determining peroxidation in processed whole peanuts products. Journal of the American Oil Chemists' Society, v.52, n.2, p.34-35, Feb. 1975.

STAZIONE SPERIMENTALE PER LE INDUSTRIE DEGLI OLI E DEI GRASSI. Norme italiane per il controllo dei grassi e derivati, 3.ed., Milano, 1976.

THOMAS, L.H.; SGOUTAS, S.A.; SGOUTAS, D.S.; HEARN, J.A. Stability of polyunsaturated fatty acids after microwave cooking of fish. Journal of Food Science, v.52, n.5, p.1430-1431. Sep./Oct. 1987.

THUERY, J. Les micro-ondes et leurs effects sur la matière - applications industrielles, agro-alimentaires et médicales. Paris: CDIUPA, 1983. 366p. 
TROST, V.W. Characterization of com oil, soybean oil and sunflowerseed oil nonpolar material. Journal of the American Oil Chemists' Society, v.66, n.3, p.325-333. Mar. 1989.

UMA COMPARAÇĀO entre instrumentos modernos para a análise de estabilidade oxidativa de óleos, gorduras e alimentos. Óleos e Grãos, n.26, p.47-51, set./out. 1995.

WANASUNDARA, U.N.; SHAHIDI, F. Canola extract as an altemative natural antioxidant for canola oil. Journal of the American Oil Chemists' Society, v.71, n.8, p.817-822, Aug. 1994.

WARNER, K.; FRANKEL, E.N.; MOUNTS, T.L. Flavor and oxidative stability of soybean, sunflower and lowerucic acid rapeseed oils. Journal of the American Oil Chemists' Society, v.66, n.4, p.558-564. Apr. 1989.

YOSHIDA, H.; KAJIMOTO, G. Effects of microwave heating on the molecular species of soybean triacylglycerols. Journal of Food Science, v.51, n.6, p.1476-1478, 1490. Nov./Dec. 1986.

YOSHIDA, H.; KAJIMOTO, G. Effects of microwave energy on the tocopherols of soybean seeds. Journal of Food Science, v.54, n.6, p.1596-1600. Nov./Dec. 1989.

YOSHIDA, H.; KAJIMOTO, G.; EMURA, S. Antioxidant effects of d-tocopherols at different concentrations in oils during microwave heating. Journal of the American Oil Chemists' Society, v.70, n.10, p.989-995. Oct. 1993.

YOSHIDA, H.; KAJIMOTO, G. Microwave heating affects composition and oxidative stability of sesame (Sesamum indicum) oil. Journal of Food Science, v.59, n.3, p.613-616, 625, May/Jun. 1994.

YOSHIDA, H.; KONDO, I.; KAJIMOTO, G. Effects of microwave energy on the relative stability of vitamin $E$ in animal fats. Journal of Food Science and Agricultural, v.58, n.4, p.531-534. 1992. 
YOSHIDA, H.; NOBUHISA, H.; KAJIMOTO, G. Microwave energy effects on quality of some seed oils. Journal of Food Science, v.55, n.5, p.1412-1416. Sep./Oct. 1990.

YOSHIDA, H.; NOBUHISA, H.; KAJIMOTO, G. Microwave heating effects on relative stabilities of tocopherols in oils. Journal of Food Science, v.56, n.4, p.1042-1046. Jul./Aug. 1991. 